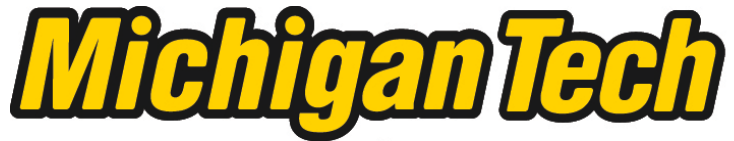 \\ Michigan Technological University Create the Future Digital Commons @ Michigan Tech
}

2013

\section{A STUDY OF SO2 EMISSIONS AND GROUND SURFACE DISPLACEMENTS AT LASTARRIA VOLCANO, ANTOFAGASTA REGION, NORTHERN CHILE}

Lucie Guihem Krewcun

Michigan Technological University

Follow this and additional works at: https://digitalcommons.mtu.edu/etds

Part of the Geology Commons, and the Remote Sensing Commons

Copyright 2013 Lucie Guihem Krewcun

Recommended Citation

Krewcun, Lucie Guihem, "A STUDY OF SO2 EMISSIONS AND GROUND SURFACE DISPLACEMENTS AT LASTARRIA VOLCANO, ANTOFAGASTA REGION, NORTHERN CHILE", Master's Thesis, Michigan

Technological University, 2013.

https://doi.org/10.37099/mtu.dc.etds/641

Follow this and additional works at: https://digitalcommons.mtu.edu/etds

Part of the Geology Commons, and the Remote Sensing Commons 


\title{
A STUDY OF $\mathrm{SO}_{2}$ EMISSIONS AND GROUND SURFACE DISPLACEMENTS AT
}

LASTARRIA VOLCANO, ANTOFAGASTA REGION, NORTHERN CHILE

\section{By}

Lucie G. Krewcun

\begin{abstract}
A THESIS
Submitted in partial fulfillment of the requirements for the degree of

MASTER OF SCIENCE

In Geology
\end{abstract}

MICHIGAN TECHNOLOGICAL UNIVERSITY

2013

(C) 2013 Lucie G. Krewcun 
This thesis has been approved in partial fulfillment of the requirements for the Degree of MASTER OF SCIENCE in Geology.

Department of Geological/Mining Engineering and Sciences

\author{
Thesis Co-Advisor: Simon A. Carn \\ Thesis Co-Advisor: Jean-Luc Froger \\ Committee Member: Gregory P. Waite
}

Department Chair: John Gierke 


\section{Table of contents}

Acknowledgments ............................................................................................................ 4

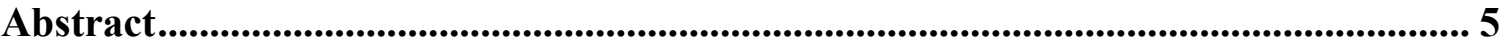

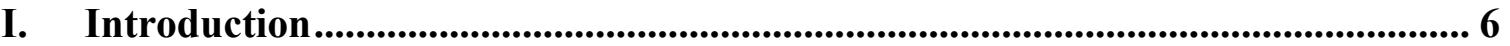

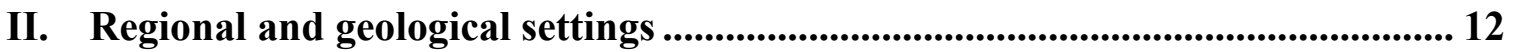

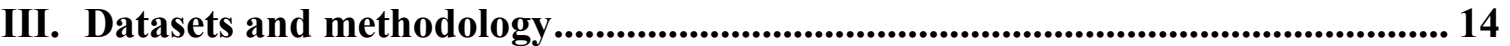

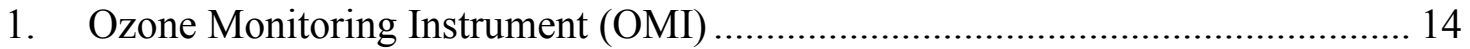

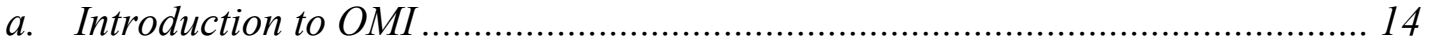

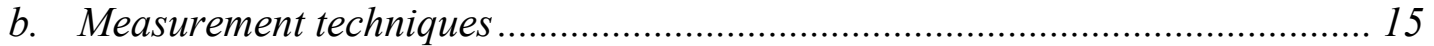

c. Presentation of datasets and methodology .................................................. 19

2. Interferometric Synthetic Aperture Radar (InSAR)........................................ 24

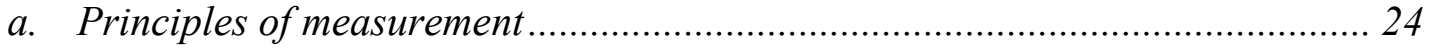

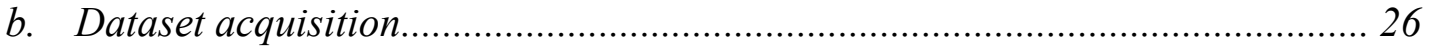

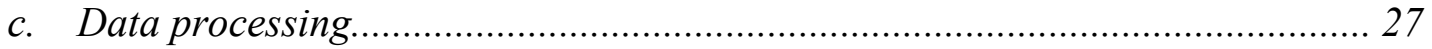

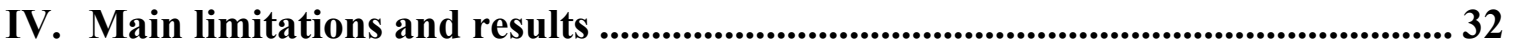

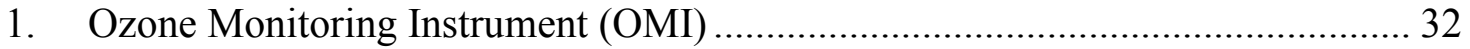

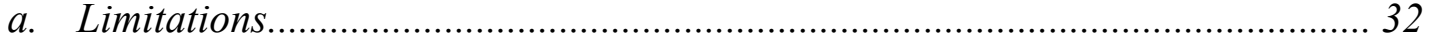

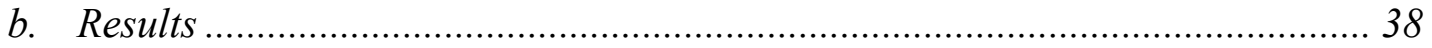

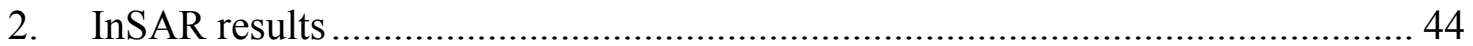

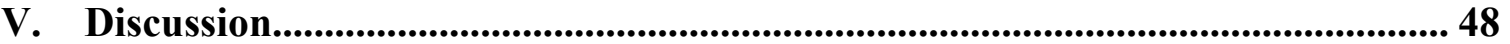

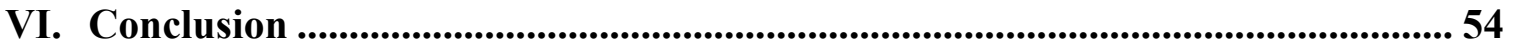

VII. References ............................................................................................................ 55

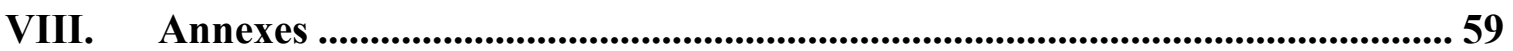




\section{Acknowledgments}

I would like to thank my advisors, Simon Carn and Jean-Luc Froger for their help and their advices and for making this all thing possible, with a special thank to Jean-Luc Froger for keeping up on this project even when so important other events were going on. Thank to all the MTU and UBP staff and professors, in and out the Geology department, so numerous that I can't name them all: your help was the basis of this project.

A special thought for the INVOGE crew, geofolks and fellow international people that helped me in so many ways along this year: Estelle, the Dragon's crew Vale and Lore, Chris, Sarah, Kelly, Verity, Riccardo, Fede, Diego and so many more... I learned so much from you, I could never thank you enough. And a special thank to Jake, for everything. 


\section{Abstract}

Lastarria volcano (Chile) is located at the North-West margin of the 'Lazufre' ground inflation signal $\left(37 \times 45 \mathrm{~km}^{2}\right)$, constantly uplifting at a rate of $\sim 2.5 \mathrm{~cm} /$ year since 1996 (Pritchard and Simons 2002; Froger et al. 2007). The Lastarria volcano has the double interest to be superimposed on a second, smaller-scale inflation signal and to be the only degassing area of the Lazufre signal. In this project, we compared daily $\mathrm{SO}_{2}$ burdens recorded by AURA's OMI mission for 2005-2010 with Ground Surface Displacements (GSD) calculated from the Advanced Synthetic Aperture Radar (ASAR) images for 2003-2010.

We found a constant maximum displacement rate of $2.44 \mathrm{~cm} /$ year for the period 2003-2007 and 0.80- $0.95 \mathrm{~cm} /$ year for the period 2007-2010. Total $\mathrm{SO}_{2}$ emitted is 67.0 $\mathrm{kT}$ for the period 2005-2010, but detection of weak $\mathrm{SO}_{2}$ degassing signals in the Andes remains challenging owing to increased noise in the South Atlantic radiation Anomaly region. 


\section{Introduction}

Space-based remote sensing techniques are used in volcanology to monitor areas where ground access is difficult or impossible. Combining different remote-sensing techniques has brought new perspectives by allowing a direct comparison between several physical parameters for the same area and on the same period of time.

This study combines sulfur dioxide $\left(\mathrm{SO}_{2}\right)$ measurements from the Ozone Monitoring Instrument (OMI), an ultraviolet-visible spectrometer mounted on the NASA Aura satellite, with Ground Surface Displacement (GSD) measurements calculated from RADAR images acquired by the Advanced Synthetic Aperture Radar (ASAR) instrument, onboard the European Space Agency (ESA) ENVISAT mission. The study primarily focuses on a $23.1 \times 21 \mathrm{~km}^{2}$ area surrounding the Lastarria volcanic system in Northern Chile (figure I.1). The following report aims to investigate, on one hand, $\mathrm{SO}_{2}$ emissions recovered from OMI measurements from 2004 to 2010 and also GSD calculated by Interferometric Synthetic Aperdure Radar (InSAR), to investigate volcanic processes from 2003 to 2010 .

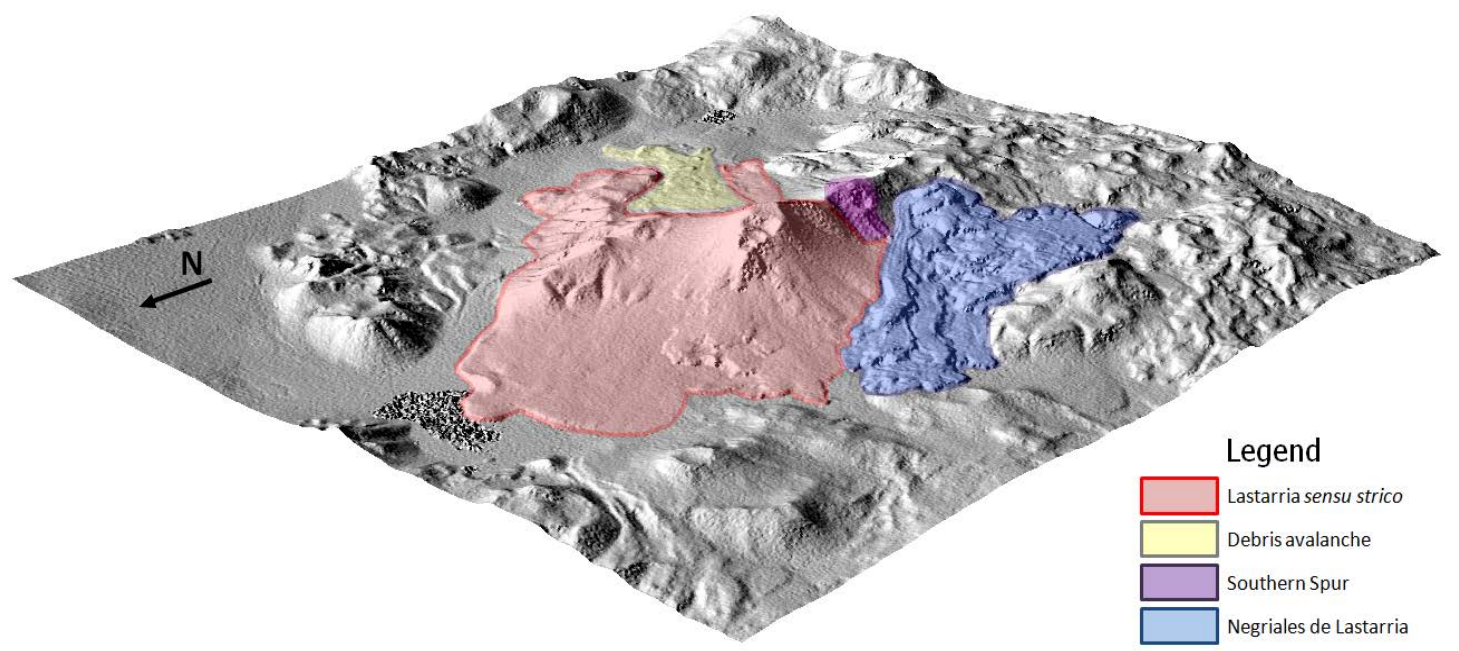

Figure I.1: simplified representation of the Lastarria Volcanic Complex (LVC) including its main volcanic units. Digital Elevation Model (DEM) used available for free at http://www.dlr.de/, displayed using ENVI 4.3 ß software (http://www.exelisvis.com/). Colored areas made with PhotoFiltre (available for free at http://www.photofiltre.com/).

Lastarria volcano $\left(-25.15^{\circ} \mathrm{N},-68.50^{\circ} \mathrm{E}, 5697 \mathrm{~m}\right.$ asl $)$ is the youngest part of the Lastarria Volcanic Complex (LVC) (figure I.2), a Quaternary volcanic system located in the Central Volcanic Zone of Andes (CVZ), $20 \mathrm{~km}$ northward of the Cordón del Azufre volcanic system (Naranjo 2010). These systems lie on the Altiplano-Puna Plateau, uplifted by the subduction of the Nazca plate under the South America plate (Oncken et 
al. 1999), at the border between Northern Chile and Argentina. Together, the LVC and Cordón del Azufre systems are referred as 'Lazufre' volcanic system after the large scale InSAR survey conducted by Pritchard and Simons (2002) over central Andes using ERS data from 1996 to 2000 .

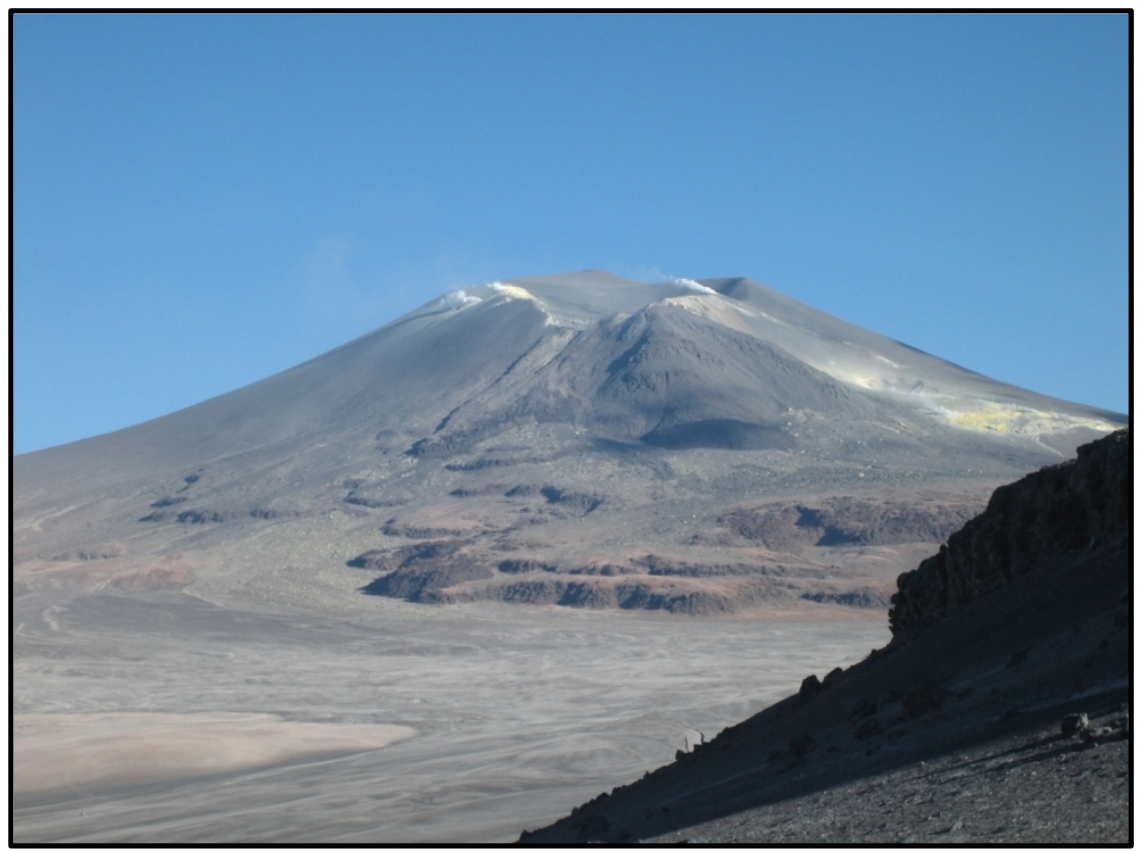

Figure I.2: The Lastarria Volcanic Complex from the North-East. Fumaroles are visible from active fumarolic fields located around the volcano crater (picture by Jean-Luc Froger, see annex IV for documentation of permission to use this material).

This survey highlighted a large-scale ground deformation signal $(45 \mathrm{~km} \mathrm{x} 37 \mathrm{~km}$, elliptical, oriented NNE-SSW) underlying the Lazufre system, associated with a deformation rate of $1 \mathrm{~cm} /$ year in the line-of-sight of the instrument for the period 19962000 (Prichard and Simons 2002). Further InSAR surveys focusing on this deformation signal found constant deformation rates of $\sim 2.5 \mathrm{~cm} /$ year from March 2003 to May 2005 (Froger et al. 2007), $3 \mathrm{~cm} /$ year for 2003-2006 (Ruch et al. 2008; Ruch et al. 2010) and 3 to $3.2 \mathrm{~cm} /$ year from 2003 to 2008 (Anderssohn et al. 2009). This signal affects an area of more than $1100 \mathrm{~km}^{2}$, comparable in size with some of the biggest volcanic systems on Earth (Ruch et al. 2010). Several models of the inflation source, based on interferometric data inversion and modelization, have been proposed. For instance, an ellipsoidal-shape reservoir horizontally expanding with an opening rate of $\sim 5$ to $8 \mathrm{~cm} /$ year (Ruch et al. 2008; Anderssohn et al. 2009) can explain the observed deformation, as well as a massive spherical source or elliptical dislocations (Froger et al. 2007). However, because of the lack of constraints the geometry, shape, depth and dynamic of the source remain uncertain.

A second, smaller scale displacement signal has been identified for the first time on interferograms spanning the period March 2003 to May 2007, located at the North-West 
margin of the Lazufre deformation signal and centered on Lastarria volcano (figure I.3, Froger et al.2007).

Modeling of InSAR data suggests a shallow (1000 meter deep) inflating body as a source for this inflation (Froger et al. 2007). Displacement rates calculated range from 0.7 to 0.9 $\mathrm{cm} /$ year (Albino et al. 2007) for the period 2003-2007.

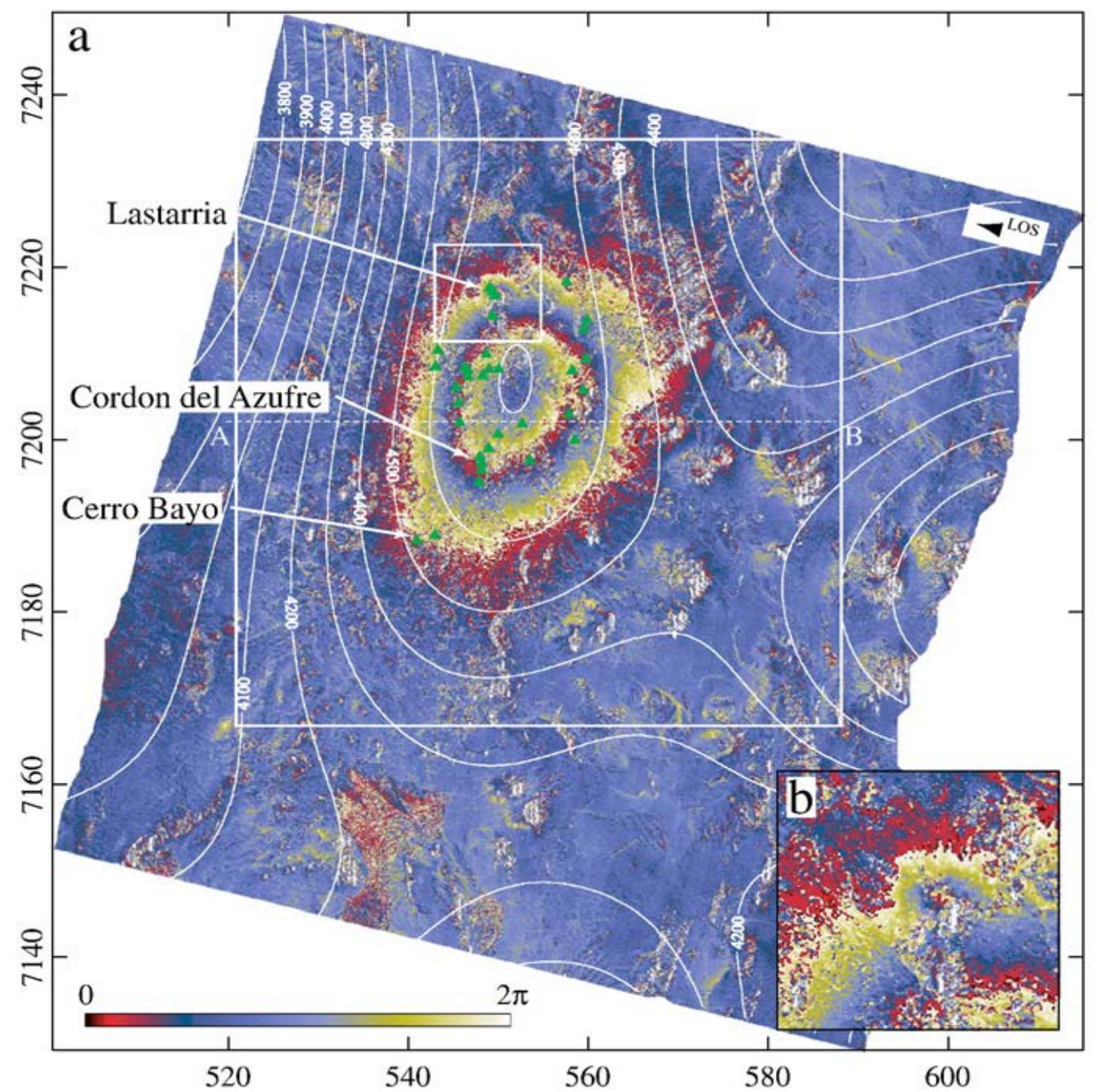

Figure I-3: a. interferogram calculated between March 2003 and June 2005 on Lazufre area. White outlines present the large-scale component of the topography and white boxes represent areas of extraction. Green triangles highlight the location of Quaternary volcanoes; b. detail of the interferogram showing the small-scale displacement is visible on Lastarria volcano (Froger et al. 2007, see annex IV for documentation of permission to use this material)

Previous studies of Lazufre and Lastarria deformation signals have been conducted on periods covering 24, 27, 36 and 60 months, respectively (Pritchard and 
Simons 2002; Froger et al. 2007; Ruch et al. 2008; Anderssohn et al. 2009). Both inflation signals showed a constant evolution for these periods, suggesting that the two deformation signals could be related (Froger et al. 2007). However, each of these results was obtained from a single swath and therefore was only able to model the displacements in the line-of-sight (LOS) of the satellite. Anderssohn et al. (2009), on the contrary, used ENVISAT images acquired in ascending geometry (Image Mode) and descending geometry (Wide Swath Mode), but only one interferogram has been obtained for the descending mode, limiting the interpretation. These limitations have restricted the interpretation of the Lastarria displacement signal in 3 dimensions, as well as its temporal evolution.

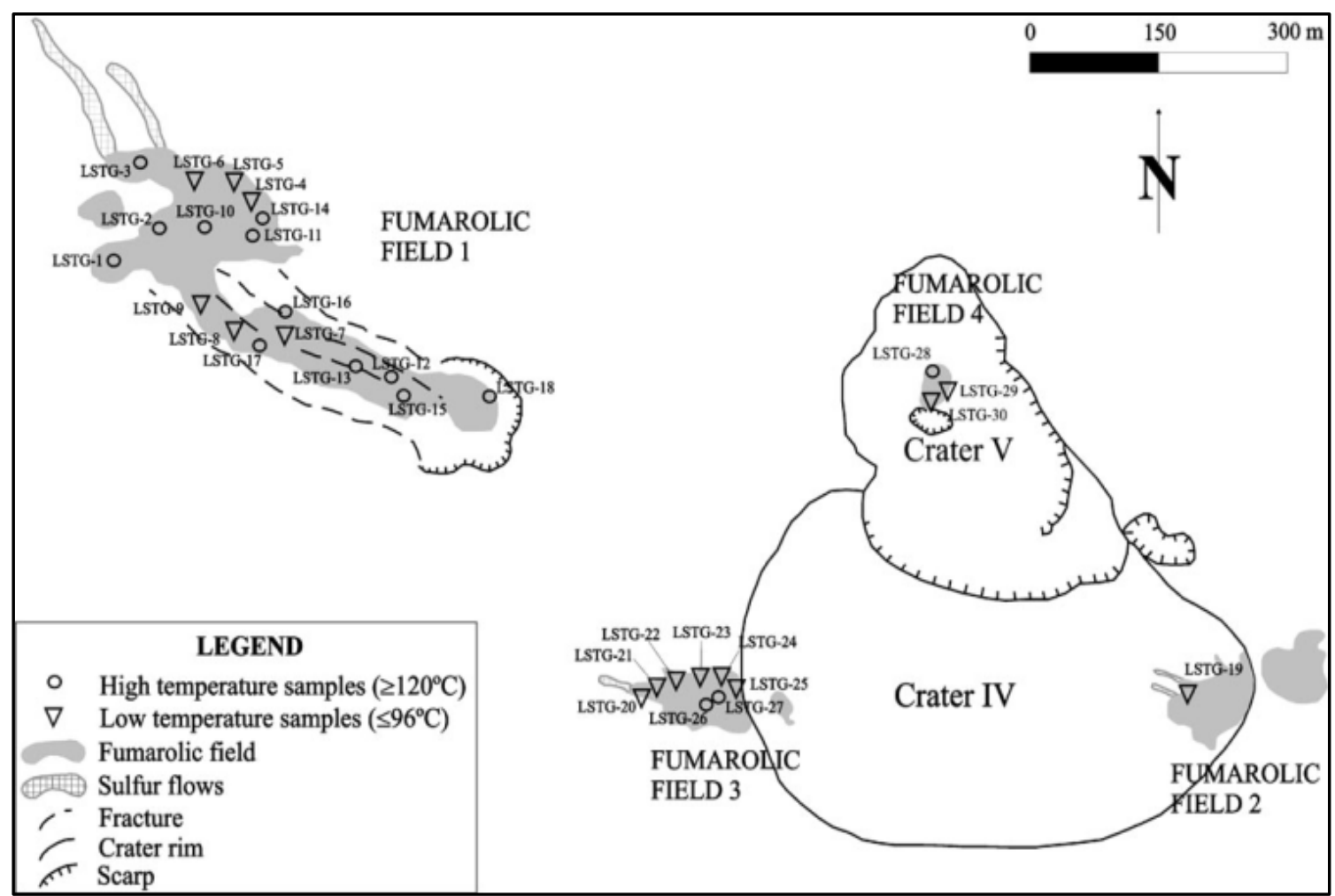

Figure I.4: Schematic representation of Lastarria volcano summit area. Down-pointing triangles corresponding to fumaroles with temperatures $\leq 96^{\circ} \mathrm{C}$ while circles represent fumaroles with temperatures $\geq 120^{\circ} \mathrm{C}$ (source: Aguilera et al. 2012, see annex IV for documentation of permission to use this material).

No historical volcanic activity has been recorded in these areas, with the exception of persistent fumarolic activity located near the summit of Lastarria volcano (de Silva and Francis 1991). Four fumarolic fields have been located and mapped (Aguilera and al. 2012) and represent the only degassing point of all the Lazufre system (figure I.4). They have been active through historical time (Naranjo 2010), but the emplacement of sulfur flows dated to the Holocene period, as well as the presence of thermally altered blocks, suggest that more extended fumarolic activity may have occurred at different places in the past (Naranjo 1985, Naranjo 1988). 
A geochemical study of Lastarria's hydrothermal system, by Aguilera et al. (2012), corroborates this hypothesis and proposes a two-step cooling model for Lastarria's hydrothermal system, where superheated vapors of magmatic origin condense at shallow depths before reaching the surface.

In addition, because the area is located in a region where ground access is difficult, remote sensing monitoring has been preferred to measure the $\mathrm{SO}_{2}$ emissions and GSD. The region is characterized by arid climatic conditions, involving a steady, layered atmosphere most part of the year and a little precipitation $(127.10 \mathrm{~mm}$ of average rainfall per year according to sdwebx.worldbank.org/). This represents very favorable conditions for space-based monitoring of atmospheric trace gases and GSD by InSAR.

The Ozone Monitoring Instrument (OMI) is a visible - ultraviolet spectrometer, mounted on NASA's Aura satellite and part of the Earth Observation System (EOS) project. The Aura mission is dedicated to studying of atmospheric processes and dynamics by providing daily global coverage of the planet, measuring key air quality $\begin{array}{llllll}\text { chemical species } & \text { such } & \text { as } & \mathrm{SO}_{2} & \text { and } & \mathrm{O}_{3}\end{array}$ (http://www.nasa.gov/mission_pages/aura/spacecraft/omi.html). OMI has already been used to monitor volcanic activity (Carn et al. 2008; Bani et al. 2011) including passive volcanic degassing in South America (Carn et al. 2007; McCormick et al. 2012), although detection and identification of weak $\mathrm{SO}_{2}$ sources remains challenging (Chance 2002) and subject to several limitations. However, climatic conditions in South America and over the Altiplano Plateau are favorable to study of low-level $\mathrm{SO}_{2}$ emissions (Carn et al. in press).

In this study, daily $\mathrm{SO}_{2}$ burdens have been extracted from OMI measurements for a 72 month period (from January 2005 to December 2010). Daily data are summed or averaged for different time spans (annual, monthly) to increase the signal-to-noise ratio (SNR) and facilitate detection of the signal, as suitable in low-level degassing conditions. Maps of $\mathrm{SO}_{2}$ burdens (figure I-5) and associated time-series plots have been produced for Lastarria volcano and for four regions recording background noise in the area. Limitations in the detection and treatment of the signal have also been considered. Other measurements have also been acquired for four additional sites containing copper smelters recognized as anthropogenic low-level sources of $\mathrm{SO}_{2}$ and detected by the OMI instrument (Carn et al. 2007). This situation brings a perfect opportunity to compare the $\mathrm{SO}_{2}$ signal detected from the copper smelters to the emissions from Lastarria's fumarolic fields, and investigate possible seasonal cycles in the $\mathrm{SO}_{2}$ measurements. 

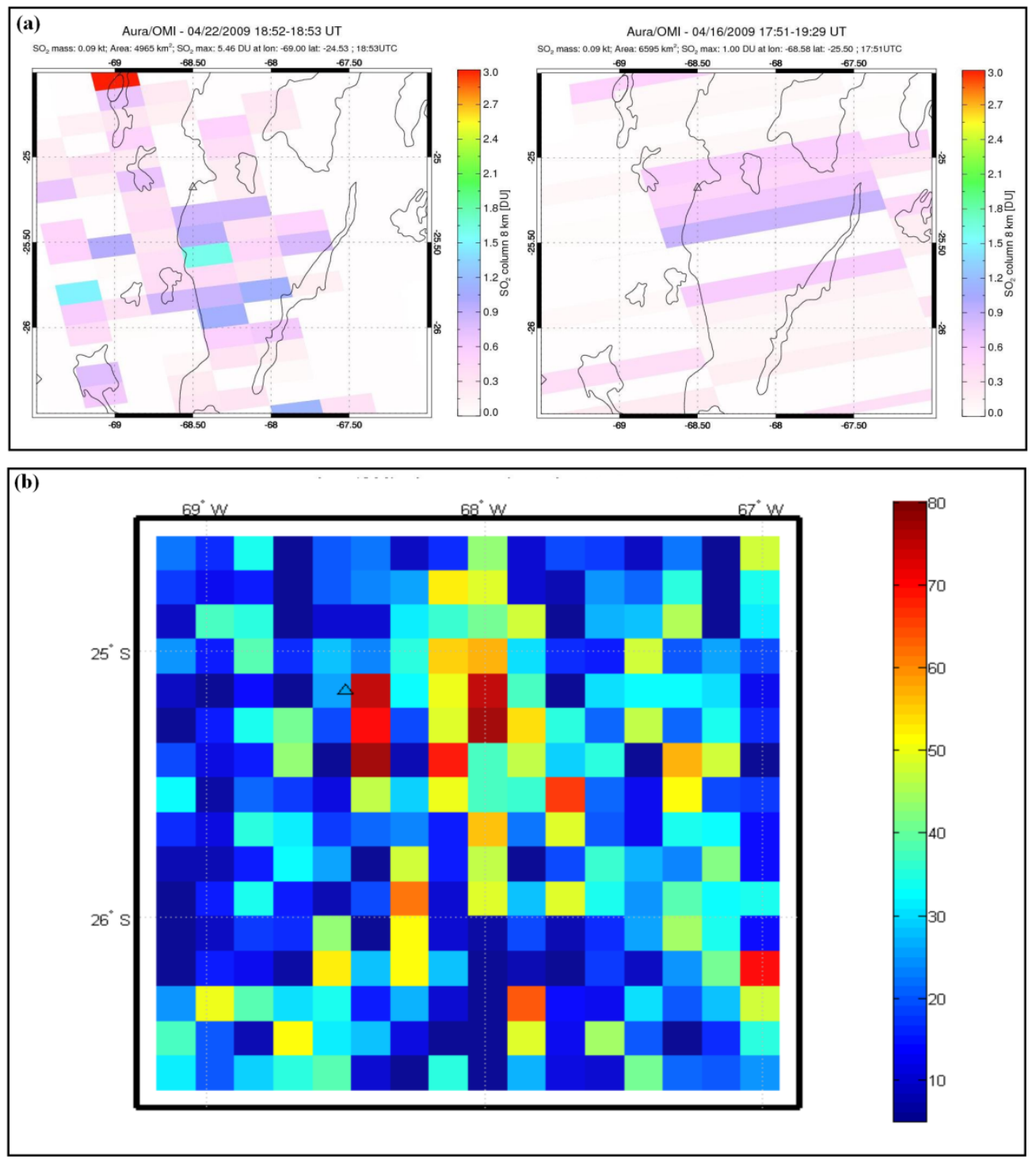

Figure I.5: $a$. Daily maps of $\mathrm{SO}_{2}$ columns in Dobson Units (DU, 1 DU $\mathrm{SO}_{2}=2.69 \times 10^{16}$ molecules $/ \mathrm{cm}^{2}$ ) for May $22^{\text {th }}$ and $16^{\text {th }}, 2009$ over Lastarria volcano (triangle), recovered from OMI pixel measurements and illustrating OMI pixel sizes variations for different days. The vertical black line represents the border between Chile and Argentina, and the other black outlines represent the contours of salars (source: OMIplot software). $b$. Cummulative map of $\mathrm{SO}_{2}$ burden in tons for 2009 for constant pixel size of $14 \mathrm{~km} \times 14 \mathrm{~km}$ (Lastarria volcano symbolized as a triangle).

Lastarria volcano represents therefore a double interest. It is the center of a small-scale GSD signal, in the North-West margin of the large Lazufre signal, and it hosts the only degassing activity of this area detected from space. In the first part of this project, $\mathrm{SO}_{2}$ emissions have been investigated for the period January 2005 - December 2010 using maps of annual $\mathrm{SO}_{2}$ amounts and time-series of $\mathrm{SO}_{2}$ emissions. Limitations in detection and data processing have been considered and investigated before interpreting the total 
$\mathrm{SO}_{2}$ amounts and the temporal variations of the signal. In the second part, GSD have been calculated from ENVISAT-ASAR instrument measurements. 67 SAR images from 3 orbital swaths in both ascending and descending modes are used to produce 59 scenes representing the retrieved GSD and covering a 89 months period. Interferograms have been produced on a small $21 \times 23 \mathrm{~km}^{2}$ area (figure I.1) surrounding the volcano with an unprecedented spatial precision $(15 \mathrm{~m})$, in order to constrain the nature of the events happening in this area. Results are presented in time-series of the displacement signals for each swath/track. Finally, joint interpretation of the two datasets, as well as comparison of the $\mathrm{SO}_{2}$ signal at Lastarria volcano with copper smelters, are discussed.

\section{Regional and geological settings}

The Lastarria - Cordón del Azufre $\left(-25.20^{\circ} \mathrm{N},-68.50^{\circ} \mathrm{E}\right)$ 'Lazufre' volcanic system is located astride Northern Chile and Argentina and is part of the CVZ of the Andes (Froger et al. 2007). Volcanism in the CVZ is triggered by the subduction of the Nazca Plate under the South American Plate, characterized by discontinuous episodes of shortening, important crustal thickening (70 km thick in average according to Wölbern et al. 2009) and crustal contamination of magmas ( $\sim 20-30 \%$ vol., Trumbull et al. 1999; Schilling and Partzsch 2001). In the Central Andes, shortening started in the Eocene and was controlled by pre-existing rifting structures (Hongn et al. 2007). The uplift of the Altiplano-Puna Plateau (or Altiplano-Puna Volcanic Complex) started $25 \mathrm{Ma}$ ago (Allmendiger et al. 1997) and resulted in the $\sim 4000 \mathrm{~m}$ altitude highlands underlying the LVC, covering 50,000 $\mathrm{km}^{2}$ (de Silva 1989). In Late Miocene and Pliocene, emplacement of large-scale magmatic chambers at $\sim 17-19 \mathrm{~km}$ depth and mechanical failure of the crust caused eruptions of large caldera complexes (Budach et al. 2011) associated with the deposition of extensive K-rich dacitic ignimbrites (about $10,000 \mathrm{~km}^{3}$ in volume according to Silva and Gosnold 2007). Recent (Quaternary) volcanic activity in the CVZ is characterized by eruption of smaller-scale stratovolcanoes.

The Cordón del Azufre is one of these Quaternary volcanic complexes covering about $60 \mathrm{~km}^{2}$ and described by de Silva and Francis (1991). It is characterized by a North-South trending ridge of four craters and associated lava flows, an eastern lava field located in Argentina and the most recent features, a crater and associated $6 \mathrm{~km}$ long blocky lava flow dated at $0.3 \pm 0.3 \mathrm{Ma}$ (Naranjo and Cornejo 1992).

The LVC, on the other hand, is composed of 3 distinct volcanic units corresponding to 3 periods of activity and related to different magma chambers. The activity migrated northward between the different phases. Description of the different units is found in Naranjo (2010). The first unit is formed by the Negriales de Lastarria, a $1.8 \mathrm{~km}^{3}$ lava field composed of numerous andesitic to dacitic lava flows and a late dacitic lava dome. It was deposited during Upper Pleistocene, as well as the second unit, the Espolón volcanic center (also called Southern Spur), located directly eastward and formed by 3 
main andesitic blocky lava flows and associated pyroclastic deposits. The more recent unit of LVC, the Lastarria volcano sensu strico, is located $3.3 \mathrm{~km}$ north from the Espolón volcano and the Negriales de Lastarria fields and petrologically and chemically different from these previous units (Naranjo 1992). It has been build during Holocene, after a period of inactivity, and is characterized by the deposition of andesitic to dacitic lava flows and block-and-ash flows caused by explosive activity triggered by magma mixing. Discontinuous effusive activity characterizes the LVC Pleistocene period, producing pyroclastic deposits containing scorias, lithiques and pumices located in the center part of the complex. Finally, late effusive activity is associated with andesitic lava flows and pyroclastic deposits. This area is still affected by intense and persistent fumarolic activity (Naranjo 1988).

Aguilera et al. (2012) distinguish between 'hot' $\left(\mathrm{T} \geq 120^{\circ} \mathrm{C}\right)$ and 'cold' degassing products $\left(\mathrm{T} \leq 96^{\circ} \mathrm{C}\right)$ that occur at the same time. They propose a two-step hydrothermal system (figure II.1) model to explain this temperature difference, where gases from a deep magmatic origin condense at shallow depth before being re-heated and reach the surface.

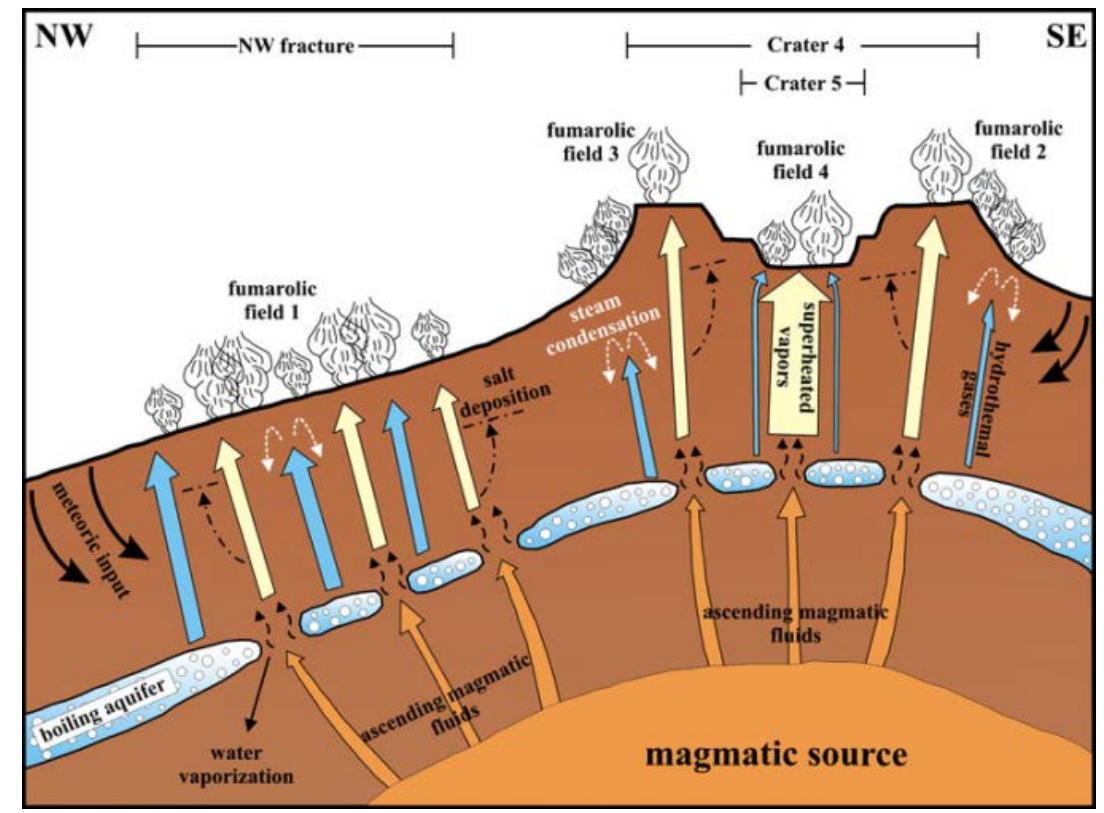

Figure II.1: Schematic representation of the two-steps hydrothermal system at Lastarria volcano showing the condensation at shallow depths of magmatic gases and interactions with the aquifer (source: Aguilera et al. 2012, see annex IV for documentation of permission to use this material)

Dry fractions of fumarolic $\mathrm{SO}_{2}$ have been calculated using ion chromatography and range between $1.17 \mathrm{mmol} / \mathrm{mol}$ and $36.2 \mathrm{mmol} / \mathrm{mol}$ for both hot and cold fumaroles. However, no estimation of the $\mathrm{SO}_{2}$ flux originating from Lastarria's fumarolic fields is available at the time of writing. 
The volcanic complex is considered as active, although no other volcanic activity has been reported during historical times.

\section{Datasets and methodology}

\section{Ozone Monitoring Instrument (OMI)}

\section{a. Introduction to OMI}

OMI is mounted onboard the NASA Aura satellite, that flies in the 'Afternoon Constellation' or 'A-train' (http://atrain.nasa.gov/). The A-train is a collaborative project consisting of a coordinated group of satellites flying within 15 min to each other on the same orbital track and crossing the equator at 1:30 pm \pm 15 min (Levelt et al. 2006b). They simultaneously image Earth's surface and atmosphere, recording several different parameters and exploring Earth systems and dynamics.

Aura was launched on July $15^{\text {th }}, 2004$ and flies within the A-train since then, at $705 \mathrm{~km}$ altitude with a sun-synchronous, near-polar orbit (inclination angle of $98.1^{\circ}$ ). It achieves 14 orbits a day with a repeat cycle of 16 days and although it was designed for a 5-years lifetime (Levelt et al. 2006b), it is still operational after more than 8 years.

OMI is one of the four instruments mounted on the Aura satellite, dedicated to studying atmospheric chemistry and dynamics (http://aura.gsfc.nasa.gov/). OMI is a nadir-viewing backscattered solar radiation CCD spectrometer built from a collaboration between the Netherlands Agency for Aerospace Programs (NIVR), the Finnish Meteorological Institute (FMI) and the National Aeronautics and Space Administration (NASA). It spectral range is 270 to $500 \mathrm{~nm}$ (UV-VIS), divided into 3 channels (UV-1, UV-2 and VIS) for accuracy purposes (table III.1). The OMI instrument is equipped with 2 dimensional CCD detectors that are used to record simultaneously spatial (across track direction, 576 pixels) and spectral (along track direction, 780 pixels) information (Levelt et al. 2006b). OMI combines a high spectral resolution (between 0.42 and $0.63 \mathrm{~nm}$, depending of the wavelength - table III.1) with a good spatial resolution $\left(13 \times 24 \mathrm{~km}^{2}\right.$ at nadir and about $13 \times 150 \mathrm{~km}^{2}$ at the edge of the swath) for a $2600 \mathrm{~km}$ wide swath, and allows a daily global coverage of the planet. 
Table III.1: OMI three spectral channels, characteristics and corresponding products (source: Levelt et al. 2006b).

\begin{tabular}{lccccc}
\hline \hline Channel & Total range & $\begin{array}{c}\text { Full perfor- } \\
\text { mance range }\end{array}$ & $\begin{array}{c}\text { Average Spectral } \\
\text { resolution }(\boldsymbol{F W H M})\end{array}$ & $\begin{array}{c}\text { Average Spectral } \\
\text { sampling distance }\end{array}$ & Data products \\
\hline $\mathrm{UV}-1$ & $270-314 \mathrm{~nm}$ & $270-310 \mathrm{~nm}$ & $0.42 \mathrm{~nm}$ & $0.32 \mathrm{~nm} /$ pixel & $\mathrm{O}_{3}$ profile, $\mathrm{O}_{3}$ column (TOMS), Surface UV-B \\
$\mathrm{UV}-2$ & $306-380 \mathrm{~nm}$ & $310-365 \mathrm{~nm}$ & $0.45 \mathrm{~nm}$ & $0.15 \mathrm{~nm} /$ pixel & $\begin{array}{c}\mathrm{O}_{3} \text { profile, } \mathrm{O}_{3} \text { column (TOMS \& DOAS), BrO, OClO, } \\
\mathrm{SO}_{2}, \mathrm{HCHO} \text {, Aerosol, Surface UV-B, } \\
\text { Surface Reflectance, cloud top pressure, cloud cover }\end{array}$ \\
VIS & $350-500 \mathrm{~nm}$ & $365-500 \mathrm{~nm}$ & $0.63 \mathrm{~nm}$ & $0.21 \mathrm{~nm} /$ pixel & $\begin{array}{c}\mathrm{NO}_{2}, \text { Aerosol, OClO, Surface UV-B, } \\
\text { Surface Reflectance, cloud top pressure, cloud cover }\end{array}$ \\
\hline \hline
\end{tabular}

The main OMI measurements include atmospheric traces gases (such as $\mathrm{O}_{3}, \mathrm{SO}_{2}, \mathrm{NO}_{2}$, $\mathrm{HCHO}, \mathrm{BrO}, \mathrm{OClO}$ ), aerosols, cloud coverage, cloud pressure, and UV radiations from Earth's surface (Levelt et al. 2006a). The Differential Optical Absorption Spectroscopy (DOAS) retrieval technique used for some OMI trace gas measurements was first introduced in 1976 by U. Platt and D. Perner, and takes advantage of the continuous measurement of the spectrum with a high spectral resolution to perform a multiple fit of absorption bands for several trace gases (Richter and Wagner 2011).

\section{b. Measurement techniques}

OMI detects a continuous spectrum of backscattered UV-visible (270 to $500 \mathrm{~nm})$ coming from Earth's atmosphere and surface. The energy received is a combination of the radiance reflected from Earth's surface and scattered by the atmosphere and clouds. Consequently, retrieval of OMI data comes in two steps. Firstly, the reflectance spectrum from Earth's surface is calculated and secondly, it serves as a basis to apply retrieval algorithms.

\section{(1) Physical principles underlying the measurements}

$\rightarrow$ Reflectance spectrum

OMI measures the radiance spectrum from Earth's atmosphere and surface and the solar irradiance spectrum directly from space. Then, the radiance spectrum is normalized by the solar irradiance to obtain the Earth's reflectance spectrum (Levelt et al. 2006b), using the following:

$$
R=\frac{\pi I}{\mu_{0} E}
$$

where $\mathrm{R}$ is the reflectance, $\mathrm{I}$ the Earth radiance, $\mathrm{E}$ the solar irradiance and $\mu_{0}$ the cosine of the Solar Zenith Angle (SZA) (OMI SO 2 AMF calculations, http://so2.gsfc.nasa.gov/). This method, used on a continuous spectrum, allows to measure simultaneously several 
trace chemical species producing small-scale absorption features, as well as ground reflectivity, cloud properties, etc. (Richter and Wagner 2011). The spectrum obtained is corrected for the strong Fraunhofer lines, but conserves the small features thanks to the Raman scattering effect (Levelt et al. 2006b). All algorithms are based on this reflectance spectrum.

$\rightarrow$ Atmospheric processes

For OMI's spectral range, two main atmospheric processes have to be accounted for: absorption of the radiation by atmospheric gases and scattering by air molecules, cloud droplets, aerosols, and trace gases.

Each element or molecule is characterized by a combination of absorption lines that forms a specific absorption spectrum. Absorption spectra are known for the main atmospheric gases. The presence of elements, within the column of atmosphere traversed by the radiation, is determined by comparing a calibrated reference spectrum with the recovered reflectance spectrum. This method allows the identification of all elements at the same time, but elements with overlapping absorption spectra such as $\mathrm{O}_{3}$ and $\mathrm{SO}_{2}$ (figure III.1) are differentiated by using specific sets of wavelengths picked to maximize absorption differences (Levelt et al. 2006b).

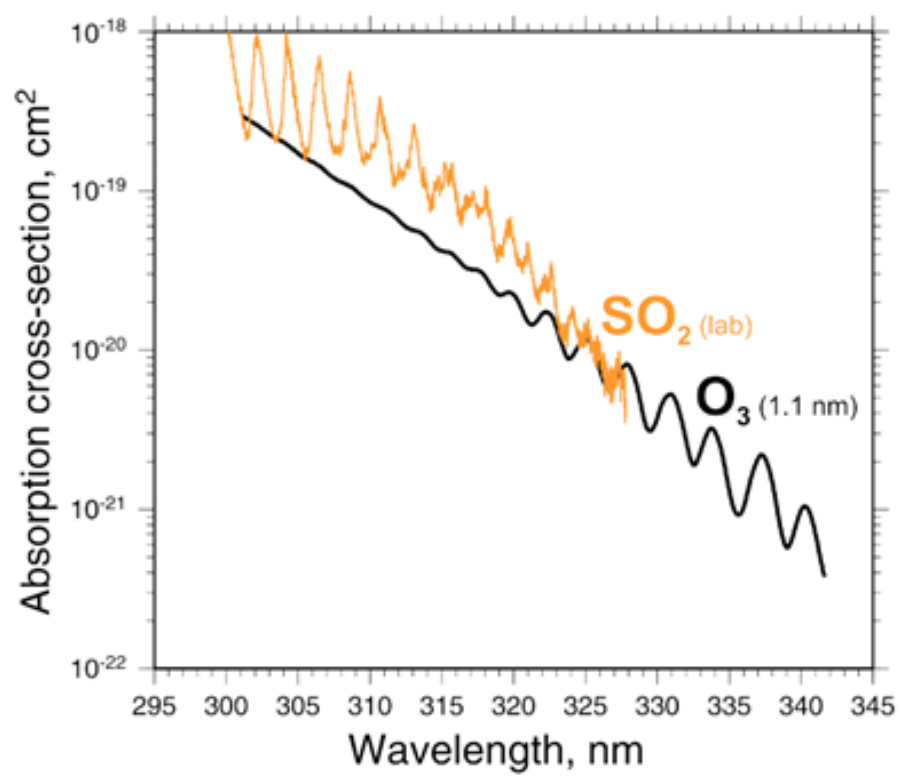

Figure III.1: Comparison of $\mathrm{SO}_{2}$ and $\mathrm{O}_{3}$ absorption cross-section for wavelengths 295 to $345 \mathrm{~nm}$. Figure (source: Simon A. Carn, personal communication, see annex IV for documentation of permission to use this material).

Scattering of solar radiation by atmospheric gases is the main source of UV and VIS radiations that contribute to the total energy scattered in the direction of the satellite (Petty 2006). Different types of scattering occur, depending on two main factors: (1) the 
particle size relative to the radiation wavelength, (2) the refractive index of the particle and of the surrounding medium. The shape and roughness of the particle control the direction in which the radiation is scattered.

In the case of OMI instrument measurements, Rayleigh scattering applies for particles with a radius of the order of $10^{-4} \mu \mathrm{m}$ (i.e. trace gases) while Mie scattering occurs for cloud droplets (5 to $50 \mu \mathrm{m}$ ) and aerosols $(<0.1 \mu \mathrm{m}$ to $>1 \mu \mathrm{m})$. In the visible band, clouds are a very important source of strong Mie scattering, and can even prevent the reflected radiation from underneath to reach the detector. Therefore, cloud coverage has to be carefully considered when interpreting data.

Interactions between radiation and atmospheric components modify the amount of radiation received by the instrument and reveal the presence of the elements within the column of atmosphere traversed by the radiation. The type and number of each element is then retrieved using mathematical algorithms described in the next section.

\section{(2) Retrieval algorithms}

This section focuses on the retrieval techniques used in $\mathrm{SO}_{2}$ calculations. Different techniques and algorithms have been developed specifically for each element, and details and calculations can be found in the Ozone Monitoring Instrument (OMI) Data User's Guide (http://so2.gsfc.nasa.gov/). All data retrieved by the OMI instrument are sent to the OMI Science Investigator-led Processing System (SIPS) center to be processed. Four levels of processing (level 0, 1B, 2 and 3) are available. The $\mathrm{OMSO}_{2}$ algorithm is used to retrieve $\mathrm{SO}_{2}$ totals from level $1 \mathrm{~B}$ data and produce level 2 data called 'data granules'. They are available for free as Hierarchical Data Format 5 (HDF-EOS5) files on the NASA Goddard Earth Science (GES) Data and Information Services Center (DISC; http://disc.sci.gsfc.nasa.gov/Aura/OMI/omso2.shtml) (Carn et al. in press). Level 2 data are geo-located, calibrated radiances presented as orbital swaths and include extended information such as ground pixel size, solar and viewing geometry. A data granule produced by $\mathrm{OMSO}_{2}$ algorithm has a general name of the form OMI-Aura_L2OMSO2 YYYYMMMDDtHHMM-OORBIT VCOL-2006m1127t164036.he5 and contains $\mathrm{SO}_{2}$ amounts calculated for different $\mathrm{SO}_{2}$ profiles.

OMISO2 algorithms derived from early retrieval techniques such as the Krueger-Kerr algorithm, used by Total Ozone Mapping Spectrometer (TOMS) instruments and based on 6 discrete band measurements in ultraviolet. Also, the later DOAS method, applied to OMI's predecessors Global Ozone Monitoring Instrument (GOME) and Scanning Imaging Absorption spectrometer for Atmospheric CHartographY (SCIAMACHY) uses measurements in a continuous window $(315-327 \mathrm{~nm})$ instead, but derived vertical column amounts of $\mathrm{SO}_{2}$ by using a Air Mass Factor (AMF) for a single wavelength (Yang et al. 2007). On the contrary, the Band Residual Difference (BRD) algorithm, developed specifically for the OMI instrument, is based on OMI ozone algorithm residual differences between 4 discrete wavelengths $(310.8,311.85,313.2$ and $314.4 \mathrm{~nm}$ ) corresponding to either maxima or minima absorption bands of $\mathrm{SO}_{2}$ (Krotkov et al. 
2006), in order to maximize the detection of small $\mathrm{SO}_{2}$ amounts. The average slant column density ( $\mathrm{SCD}$ ), that represents the concentration of trace gases along the path of light in the atmosphere, is derived from the SCDs calculated from the wavelength differences. The $\mathrm{SO}_{2}$ Vertical Column Density is calculated assuming a constant AMF of 0.36 (OMI SO 2 AMF calculations, http://so2.gsfc.nasa.gov/):

$$
\text { totalSO }_{2}=\frac{S C D}{A M F}
$$

Finally, the Linear Fit (LF) algorithm, used in this study, extends and improves BRD results for high $\mathrm{SO}_{2}$ amounts by considering 6 more wavelengths covering weaker $\mathrm{SO}_{2}$ absorption bands (Yang et al. 2007). Additionally, in order to convert $\mathrm{SO}_{2}$ slant column amounts into vertical column (column density), a realistic value of AMF and vertical $\mathrm{SO}_{2}$ distribution profiles are used as initial inputs (McCormick et al. 2012). Four prescribed profiles of vertical $\mathrm{SO}_{2}$ distribution in the atmosphere are proposed, based on a $\mathrm{SO}_{2}$ center of mass altitude (CMA) and corresponding to four typical $\mathrm{SO}_{2}$ distributions as a function of altitude: the planetary boundary layer $(\mathrm{PBL}, \sim 0-2 \mathrm{~km}, \mathrm{CMA}=0.9 \mathrm{~km})$ used by the BRD algorithm, the lower troposphere (TRL, $0-5 \mathrm{~km}, \mathrm{CMA}=2.5 \mathrm{~km}$ ), the midtroposphere $(\mathrm{TRM}, 5-10 \mathrm{~km}, \mathrm{CMA}=7.5 \mathrm{~km})$, and the upper troposphere - lower stratosphere $(\mathrm{STL}, 15-20 \mathrm{~km}, \mathrm{CMA}=17 \mathrm{~km})\left(\mathrm{OMSO}_{2}\right.$ Release Specific Information, http://so2.gsfc.nasa.gov/).

The $\mathrm{BRD}$ algorithm is used to calculate the $\mathrm{PBL} \mathrm{SO}_{2}$ amounts while the $\mathrm{LF}$ algorithm is used to derive the TRL, SRM and STL amounts $\left(\mathrm{OMSO}_{2}\right.$ Release Specific Information, http://so2.gsfc.nasa.gov/). Both BRD and LF algorithms are derived from the residuals of the OMTO3 algorithm. Here, the TRM $5 \mathrm{KM} \mathrm{SO}_{2}$ profile has been used, suitable for volcanic degassing in the lower troposphere (Carn et al. in press).

\section{(3) OMIplot}

OMI derived data used in this study have been processed by OMIplot software. OMIplot is an Interactive Data Language (IDL) based graphic tool, optimized to analyze and display level $2 \mathrm{OMI} \mathrm{SO}_{2}$ data for volcanic degassing (Carn 2011). It is available for free at https://vhub.org/resources/682. Products include daily and monthly maps of SO2 burdens, expressed in Dobson Units $\left(1 \mathrm{DU}=2.69 \times 10^{16} \mathrm{molecules} / \mathrm{cm}^{2}\right)$, and daily text files containing information about several physical parameters, listed in table III.2. The values obtained have been scaled for a constant size of pixel $\left(13 \times 13 \mathrm{~km}^{2}\right)$ and are stored in daily text files ('name of extracted area_so2lf_YYYYMMDD.txt') for each area. For more information about OMiplot, see https://vhub.org/resources/682/about). 
Table III.2: $a$. OMIplot output data and signification as displayed in daily text files. DU = Dobson Unit $\left(1 \mathrm{DU}=2.69 \times 10^{16}\right.$ molecules $\left./ \mathrm{cm}^{2}\right)$

\begin{tabular}{|c|c|c|c|}
\hline Shortcut & Name & Unit & Description \\
\hline lat & Latitude & Decimal degree & Latitude of the pixel center \\
\hline lon & Longitude & Decimal degree & Longitude of the pixel center \\
\hline so2_pbl & PBL SO2 density column & DU & SO2 VDC calculated with the BRD algorithm for a CMA of $0.9 \mathrm{~km}$ \\
\hline so2_3k & TRL SO2 density column & DU & SO2 VDC calculated with the LF algorithm for a CMA of $2.5 \mathrm{~km}$ \\
\hline so2_5k & TRM SO2 density column & DU & SO2 VDC calculated with the LF algorithm for a CMA of $7.5 \mathrm{~km}$ \\
\hline so2_15k & STL SO2 density column & DU & SO2 VDC calculated with the LF algorithm for a CMA of $17 \mathrm{~km}$ \\
\hline soip1 & Normalized UV reflectance pair 1 & 1 & Difference in normalized UV reflectances for 311.9 and $310.8 \mathrm{~nm}$ \\
\hline soip2 & Normalized UV reflectance pair 2 & 1 & Difference in normalized UV reflectances for 313.2 and $311.9 \mathrm{~nm}$ \\
\hline soip3 & Normalized UV reflectance pair 3 & 1 & Difference in normalized UV reflectances for 314.4 and $313.2 \mathrm{~nm}$ \\
\hline sp & OMI scan position & 1 & Give the position of the satellite on a scale from 1 to 60 \\
\hline sza & Solar Zenith Angle & degree & Position of the Sun relatively to the vertical direction \\
\hline vza & Viewing Zenith Angle & degree & Viewing angle of the sensor measured from the vertical direction \\
\hline cldfrac & Cloud Fraction & $\%$ & Fraction of the pixel covered by clouds \\
\hline bstoz & OMI ozone column amount & DU & Vertical ozone amounts \\
\hline ref331 & Reflectivity & $\%$ & Reflectivity of the pixel, estimated using wavelength $331 \mathrm{~nm}$ \\
\hline ai & Aerosol Index & 1 & Index used to detect the occurrence of aerosols \\
\hline errflg & Error flag & / & Quality measurement \\
\hline utc & Time & UTC & Time of measurement in UTC format \\
\hline
\end{tabular}

\section{c. Presentation of datasets and methodology}

\section{(1) Determination of study areas}

The primary goal of this study is to use OMI data to obtain temporal and time averaged values of $\mathrm{SO}_{2}$ burdens released at Lastarria volcano. A secondary goal is to repeat the same process for four copper smelters in order to compare their $\mathrm{SO}_{2}$ signals with the Lastarria signal. In addition, four areas sampling the background noise recorded by OMI instrument have been selected to investigate the contribution of background noise on retrieved $\mathrm{SO}_{2}$ emissions. Figure III. 2 represents the geographic locations of the 10 selected areas and table III.3 lists their respective coordinates, spatial extend, surface areas and specificities. They have been divided into 3 main groups regarding their purpose. 


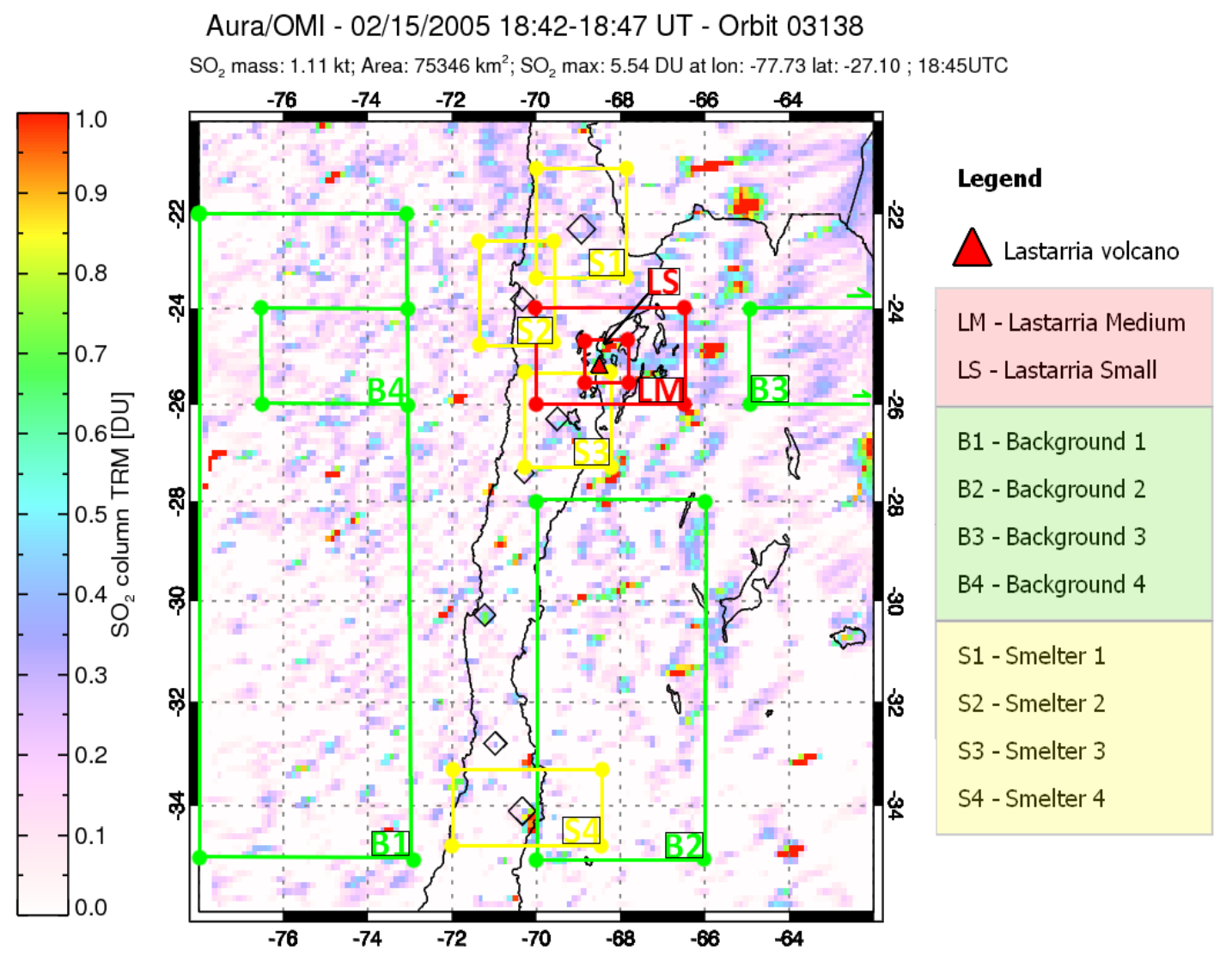

Figure III.2: location and spatial extend of the 10 sampled areas, divided up in 3 groups. See text below for more information and description of the groups. Lastarria volcano is located as a red triangle, while other volcanoes are empty triangles and copper smelters are represented as diamonds. Continuous black lines either represent the West coast of Chile - Pacific Ocean, frontiers or salars. The background was produced by OMIplot software (Carn 2011), for $\mathrm{SO}_{2}$ burdens in DU for one day.

$\rightarrow$ Group $\mathrm{n}^{\circ} 1$ (red): Lastarria volcano

Two regions respectively called Lastarria Small (LS) and Lastarria Medium (LM) have been extracted in this category. They are both centered on Lastarria volcano $\left(-25.15^{\circ} \mathrm{N}\right.$, $68.50^{\circ} \mathrm{E}$ ) and are used to constrain and investigate the spatial extent of Lastarria $\mathrm{SO}_{2}$ plume while minimizing the amount of background noise and any external source of $\mathrm{SO}_{2}$. LM holds the best representation of the $\mathrm{SO}_{2}$ plume.

$\rightarrow$ Group $n^{\circ} 2$ (green): Background noise

Background 1 (B1) and Background 2 (B2) are respectively located over land and ocean and have the largest surface areas of all the extracted regions. They sample large amounts of background noise to avoid local influences. Background 3 (B3) and Background 4 (B4) have been chosen to facilitate direct comparison with Lastarria Medium. Therefore, 
they have the same surface area and the same latitude as LM, and are as close as possible to LM.

$\rightarrow$ Group n`3 (yellow): Copper smelters

Copper smelters are anthropogenic sources of $\mathrm{SO}_{2}$ generally associated with large ore exploitations that are assumed to emit sulfur dioxide at a relatively constant rate on an annual time scale. Their $\mathrm{SO}_{2}$ emissions are comparable in magnitude to passive volcanic degassing and they are located in the same region as Lastarria volcano, which offer the unique opportunity to compare their respective $\mathrm{SO}_{2}$ emissions with the same background noise (Carn et al. in press), and assess the impact of seasonal cycles on the $\mathrm{SO}_{2}$ measurements. Smelter 1 (S1), Smelter 2 (S2) and Smelter 3 (S3) areas are located at almost the same latitude as Lastarria volcano and cover smaller areas (ranging from 4.9 to $6.0 \times 10^{4} \mathrm{~km}^{2}$ ) in order to minimize the contribution of background noise and to avoid other close sources of $\mathrm{SO}_{2}$. Smelter 4 (S4) is located southward and has the same surface area as Lastarria Medium.

Table III.3: list of the selected areas, names and associated tags, geographic coordinates (in decimal degrees), areas and short description.

\begin{tabular}{|c|c|c|c|c|c|c|c|c|c|c|}
\hline \multirow{2}{*}{ Name } & \multirow{2}{*}{ Type } & \multirow{2}{*}{ Tag } & \multirow{2}{*}{\multicolumn{2}{|c|}{$\begin{array}{c}\text { OMIplot } \\
\text { tag }\end{array}$}} & \multicolumn{2}{|c|}{ Latitude } & \multicolumn{2}{|c|}{ Longitude } & \multicolumn{2}{|c|}{ Extend $\left({ }^{\circ}\right)$} \\
\hline & & & & & $\min$ & $\max$ & $\min$ & $\max$ & Lat. & Lon. \\
\hline Lastarria Small & \multirow{2}{*}{ Lastarria } & LS & L4 & & $-25.6^{\circ}$ & $-24.8^{\circ}$ & $-68.7^{\circ}$ & -67.8 & 0,80 & 0,9 \\
\hline Lastarria Medium & & $\mathbf{L M}$ & $\overline{\mathrm{L} 1}$ & & $-26.0^{\circ}$ & $-24.0^{\circ}$ & $-70.0^{\circ}$ & $-66.5^{\circ}$ & 2 & 3,5 \\
\hline Smelter 1 & \multirow{4}{*}{ Smelter } & S1 & S1 & & $-23.3^{\circ}$ & $-21.0^{\circ}$ & $-70.0^{\circ}$ & $-67.9^{\circ}$ & 2,3 & 2,1 \\
\hline Smelter 2 & & \begin{tabular}{|l|}
$\mathbf{S 2}$ \\
\end{tabular} & $\mathrm{S} 2$ & & $-24.8^{\circ}$ & $-22.5^{\circ}$ & $-71.3^{\circ}$ & $-69.3^{\circ}$ & 2,3 & 2 \\
\hline Smelter 3 & & S3 & $\mathrm{S3}$ & & $-27.3^{\circ}$ & $-25.1^{\circ}$ & $-70.5^{\circ}$ & $-68.3^{\circ}$ & 2,2 & 2,2 \\
\hline Smelter 4 & & S4 & S5 & & $-35.5^{\circ}$ & $-33.5^{\circ}$ & $-68.5^{\circ}$ & $-72.0^{\circ}$ & 2 & 3,5 \\
\hline Background 1 & & B1 & $\mathrm{T} 2$ & & $-33.0^{\circ}$ & $-28.0^{\circ}$ & $-70.0^{\circ}$ & $-66.0^{\circ}$ & 5 & 4 \\
\hline Background 2 & Background & B2 & $\mathrm{T} 4$ & & $-35.0^{\circ}$ & $-22.0^{\circ}$ & $-78.0^{\circ}$ & $-73.0^{\circ}$ & 13 & 5 \\
\hline Background 3 & noice & B3 & $\mathrm{T3}$ & & $-26.0^{\circ}$ & $-24.0^{\circ}$ & $-65.0^{\circ}$ & $-61.5^{\circ}$ & 2 & 3,5 \\
\hline Background 4 & & B4 & $\mathrm{T} 5$ & & $-26.0^{\circ}$ & $-24.0^{\circ}$ & $-76.5^{\circ}$ & $-73.0^{\circ}$ & 2 & 3,5 \\
\hline Name & $\begin{array}{l}\text { Area } \\
\left(\mathrm{km}^{2}\right)\end{array}$ & \multicolumn{2}{|c|}{$\begin{array}{c}\text { Altitude as } \\
\text { (m) }\end{array}$} & \multicolumn{7}{|c|}{ Description } \\
\hline Lastarria Small & 8903,12 & \multicolumn{2}{|r|}{5697} & \multicolumn{7}{|c|}{ Small area above Lastarria vent } \\
\hline Lastarria Medium & 86558,08 & \multicolumn{2}{|r|}{5697} & \multicolumn{7}{|c|}{ Lastarria $\mathrm{SO}_{2}$ plume } \\
\hline Smelter 1 & 59725,08 & \multicolumn{2}{|r|}{2708} & \multicolumn{7}{|c|}{ Chuquicamata (open pit copper mine and smelter) } \\
\hline Smelter 2 & 56881,02 & \multicolumn{2}{|r|}{422} & \multicolumn{7}{|c|}{ La Negra (Altonorte copper smelter) } \\
\hline Smelter 3 & 59848,73 & \multicolumn{2}{|r|}{2368} & \multicolumn{7}{|c|}{ E1 Salvador copper mine (Potrerillos) } \\
\hline Smelter 4 & 86558,08 & \multicolumn{2}{|r|}{2115} & \multicolumn{7}{|c|}{ E1 Teniente ore mine and copper smelter } \\
\hline Background 1 & 247308,80 & \multicolumn{2}{|c|}{$\sim 2500$} & \multicolumn{7}{|c|}{ Large area of background noise over lands } \\
\hline Background 2 & 803753,60 & \multicolumn{2}{|r|}{0} & \multicolumn{7}{|c|}{ Large area of background noise over the Ocean } \\
\hline Background 3 & 86558,08 & \multicolumn{2}{|c|}{$\sim 3000$} & \multicolumn{7}{|c|}{ Same area and latitude as LM, over lands } \\
\hline Background 4 & 86558,08 & \multicolumn{2}{|r|}{0} & \multicolumn{7}{|c|}{ Same area and latitude as LM, over the Ocean } \\
\hline
\end{tabular}




\section{(2) Data processing and corrections}

Further processing of data obtained with OMIplot is necessary, in order to select pixels corresponding to 'true' $\mathrm{SO}_{2}$ values, as opposed to $\mathrm{SO}_{2}$ values caused by artifacts arising from retrieval noise (especially considering low-level degassing). These corrections are made using Matlab software. Matlab (C) MathWorks, www.mathworks.com/products/matlab/) is an interactive technical computing language suitable for scientific algorithm development, data analysis and data modelization. It has been used in this study to produce time-averaged maps of $\mathrm{SO}_{2}$ burdens and to compute time-series of $\mathrm{SO}_{2}$ emissions, cloud coverage and reflectivity for all extracted areas. Associated scripts are available in annex I. Three distinct steps are distinguished in data processing.

\section{$\rightarrow$ Extraction and selection of pixels}

Pixels containing 'true' $\mathrm{SO}_{2}$ values are evaluated using criteria described in Carn et al. (in press) in order to account with known issues affecting OMI data (see IV. Results and main limitations). Issues include the influence of the South Atlantic radiation Anomaly (SAA), associated with the occurrence of elevated $\mathrm{SO}_{2}$ values randomly detected for single pixels, as well as the influence of cloud coverage. The pertinence of each pixel is estimated using the comparison of OMTO3 algorithm residuals retrieved for three wavelength differences (respectively 311.9 - 310.8, 313.2 - 311.9 and $314.4-313.2 \mathrm{~nm}$ ) that correspond to local extrema (either minima or maxima) of the $\mathrm{SO}_{2}$ absorption spectrum. These differences are automatically calculated by OMIplot using the following relationship (Carn et al. in press). These differences are called soip1, soip2 and soip3 in daily text files produced by OMIplot software (table III.4). For this study, limit values for criteria selections were set according to previous experimentations (Carn et al. in press) and empirical evaluation of the influence of the selection algorithm used in Matlab script (annex I).:

$$
\begin{gathered}
\text { soipLim }=0 \\
\text { cldfracLim }=0.2
\end{gathered}
$$

\section{Unit conversion}

All the $\mathrm{SO}_{2}$ values extracted from OMIplot are expressed in Dobson Units (DU), where: $1 D . U .=28.48 \mathrm{~kg} / \mathrm{km}^{2}$. They are immediately converted in mass (tons) or mass per squared kilometers (tons $/ \mathrm{km}^{2}$ ), to estimate the total $\mathrm{SO}_{2}$ released for a single area and to compare between different areas, respectively. The conversion is made using:

$$
\text { mass } \mathrm{SO}_{2}=2.848 * A * 10^{-2} * \sum_{i=1}^{N}\left[\mathrm{SO}_{2}\right]=2.848 * A * * 10^{-2} \overline{\left[\mathrm{SO}_{2}\right]} * N
$$

where $\mathrm{A}$ is the area of a pixel in $\mathrm{km}^{2}, \mathrm{~N}$ the number of pixels selected, and $\left[\mathrm{SO}_{2}\right]$ the $\mathrm{SO}_{2}$ value in DU. The methodology used to calculate these values implies a spatial average of data, followed by a temporal average as illustrated in figure III.3. 


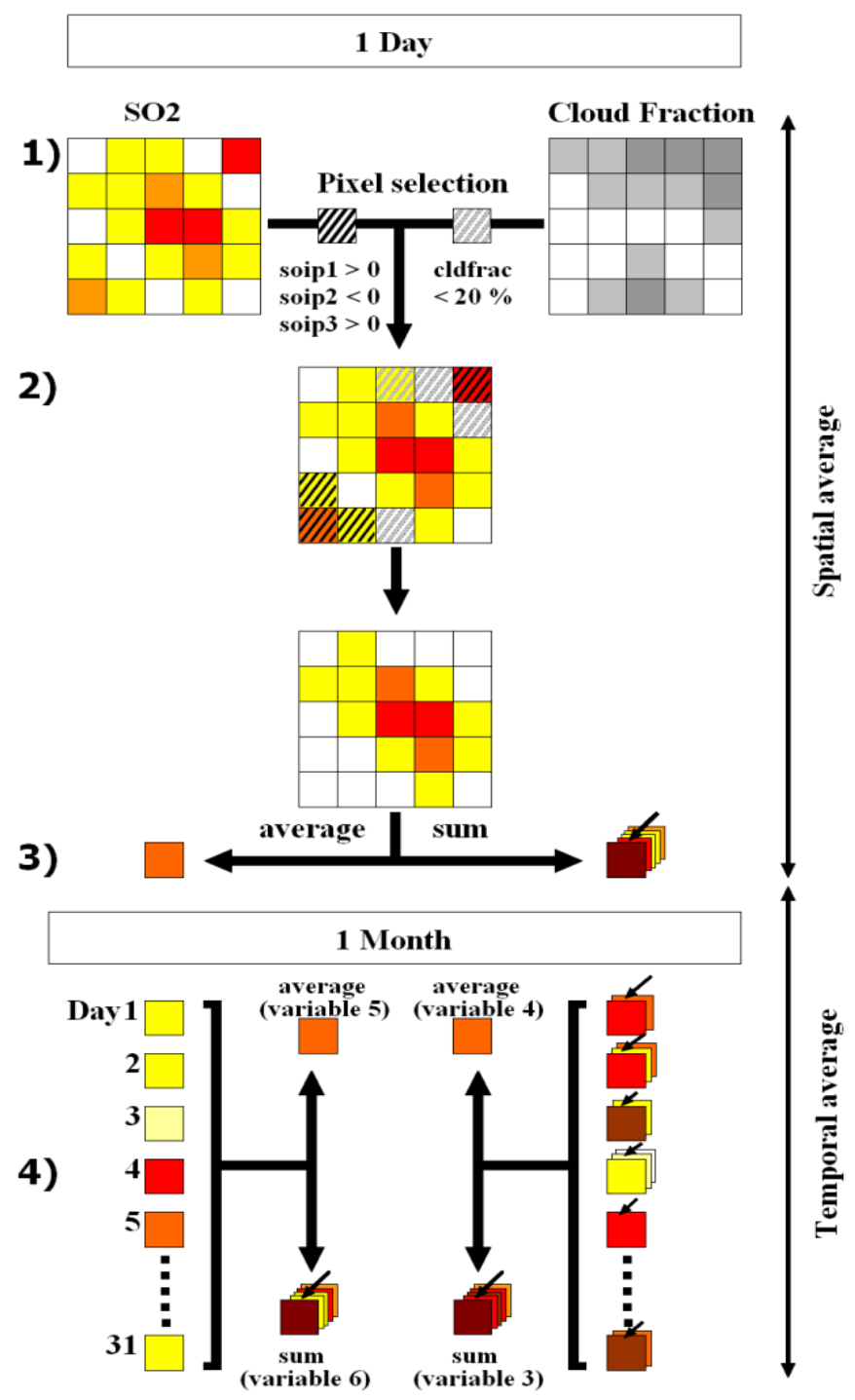

Figure III.3: Schematic representation of the methodology used in the OMISO2time_series.m file to calculate the spatial and temporal averages for $\mathrm{SO}_{2}$ amounts. See further description is the text below.

For each day, $\mathrm{SO}_{2}$ values (in DU) are obtained from OMIplot text files for each pixel (1) within one area. They are associated with values of soip1, soip2, soip3 and cloud fraction that are used to select relevant pixels (2) containing 'true' $\mathrm{SO}_{2}$ values. Pixels that do not match the selection criteria are removed from calculations, and all the remaining pixels are either averaged or summed. Thus, two values are obtained at the end of step (3): the averaged $\mathrm{SO}_{2}$ value (in tons $/ \mathrm{km}^{2}$ ) that will be used to compare between the different areas, and the total mass of $\mathrm{SO}_{2}$ in tons. This constitutes the spatial average. 
This is followed by a temporal average, where daily $\mathrm{SO}_{2}$ values obtained in step (3) are either averaged or summed again. At the end of step (4), four final variables are obtained (details in annex $I$ ) and used to display and calculate results (for each area):

- variable 3: total $\mathrm{SO}_{2}$ mass (in tons) produced per month;

- variable 4: average $\mathrm{SO}_{2}$ mass (in tons) produced per day;

- variable 5: average $\mathrm{SO}_{2}$ mass per surface area (tons $/ \mathrm{km}^{2}$ ) produced per day;

- variable 6: total $\mathrm{SO}_{2}$ mass per surface area (tons $/ \mathrm{km}^{2}$ ) produced per month.

$\rightarrow$ Data display and results

Final products are time-series plots for all of the variables described hereabove, month per month, for all areas. Difference is made between total $\mathrm{SO}_{2}$ amounts (tons) calculated from variable 3 and mean $\mathrm{SO}_{2}$ values (tons $/ \mathrm{km}^{2}$ ), calculated from variable 5 and used to compare different areas. Other results are georeferenced maps of the $\mathrm{SO}_{2}$ burdens (see annex I, sO2maps.m), computed by re-defining a fixed grid of pixels and resampling the OMIplot $\mathrm{SO}_{2}$ values on this grid. Finally, tables containing correlation values for the different zones have been calculated.

\section{Interferometric Synthetic Aperture Radar (InSAR)}

\section{a. Principles of measurement}

The acronym Radar stands for Radio Detection and Ranging. It is an active detection technique using one or several antennas sending electromagnetic pulses in radio and microwave wavelengths $(1 \mathrm{~mm}$ up to $100 \mathrm{~m})$ and recording the backscattered radiations. Radar recovering techniques use reflection and scattering properties of objects, described by Maxwell equations, as a basis to obtain information about size, roughness and distance of targets. Different frequency bands corresponding to various ranges of frequencies are historically used in radar detection. Bands $X(2.5-3.75 \mathrm{~cm}), \mathrm{C}$ $(3.75-7.5 \mathrm{~cm})$ and $\mathrm{L}(15-30 \mathrm{~cm})$ are used in ground deformation measurements. As an active detection technique, radars can be used in both days and nights and measured signals are not attenuated by atmospheric components (clouds, fog, aerosols, etc.), although interactions with atmospheric components can result in a reduction in radar wave velocity.

Synthetic Aperture Radar (SAR) is a specific imaging radar technique used in remote sensing, recording both phase and amplitude of echoes backscattered from the ground. The technique dramatically improves the resolution in the azimuth direction (Hanssen 2001) and the general image resolution ( $\sim$ x 1000) with respect to basic radar images (Massonnet and Feigl 1998).

Side-looking radars mounted on satellites, moving in azimuth direction, send pulses of radiation in the satellite across-track (range) direction, on a portion of Earth surface or 
ground cell. SAR method exploits shifts in Doppler effects to differentiate between targets located with a same cell and to synthesize a much larger aperture.

Interferometric Synthetic Aperture Radar (InSAR) is used to study ground deformation. The technique exploits the phase difference between two SAR images (respectively called 'master' for the older image and 'slave' for the most recent image) of the same area acquired with the same geometry but in different times to produce images of the phase differences, or interferograms.

The phase of each SAR pixel is the sum of two parameters and varies as a function of (1) the round trip travel time of the radiation from the satellite to the target and (2) the scattering characteristics of each resolution cell. The extreme spatial variability of this last contribution makes single phase images appearing noisy and unworkable.

Subtracting the two phase images comes down to cancel the random phase difference for each pixel and only conserves the phase contribution of the wave's travel. If the scattering characteristics of each resolution cell remain constant between the two acquisitions, their contributions cancel and one obtains a new image, the interferogram, where coherent interferometric fringes express the change in travel time of the radar wave. However, any change in the satellite-ground distance (typically target moving toward or away from the satellite) will be recorded. Since deformations alter the distance between the ground and the satellite, they result in fringe patterns in the interferogram. One fringe accounts for $0.5 \lambda$ of range change, where $\lambda$ is the radar wavelength. Satellites operating in the C-band (5.6 cm wavelength) such as ASAR-ENVISAT have a minimum sensitivity to deformations of $2.3 \mathrm{~cm}$, but can be potentially more sensitive depending on the spatial extent of the observed pattern and the temporal coverage of the data.

Shifts in the position of the satellite change the viewing angle and cause a stereoscopic effect in the line-of-sight of the satellite that lead to unwanted fringes correlated to the relief. This effect, called orbital contribution, mostly depends on the distance between satellite positions that is perpendicular to the looking direction of the instrument (perpendicular baseline). Massonnet and Rabaute (1993) define the altitude of ambiguity (Aa), that is an inverse function of the perpendicular baseline, as the change in elevation between two topographic fringes. Thus, a higher value of altitude of ambiguity corresponds to a higher change in elevation between two fringes and to a lower sensitivity to topography.

Changes in atmospheric conditions, in another hand, cause atmospheric contributions and additional unwanted fringes. Atmospheric contributions to the interferogram are divided between turbulent and stratified atmospheric contributions (Hanssen 2001). Turbulent atmospheric contribution corresponds to the local weather patterns that change with geographic location and time. Correction of turbulent atmospheric contribution requires accurate knowledge of the weather conditions at the time and place of the measurements. Modeling of such patterns is challenging and remains one of the principal limiting factors in interpreting interferograms. However, the stratified atmospheric contribution describes the influence of the vertical distribution of the atmosphere in regards to the influence of reflectivity of each layers traversed by the waves. Basically, the stratified atmosphere 
contribution causes interferometric fringes correlated with the relief, in response to the difference of layers traversed by the waves for different relief elevations (Hanssen 2002). This contribution can be modeled and corrected. Fortunately, the atmosphere over the Altiplano Plateau in Chile and Argentina has a weak turbulent component and is very calm and steady, which minimize the bias due to this contribution.

A more complete review of the InSAR technique can be found in Massonnet and Feigl (1998), Bürgmann et al. (2000) and Hanssen (2001).

\section{b. Dataset acquisition}

\section{(1) ENVISAT and ASAR systems}

The ENVISAT mission, launched in March $1^{\text {st }} 2002$ by the European Space Agency (ESA) is a polar-orbiting satellite following a sun-synchronous orbit. It flies at $709 \mathrm{~km}( \pm 10 \mathrm{~km})$ of altitude with an inclination angle of $98.6^{\circ}$. With a 100.6 minutes period (global coverage achieved in 1 to 3 days) and a repeat cycle of 35 days, it has been used to image Earth's atmosphere, land, ice and ocean through the 10 instruments it carried onboard, including the Advanced Synthetic Aperture Radar (ASAR) instrument (European Space Agency, https://earth.esa.int/). All communications were lost with the satellite on April $8^{\text {th }} 2012$ and although the causes remain unclear, the ENVISAT mission officially ended shortly after that.

The ENVISAT mission follows and inherits from the European Remote Sensing 1 (ERS 1, 1991) and European Remote Sensing 2 (ERS 2, 1995) missions of ESA. The main improvement of ASAR instrument, compared to its predecessors on ERS-1/2, is the phased-array antenna that offers the possibility to change between 7 swaths with various distances to the satellite and incident angles (Atterna et al. 1998). As a result, ASAR offers various acquisition modes in high- (Narrow Swath Mode), medium- (Wide Swath Mode), and reduced- (Global Monitoring Mode) resolution. The data acquired in Narrow Swath Image Mode (IM) are suitable for interferometric calculations and have been used in this study. Depending on the incidence angle, these modes cover swath widths ranging from $60 \mathrm{~km}$ to $110 \mathrm{~km}$ with a spatial resolution of few tens of meters. For a more technical review of the ASAR-ENVISAT specifications one can read the online documentation available on the ESA web server.

\section{(2) Datasets}

67 Single Look Complex images (SLC or ASA_IMS_1P from the IM mode of the ASAR instrument) have been used for this study, spanning a 87 months period from March 2003 to May 2010. The images have been acquired in 3 different swath/track combinations $(2 / 282,2 / 318$ and 6/404) in both ascending and descending mode (table III.4). For clarity purpose, SLC images will be further referred using [swath number] [track number] _ [absolute orbit number] (i.e. the image acquired in swath 2, track 318, 
orbit 17907 is referred as 2318 17907) and interferograms will be referred as [swath number] [track number] _ [absolute master orbit number] _ [absolute slave orbit number] where the master image is the oldest one and the slave the youngest one (i.e. the interferogram 2318_30933_41955 has been calculated using master image 2318_30399 and slave image $23 \overline{18} \_419 \overline{5} 5$ ) (complete list of all images found in annex II).

Images from swath/track 2282 have already been used by Froger et al. (2007), Ruch et al. (2008) and Anderssohn et al. (2009) to compute interferograms covering the Lazufre signal for the periods March 2003 to May 2005, 2003-2006 and 2003-2008 respectively. The same dataset was used in the present study, over an extended period of time up to May 2010, and data from two other swath/tracks were added.

Table III.4: Summary of the main characteristics of the 3 ASAR swath/tracks in this study.

\begin{tabular}{|l|c|c|c|}
\hline Datasets & "2282" & “2318” & "6404" \\
\hline Swath & IS 2 & IS 2 & IS6 \\
\hline Track & 282 & 318 & 404 \\
\hline Swath width (km) & 105 & 105 & 70 \\
\hline Ground position from nadir & $242-347 \mathrm{~km}$ & $242-347 \mathrm{~km}$ & $550-620 \mathrm{~km}$ \\
\hline Incident Angle Range & $19.2-26.7$ & $19.2-26.7$ & $39.1-42.8$ \\
\hline Mode & IMS & IMS & IMS \\
\hline Path & Ascending & Descending & Descending \\
\hline Polarization & V/V & V/V & V/V \\
\hline Data level used & $1 \mathrm{P}$ & $1 \mathrm{P}$ & $1 \mathrm{P}$ \\
\hline Dates & $03 / 09 / 03-05 / 12 / 10$ & $08 / 03 / 05-04 / 14 / 10$ & $11 / 22 / 05-04 / 20 / 10$ \\
\hline Time span (years) & 7 & $\sim 5$ & $\sim 4.5$ \\
\hline Number of scenes & 31 & 17 & 19 \\
\hline
\end{tabular}

\section{c. Data processing}

\section{(1) Extraction of the region of interest}

Previous studies used the $90 \mathrm{~m}$ STRM DEM distributed for no cost by the National Aeronautics and Space Administration (NASA), sometimes sampled to $45 \mathrm{~m}$ (Froger et al. 2007). Since 2012, the German Aerospace Center (DLR) has released the new $30 \mathrm{~m}$ version of the TanDEM-X DEM, available for free by registering on the EOWEB server (http://www.dlr.de/dlr/en/desktopdefault.aspx/tabid-10212/332 read-817/year-

all/\#gallery/1675). The DEM has been obtained from X-band Radar measurement by the two satellites of the German TanDEM-X mission (http://www.dlr.de/), covering discontinuous $2.5 \times 2.5^{\circ}$ areas of the globe, including the area surrounding the Lastarria volcano. 
Geographic coordinates of a reduced area (latitude min. -25.25, max. -25.04; longitude min. -68.61, max. -68.40) centered on Lastarria volcano have been manually calculated for each swath/track and used to extract a 21 x $23 \mathrm{~km}^{2}$ area from the SLC images corresponding to the area covered by the $30 \mathrm{~m}$ SRTM DEM from DLR. The DEM has also been oversampled at $15 \mathrm{~m}$. The use of this dataset with higher resolution than the previous studies allows more precise interferometric calculations and is better suited for the study of small-scale Lastarria deformation signal.

\section{(2) Calculation of interferograms}

After removing from the calculation process all the images with altitudes of ambiguity superior to $20 \mathrm{~m}$, interferograms have been produced using the Differential Interferometric Automated Process Applied to Survey Of Nature (Diapason) software, developed by the CNES and Altamira Information (Centre National d'Etudes Spatiales 1996) for each of the three swath/tracks (figure III.4).

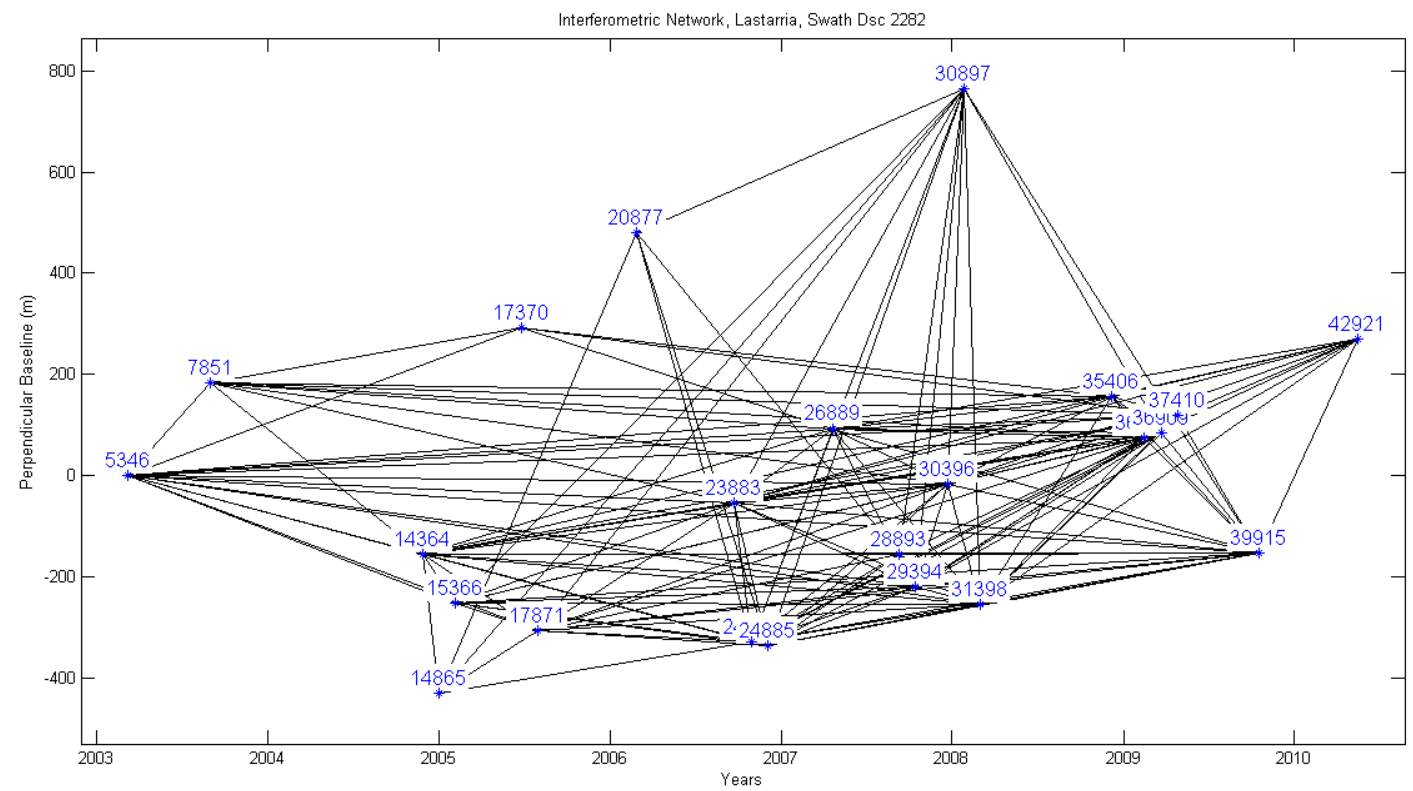

Figure III.4: scheme of the network of interferograms (black lines) obtained for swath 2282 in this study. The scenes used to calculate interferograms are displayed in blue and plotted as a function of their acquisition date (considering the earliest image as the reference) and baseline.

The first series of interferograms calculated had important topographic residuals (interferometric fringes correlated to the relief). The process implies radar images simulations (or SIMU) calculated from the DEM, which represent the relief as seen by the instrument for each different viewing angle. A SIMU is produced for each scene and then both SLC and SIMU images are correlated in order to obtain a precise value of Near Range (NR). The Near Range is the range value that is the closest to the satellite position. A bad correlation between SIMU and SAR images can affect the retrieved value of Near Range and cause the observed topographic residuals. For a still unclear reason, Diapason 
software fails to correctly correlate most of the SIMU-Master combinations for the swath-track 2282, so we developed an alternative procedure to pass by this correlation and determine the best NR value in another way. We produced three series of interferograms and tested a full range of NR values for each scene, in order to find the best correlation possible for each SIMU and SAR couple. The validity of each interferogram was judged by using the gradient of each interferogram. The Near Range value corresponding to the minimum total gradient for each interferogram was selected and used for further calculations.

\section{(3) Unwrapping}

After this step, interferograms are unwrapped. Because the phase for each cell is retrieved modulo $2 \pi$ from the satellite measurements, an uncertainty arises from the phase measurement when it comes to the estimation of displacements. The ambiguity is $2 \pi$ for the phase, and $\frac{\varphi}{2 \pi} \lambda$ for displacements, where $\varphi$ is the phase and $\lambda$ the wavelength. Unwrapping process implies to integrate phase gradients over coherent areas to retrieve their total deformation and differentiate with incoherent areas in between (Hanssen 2001). The result is the absolute value of deformation affecting coherent areas.

\section{(4) Corrections}

The last step of the interferometric calculation is to correct the interferograms from orbital residuals, large-scale ground deformation signal from the Lazufre (in this case) and atmospheric residuals (stratified atmospheric contribution only).

All these contributions are removed at once, by modeling and removing a regression surface, using a polynomial of the following form:

$$
\begin{gathered}
\varphi=\alpha x^{7}+\beta y^{7}+\gamma x^{6} y+\delta x^{5} y^{2}+\varepsilon x^{4} y^{3}+\cdots+\theta x^{6}+\vartheta y^{6}+\mu x^{5} y+\rho x^{4} y^{2} \\
+\sigma x^{3} y^{3}+\cdots+\tau x^{2}+\omega y^{2}+\zeta x y+\eta x+\varsigma y+\varkappa
\end{gathered}
$$

Where $\mathrm{x}$ and $\mathrm{y}$ are the geographic coordinates, multiplied by various constants symbolized as Greek letters, depending on the characteristics of each situation. A linear term is added to this polynomial and accounts for the stratified atmospheric contribution, along the z-direction (vertical, in red):

$$
\begin{gathered}
\varphi=\alpha x^{7}+\beta y^{7}+\gamma x^{6} y+\delta x^{5} y^{2}+\varepsilon x^{4} y^{3}+\cdots+\theta x^{6}+\vartheta y^{6}+\mu x^{5} y+\rho x^{4} y^{2} \\
+\sigma x^{3} y^{3}+\cdots+\tau x^{2}+\omega y^{2}+\zeta x y+\eta x+\varsigma y+\varrho z+\varkappa
\end{gathered}
$$

The order of magnitude of the polynomial is chosen empirically from a tradeoff between (1) choosing an order high enough to model all the possible scales of signal to remove, and (2) do not remove the signal of interest and (3) avoid extended calculations necessary to solve a higher-degree polynomial. In addition, in order to avoid correcting and removing the signal of interest, the corresponding area is blanked during the inversion process used to solve the polynomial. In this study, we used a $7^{\text {th }}$ order polynomial to 
remove all the undesired contributions. Figure III. 5 presents an example of the regression surface obtained from the polynomial, representing the contribution of the atmosphere and the large-scale Lazufre signal, and the interferogram after correction. The Lastarria signal is clearly visible in the center of the image and has not been removed by the corrections.
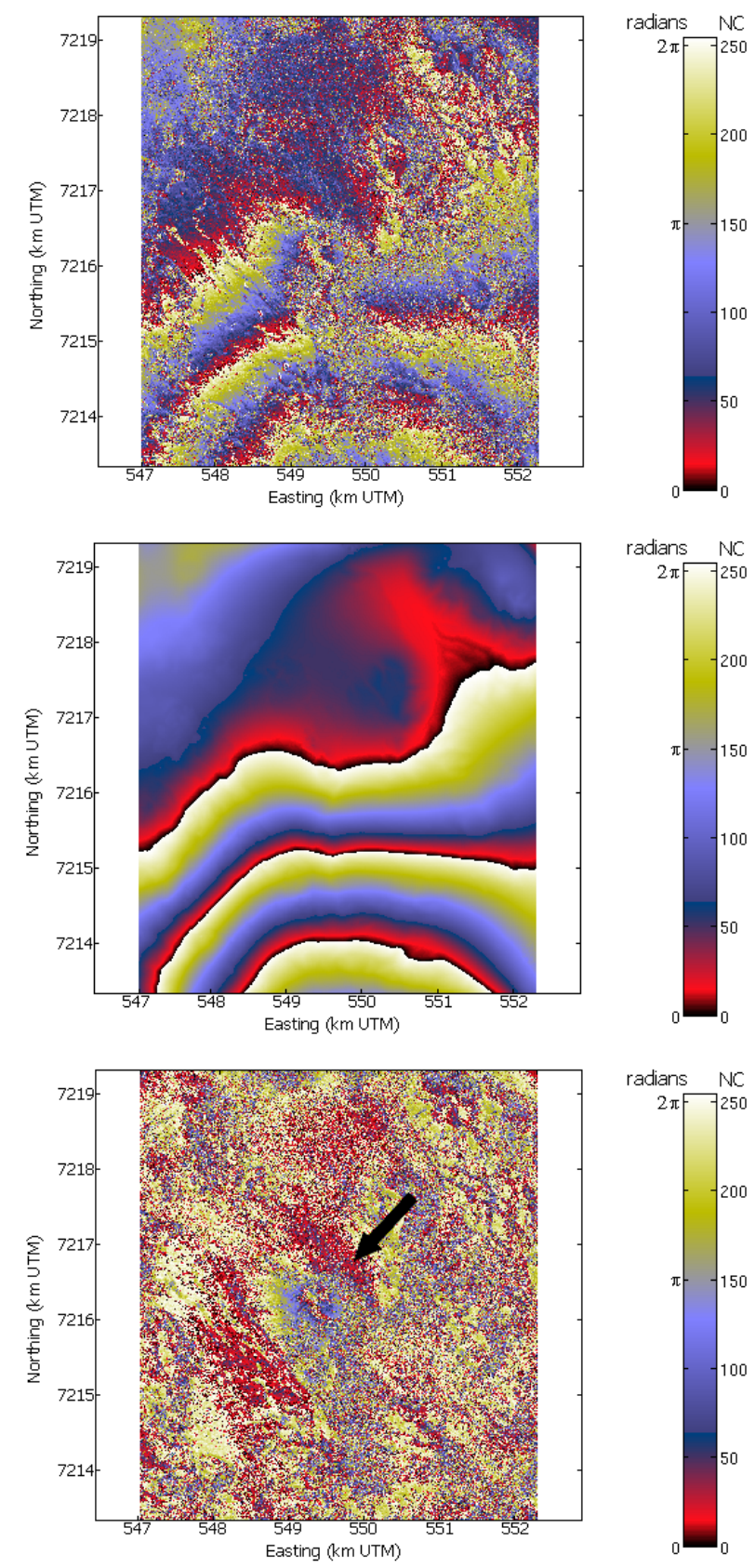

Figure III.5: (from top to bottom) example of interferogram obtained after step 3 (unwrapping), modeled regression surface corresponding to this scene and interferogram after correction with a black arrow pointing the recovered signal of interest. 


\section{(5) Time series calculation}

Finally, time-series of the displacements are calculated and used to present the results for each swath. Calculations start with a set of $\mathrm{N}$ interferograms (i.e.: $\mathrm{A}, \mathrm{B}, \mathrm{C}, \mathrm{D}, \mathrm{E}, \mathrm{F}$ ), that can be used to calculate $\sum_{i=1}^{N-1}(N-i)$ scenes (where $\mathrm{N}$ is the number of interferograms) by a matrix inversion process, using a squared matrix of the form:

$$
\left[\begin{array}{l}
A B \\
A C \\
A D \\
A E \\
A F \\
B C \\
B D \\
B E \\
B F \\
C D \\
C E \\
C F \\
D E \\
D F \\
E F
\end{array}\right]=\left[\begin{array}{cccccc}
-1 & 1 & 0 & 0 & 0 & 0 \\
-1 & 0 & 1 & 0 & 0 & 0 \\
-1 & 0 & 0 & 1 & 0 & 0 \\
-1 & 0 & 0 & 0 & 1 & 0 \\
-1 & 0 & 0 & 0 & 0 & 1 \\
0 & -1 & 1 & 0 & 0 & 0 \\
0 & -1 & 0 & 1 & 0 & 0 \\
0 & -1 & 0 & 0 & 1 & 0 \\
0 & -1 & 0 & 0 & 0 & 1 \\
0 & 0 & -1 & 1 & 0 & 0 \\
0 & 0 & -1 & 0 & 1 & 0 \\
0 & 0 & -1 & 0 & 0 & 1 \\
0 & 0 & 0 & -1 & 1 & 0 \\
0 & 0 & 0 & -1 & 0 & 1 \\
0 & 0 & 0 & 0 & -1 & 1
\end{array}\right] \times\left[\begin{array}{c}
A \\
B \\
C \\
D \\
E \\
F
\end{array}\right]
$$

Time series calculation starts with setting the oldest interferogram to zero, as a reference for further displacements:

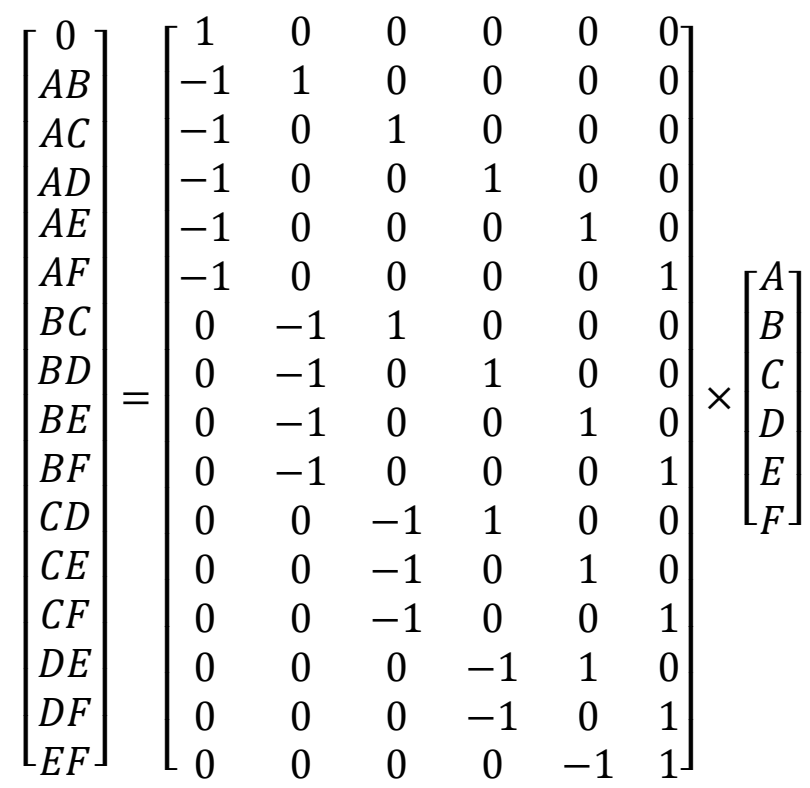


In addition, some interferograms can be removed if they are not suitable for calculations or if a scene is not represented enough to be constrained in the results. The matrix equation can be written as a more compact form as follow:

$$
\left[\delta_{\varphi}\right]=[D] \times[\varphi]
$$

Where $[\varphi]$ is the matrix containing the scenes $(\mathrm{A}, \mathrm{B}, \mathrm{C}$, etc. $),[D]$ is the coefficient matrix (or design matrix) and $\left[\delta_{\varphi}\right]$ is the matrix containing the interferograms. Then, the scenes are found by a network inversion:

$$
[\varphi]=\left(\left[D^{\tau}\right] \times[D]\right)^{-1} \times\left[D^{\tau}\right] \times\left[\delta_{\varphi}\right]
$$

The result of the inversion calculation is the relative displacement for each scene, relative to the first one. Results are plotted as a function of time.

\section{Main limitations and results}

\section{Ozone Monitoring Instrument (OMI)}

\section{a. Limitations}

OMI's high sensitivity to $\mathrm{SO}_{2}$ (Thomas et al. 2009) has already been exploited to record and monitor passive $\mathrm{SO}_{2}$ degassing emissions, and reasonable agreements have been found by comparison with ground-based $\mathrm{SO}_{2}$ measurement in several cases (Carn et al. 2008; Spinei et al. 2010; Carn and Lopez 2011; Carn et al. 2011). However, detecting low-level degassing remains challenging for OMI (Chance 2002) and several limitations have to be accounted for. The $\mathrm{OMSO}_{2}$ Release Specific Information document (http://so2.gsfc.nasa.gov/) proposes a list of the known limitations of the current $\mathrm{OMSO}_{2}$ algorithm version (1.1.1). Limitations encountered in this study arise from 3 main sources: (1) detection limits of the instrument, (2) uncertainties and errors in retrieval of the data by the $\mathrm{OMSO}_{2}$ algorithm and (3) uncertainties in the selection criteria used in the Matlab program (annex I).

\section{(1) Detection limits of the instrument}

$\rightarrow$ South Atlantic radiation Anomaly (SAA)

Space-based measurements over South America are affected by an increased noise caused by the SAA. Flux of energetic particles traverse the inner Van Allen radiation belt and interfere with the instrument detection (Carn et al. in press), causing spikes of $\mathrm{SO}_{2}$ randomly distributed over South America. These spikes are a few pixels in size and but 
their intensity is comparable to that of weak $\mathrm{SO}_{2}$ sources such as Lastarria or copper smelters. However, they are temporally limited to a single overpass and their influence is reduced when considering time and spatial averaged data (Carn et al. in press). Thus, their influence has been reduced (see III.1.c) by taking the average of all $\mathrm{SO}_{2}$ emissions for each day and estimating the total $\mathrm{SO}_{2}$ from the calculated value, and also by considering the monthly total $\mathrm{SO}_{2}$ emissions for analysis and interpretation. This method increases the signal-to-noise ratio and lowers the detection limit (McCormick et al. 2012).

$\rightarrow$ Limit of detection of the OMI instrument

Although the OMI instrument is suitable for detection of passive volcanic degassing (McCormick et al. 2012), the standard deviation corresponding to the TRM profile, in normal conditions and for the LF algorithm, is $0.3 \mathrm{DU}\left(8.5 \mathrm{~kg} / \mathrm{km}^{2}\right)\left(\mathrm{OMSO}_{2} \mathrm{README}\right.$ File, http://so2.gsfc.nasa.gov/). Yet, the daily emissions measured for Lastarria volcano (from ranging from $9.8 \mathrm{~kg} / \mathrm{km}^{2}$ to $22.2 \mathrm{~kg} / \mathrm{km}^{2}$ ) appear to have the same order of magnitude, resulting in a very low signal-to-noise ratio (SNR). Thus, it has been necessary to estimate the contribution of the background noise on the recovered $\mathrm{SO}_{2}$ totals. Investigations comprise (1) estimation of the contribution of background noise on Lastarria calculated $\mathrm{SO}_{2}$ total mass from $\mathrm{B} 3$ and $\mathrm{B} 4$ and (2) determination of a temporal cyclicity affecting all $\mathrm{SO}_{2}$ measurements for the region using $\mathrm{B} 1$ and $\mathrm{B} 2$.

(1) The intensity of the background noise appears to vary locally for different latitudes and longitudes. Thus, B3 and B4 areas are used to estimate the local intensity of background noise for Lastarria volcano, as they are located East and West of LM area respectively and they are recording the same background noise. Averaged $\mathrm{SO}_{2}$ amounts (tons $/ \mathrm{km}^{2}$ ) have been calculated on a monthly basis for B3 and B4, and the values have been used to estimate the noise contribution to LM measurements (figure IV.1).

The contribution of background noise to Lastarria Medium $\mathrm{SO}_{2}$ totals is estimated on a monthly basis, by direct comparison with the $\mathrm{SO}_{2}$ totals for $\mathrm{B} 3$ and $\mathrm{B} 4$. However, these values do not represent the background noise on Lastarria Medium are, but are estimations of local noise intensity on $\mathrm{SO}_{2}$ measurements. Results are expressed as percentage of Lastarria total $\mathrm{SO}_{2}$ emissions that can be attributed to noise influence (figure IV.1). Estimations of the contribution of the noise range from $39.5 \%$ to $72.78 \%$ for $\mathrm{B} 4$ and $58.06 \%$ to $79.26 \%$ for $\mathrm{B} 3$. In other words, $\mathrm{SO}_{2}$ emissions over Lastarria Medium area are in average $\sim 25 \%$ to $\sim 50 \%$ superior to $\mathrm{SO}_{2}$ emissions over neighboring empty areas. 


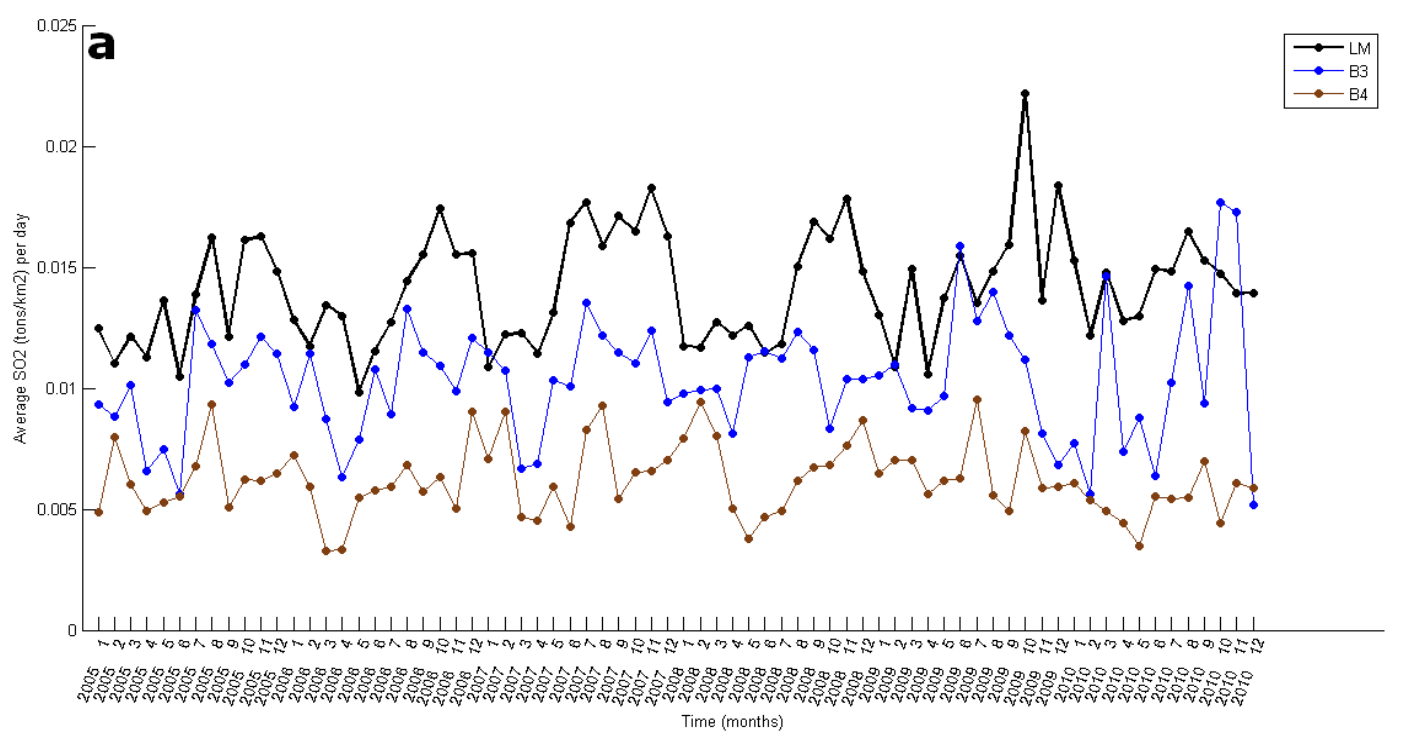

\begin{tabular}{|c|c|c|c|c|c|c|c|}
\cline { 2 - 9 } \multicolumn{1}{c|}{$\mathbf{n}$} & \multicolumn{6}{c|}{ S02 totals (tons) } & \multicolumn{2}{c|}{$\%$} \\
\hline Years & LM & B3 & B4 & LM - B3 & LM - B4 & B3/LM & B4/LM \\
\hline $\mathbf{2 0 0 5}$ & 11,57 & 8,45 & 5,42 & 3,12 & 6,30 & 73,03 & 46,87 \\
\hline $\mathbf{2 0 0 6}$ & 13,47 & 7,82 & 9,81 & 3,67 & 7,82 & 58,06 & 72,78 \\
\hline $\mathbf{2 0 0 7}$ & 11,95 & 8,47 & 5,32 & 3,48 & 6,49 & 70,87 & 44,55 \\
\hline $\mathbf{2 0 0 8}$ & 11,95 & 9,47 & 5,61 & 2,48 & 6,12 & 79,26 & 46,93 \\
\hline $\mathbf{2 0 0 9}$ & 8,52 & 6,51 & 3,85 & 2,01 & 5,36 & 76,40 & 45,25 \\
\hline $\mathbf{2 0 1 0}$ & 9,09 & 6,89 & 3,59 & 2,20 & 5,43 & 75,83 & 39,50 \\
\hline
\end{tabular}

Figure IV.1: a. comparison of average $\mathrm{SO}_{2}$ burdens (tons per $\mathrm{km}^{2}$ ) produced per day for Lastarria Medium (LM), Background 3 (B3) and Background 4 (B4) b. annual B3 and B4 contribution in tons of $\mathrm{SO}_{2}$, estimated for the same area as LM.

(2) Comparison of time-series of average $\mathrm{SO}_{2}$ burdens (tons $/ \mathrm{km}^{2}$ ) for the four background areas highlights an annual variation of $\mathrm{SO}_{2}$ recovered amounts (figure IV.2). $\mathrm{SO}_{2}$ emissions appear to be about 50\% higher (minimum) for the months 5, 6 and 7 (May to July, corresponding to austral winter) than for the months 11, 12 and 1 (November to January, corresponding to austral summer). This variation is observed on all background areas, but its effects are stronger on B1 and B2, that sample larger areas. 


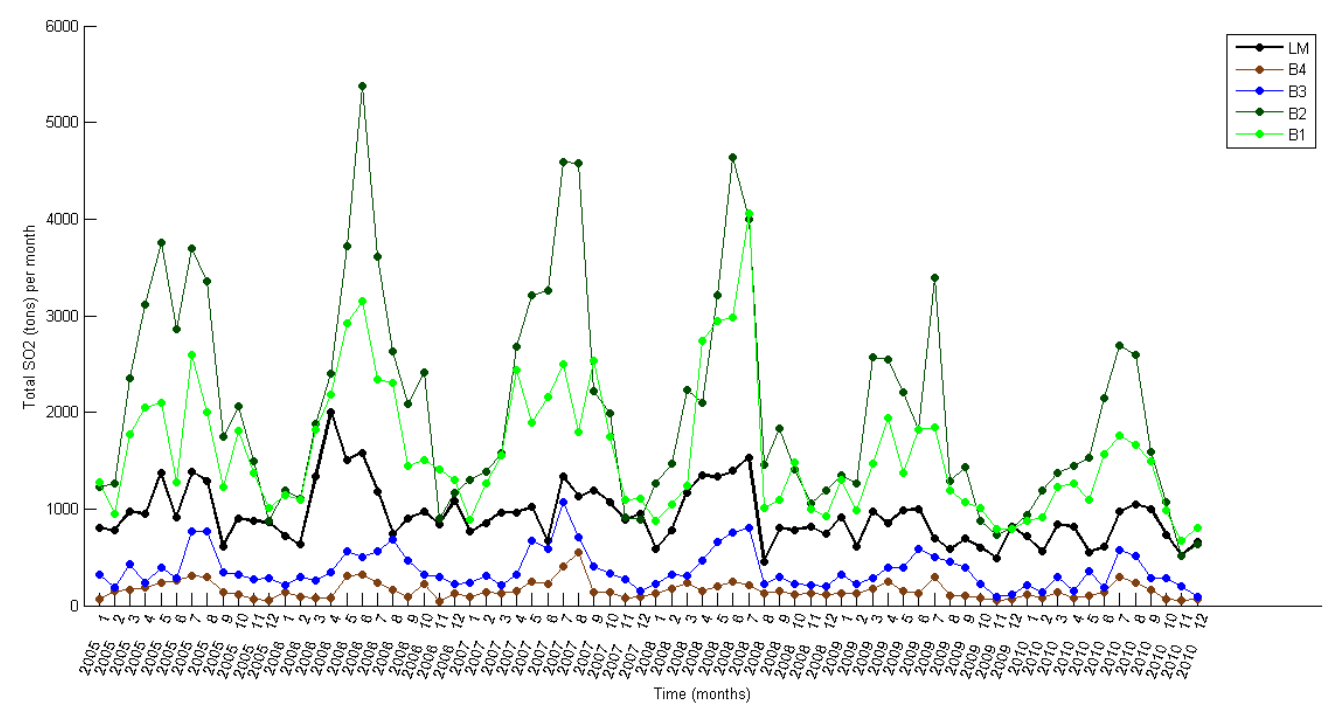

Figure IV.2: time-series of total $\mathrm{SO}_{2}$ burdens (tons) for the four background areas and LM.

The $\mathrm{SO}_{2}$ signals from the different background regions are correlated, with coefficients ranging from $55.6 \%$ for B1/B4 up to $85.5 \%$ for B1/B2 (see table V.1 in V.Discussion). A hypothesis to explain these annual variations is the influence of cloud coverage, that affects the amount of $\mathrm{SO}_{2}$ detected by the instrument (see (2) on next page).

As a conclusion, $\mathrm{SO}_{2}$ emissions over Lastarria area are in average $\sim 25 \%$ to $\sim 50 \%$ superior to the local noise, which also means that the noise accounts for $\sim 50 \%$ to $\sim 75 \%$ of the recovered $\mathrm{SO}_{2}$ totals for Lastarria area. A strong annual variation in the $\mathrm{SO}_{2}$ amounts is observed on both large areas (B1 and B2) and smaller areas (B3 and B4) that do not contain any source of $\mathrm{SO}_{2}$. These variations, included in the background noise, affect the detection of $\mathrm{SO}_{2}$ in this region and are expected to be found on Lastarria $\mathrm{SO}_{2}$ totals. They can be related with the influence of cloud coverage on $\mathrm{SO}_{2}$ detection. Thus, Lastarria $\mathrm{SO}_{2}$ totals are the combination of the original $\mathrm{SO}_{2}$ emissions from Lastarria fumaroles, and this local noise contribution.

\section{(2) Retrieval algorithm limitations}

$\rightarrow$ Negative $\mathrm{SO}_{2}$ values

Negatives values of $\mathrm{SO}_{2}$ (generally lower than 1DU in intensity) have been regularly observed in daily text files retrieved from $\mathrm{OMSO}_{2}$, for all areas. According to $\mathrm{OMSO}_{2}$ Release Specific Information document (http://so2.gsfc.nasa.gov/), negative $\mathrm{SO}_{2}$ columns of about $1 \mathrm{DU}$ are produced by the OMTO3 ozone retrieval algorithm when high total ozone values extend across the ozone profile used for calculations. Although the order of magnitude of these residuals might not be significant compared to high-level $\mathrm{SO}_{2}$ 
degassing, they have comparable negatives values to low-level $\mathrm{SO}_{2}$ degassing. Therefore, the results obtained must be considered as minimum $\mathrm{SO}_{2}$ emissions.

$\rightarrow$ Cloud coverage influence

Previous studies using OMI measurements (McCormick at al. 2012; Carn et al. in press) highlight the influence of cloud coverage over the detection of $\mathrm{SO}_{2}$ emissions. This issue is also discussed in the Ozone Monitoring Instrument (OMI) Data User's Guide (http://so2.gsfc.nasa.gov/). Meteorological clouds have different effects of $\mathrm{SO}_{2}$ measurements depending on the relative position of the clouds and the $\mathrm{SO}_{2}$ layer. According to Carn et al. (in press), the presence of meteorological clouds above the $\mathrm{SO}_{2}$ layer partly masks the $\mathrm{SO}_{2}$ signal at low altitudes and accentuate $\mathrm{SO}_{2}$ precipitation and deposition by enhanced wet processes, resulting in an apparent lost of $\mathrm{SO}_{2}$. Conversely, the presence of high cloud coverage (over 20\%) can also be associated with unrealistically high $\mathrm{SO}_{2}$ values and therefore results in an overestimation of the $\mathrm{SO}_{2}$ amount. In addition, values calculated at clouds' edges can take false very high negative or positive values (OMSO 2 Release Specific Information, http://so2.gsfc.nasa.gov/).

The influence of cloud coverage is observed at two different scales in this study. At first, the annual variations of cloud coverage on background areas correspond to annual variations of the detected $\mathrm{SO}_{2}$ totals (figure IV.3.a). Austral summer corresponds to higher cloud coverage and lower $\mathrm{SO}_{2}$ totals while austral summer corresponds to lower cloud coverage and higher $\mathrm{SO}_{2}$ totals. These variations are caused by the influence of cloud coverage on the detection of the instrument, and are observed regionally.

Then, the influence of cloud coverage is also observed in a local scale (over Lastarria volcano). The same annual variations are found (elevated values in austral summer, low values in austral winter), associated, for cloud fraction values higher than $20 \%$, to drops in the $\mathrm{SO}_{2}$ totals (figure IV.3.b). This effect is observed for $\mathrm{SO}_{2}$ emissions in austral summer (December-January) 2006, 2007 and 2008.

These are two aspects of the same influence of cloud fraction on $\mathrm{SO}_{2}$ detection, causing strong annual variations of the $\mathrm{SO}_{2}$ detected on a regional scale, and local drops in $\mathrm{SO}_{2}$ totals recovered for Lastarria volcano. 

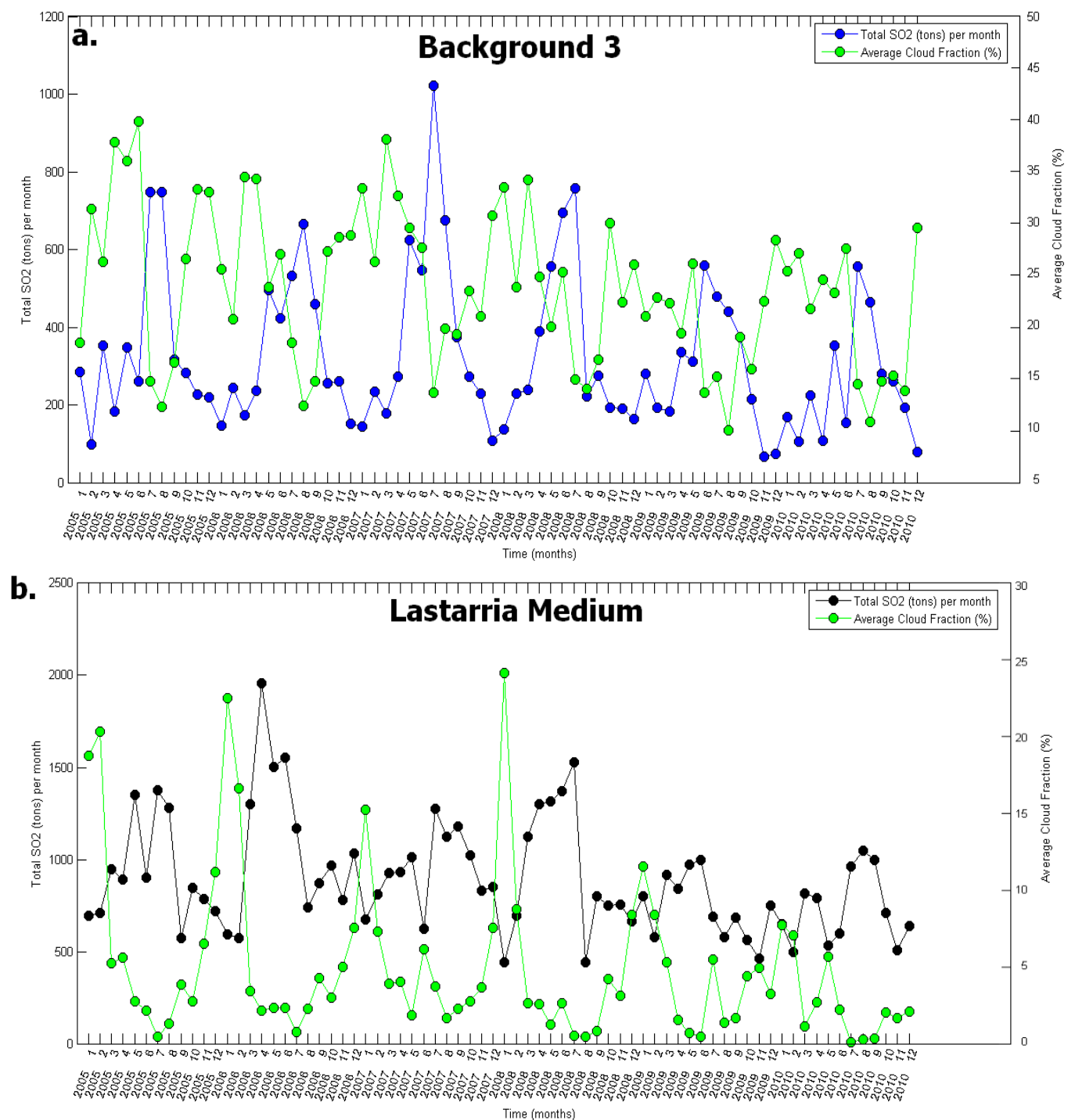

Figure IV.3: $a$. time-series of total $\mathrm{SO}_{2}$ burdens (in tons) and associated cloud fraction variations for $\mathrm{B} 3 ; b$. time-series of total $\mathrm{SO}_{2}$ burdens (in tons) and associated cloud fraction variations for LM.

The second effect of cloud coverage described by Carn et al. (in press) is avoided by setting the cldfracLim (see III.1.c) to $20 \%$, so that all the pixels associated with a cloud coverage value higher than $20 \%$ are not involved in calculations.

$\rightarrow$ Reflectivity influence

The reflectivity of underlying surfaces influences the detection of $\mathrm{SO}_{2}$ by maximizing or minimizing the amount of radiation directed toward the instrument (Carn et al. in press). Changes in ground reflectivity can therefore cause local variations of the $\mathrm{SO}_{2}$ amount detected. The primary cause of variations in ground reflectivity for the studied area is the deposition of fresh snow on the ground. Variations of $\mathrm{SO}_{2}$ signal in regards to reflectivity have been investigated, but no correlation has been found between reflectivity and $\mathrm{SO}_{2}$ 
emissions for any of the areas. In addition, the uniformity of the landscapes in these high altitude plateaus is a great advantage for $\mathrm{OMI} \mathrm{SO}_{2}$ retrieval (Carn et al. in press).

\section{(3) Data selection}

The daily data retrieved from OMIplot are corrected before being plotted using the Matlab protocol in annex I. Following the protocol described in Carn et al. (in press), each pixel is judged and removed from calculation if it corresponds to a cloud coverage superior to $20 \%$ or if the soip differences are not satisfied (see section III.1.c). This selection protocol allows differentiating between 'real' $\mathrm{SO}_{2}$ pixels and 'false' $\mathrm{SO}_{2}$ pixels created by either high cloud coverage or South Atlantic radiation Anomaly (Carn et al. in press). However, the cloud fraction criteria only remove a small amount of pixels, though corresponding to very elevated values of $\mathrm{SO}_{2}$ (figure IV.4), while the soip criteria (soipLim $=0$ ) select in average only $\sim 15 \%$ of the total number of pixels. However, according to Carn et al. (in press), these pixels represent the 'true' $\mathrm{SO}_{2}$ signal for each day.

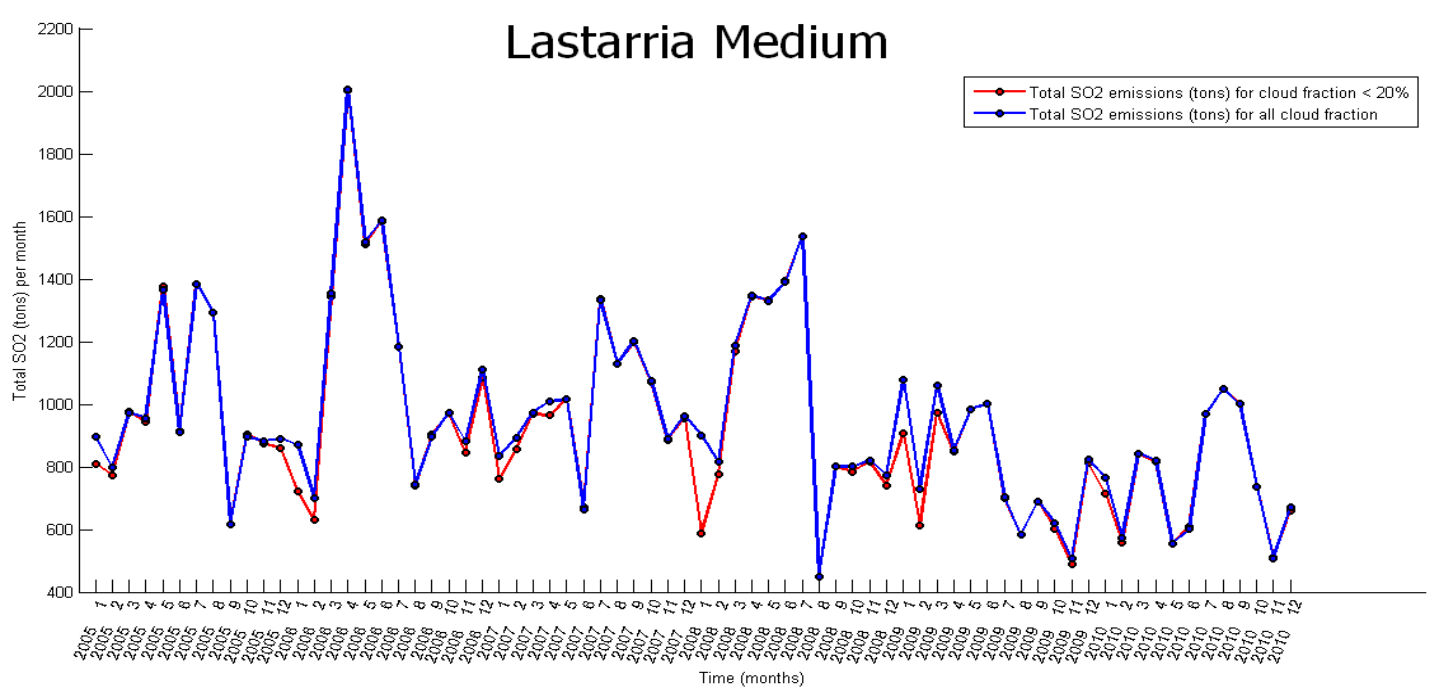

Figure IV.4: comparison of time-series of $\mathrm{SO}_{2}$ burdens for $\mathrm{LM}$ with and without cloud fraction correction.

\section{b. Results}

The $\mathrm{SO}_{2}$ detected at Lastarria volcano is produced by low-level degassing. Because they are very close in intensity to the standard deviation of the instrument and have the same order of magnitude that the background noise, the following results are subject to some limitations that have to be accounted with, in the reading and interpretation. However, using time-averaged plots of the $\mathrm{SO}_{2}$ burdens to increase the SNR ratio, and selecting 'true' $\mathrm{SO}_{2}$ values in accord with predetermined criteria (Carn et 
al. in press), permit to obtain significant results. The results of this study are divided in three steps. At first, the $\mathrm{SO}_{2}$ signal emitted by Lastarria fumaroles is identified (figure $I V .5)$ on maps, as zone of high $\mathrm{SO}_{2}$ concentration, coherent in space and recurrent in time. Then, total $\mathrm{SO}_{2}$ burdens are calculated for all areas, giving an estimation of the total $\mathrm{SO}_{2}$ emissions for the period studied. Finally, the temporal variations of the signal at Lastarria volcano are studied and discussed.

Figure IV.5 presents the maps of total $\mathrm{SO}_{2}$ burdens over LM, B3 and B4 areas. A significantly higher amount of $\mathrm{SO}_{2}$ is observed on LM maps ( $\sim 25 \%$ to $\sim 50 \%$ superior, on monthly totals). This $\mathrm{SO}_{2}$ cloud is located at the same place, close to Lastarria volcano, every year covered by the study, and similar feature does not appear on $\mathrm{SO}_{2}$-source free areas such as B1, B2, B3 or B4. Therefore, it can be interpreted as the signal of a distinct $\mathrm{SO}_{2}$ emission originating for a single source (spatially consistent) regularly degassing through time (temporally recurrent).

Then, total $\mathrm{SO}_{2}$ emissions (in tons) have been calculated for each month, then summed or averaged year per year and presented in table IV.I below. Because of the limitations and the correction performed to obtain these results, the $\mathrm{SO}_{2}$ totals have to be considered as minimum estimations of $\mathrm{SO}_{2}$ emissions. A total $\mathrm{SO}_{2}$ emission of $67.0 \mathrm{kT}$ is found for Lastarria Medium on the period 2005-2010. Higher values (114.4 kT and 148.7 kT) are found for B1 and B2, as expected for areas covering larger surface areas, but totals found for B3 and B4 only represent $40 \%$ and $17 \%$ of $\mathrm{LM} \mathrm{SO}_{2}$ total amount, respectively.

Additional monthly values are available in annex III for Lastarria Medium area, which contains the best estimation of Lastarria's $\mathrm{SO}_{2}$ plume.

Table IV.1: annual $\mathrm{SO}_{2}$ amounts measured for each area. The units are indicated for each column. All the areas have been processed with the same criteria parameters and using the same algorithm (OMISO2time_series.m, in annex I). 

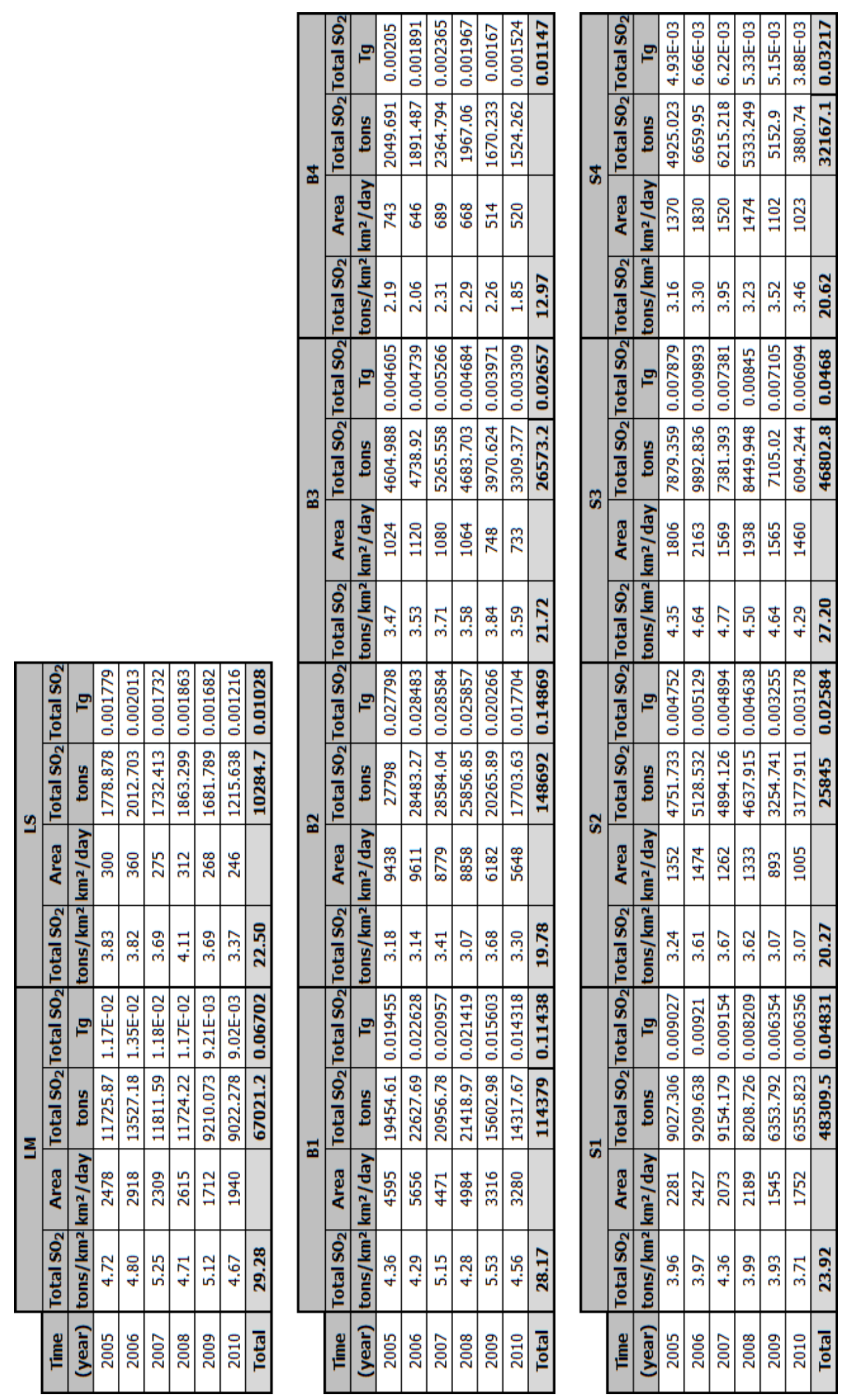

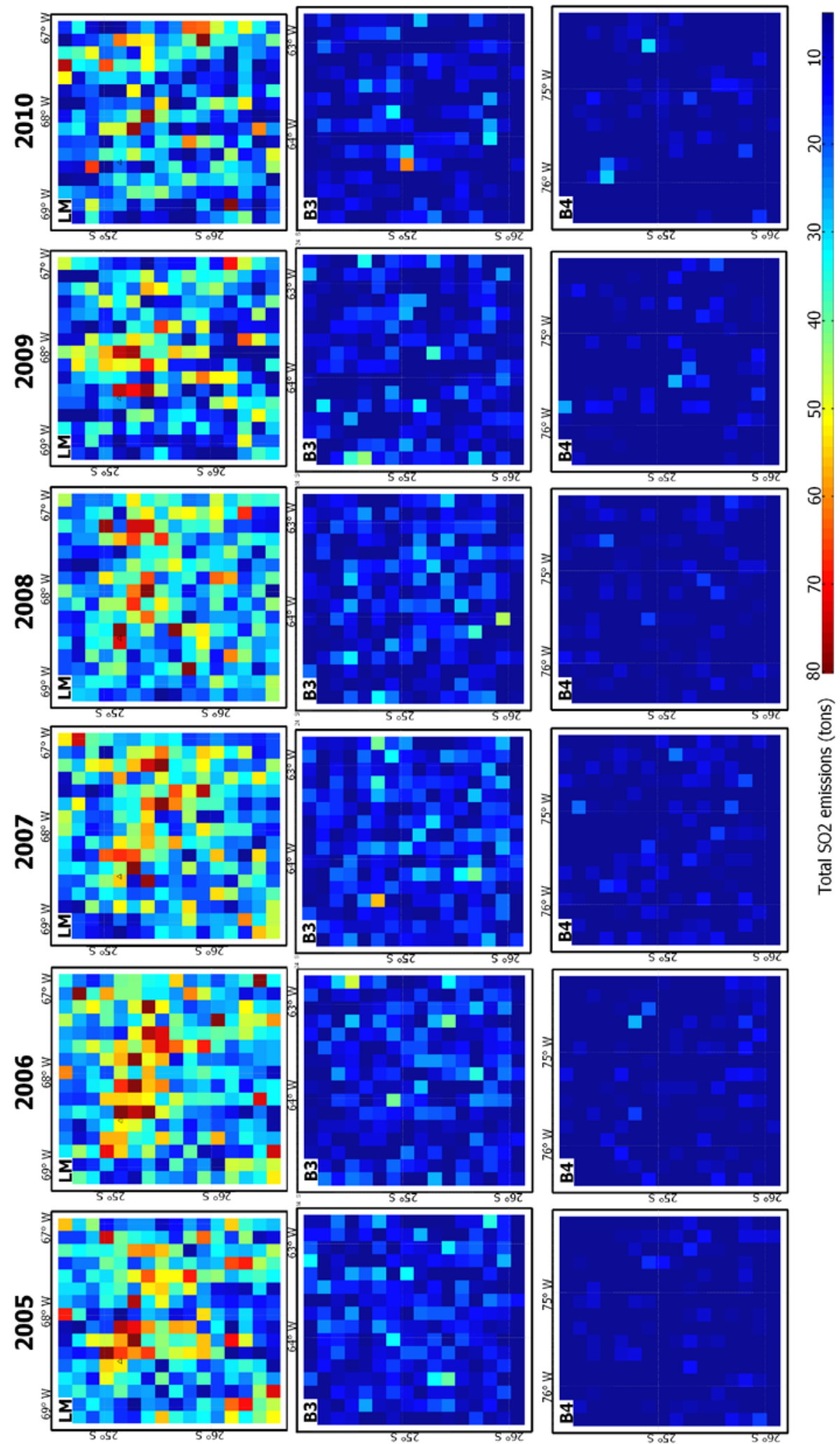

Figure IV.5: annual maps of total $\mathrm{SO}_{2}$ burdens in tons (with constant scale) over LM, B3 and B4 areas. Lastarria is displayed as a black triangle. Data plotted with the Matlab algorithm so2maps.m in annex $I$. 
Finally, monthly values are used to plot time-series of the different variables obtained for Lastarria Medium area (figure IV.6).
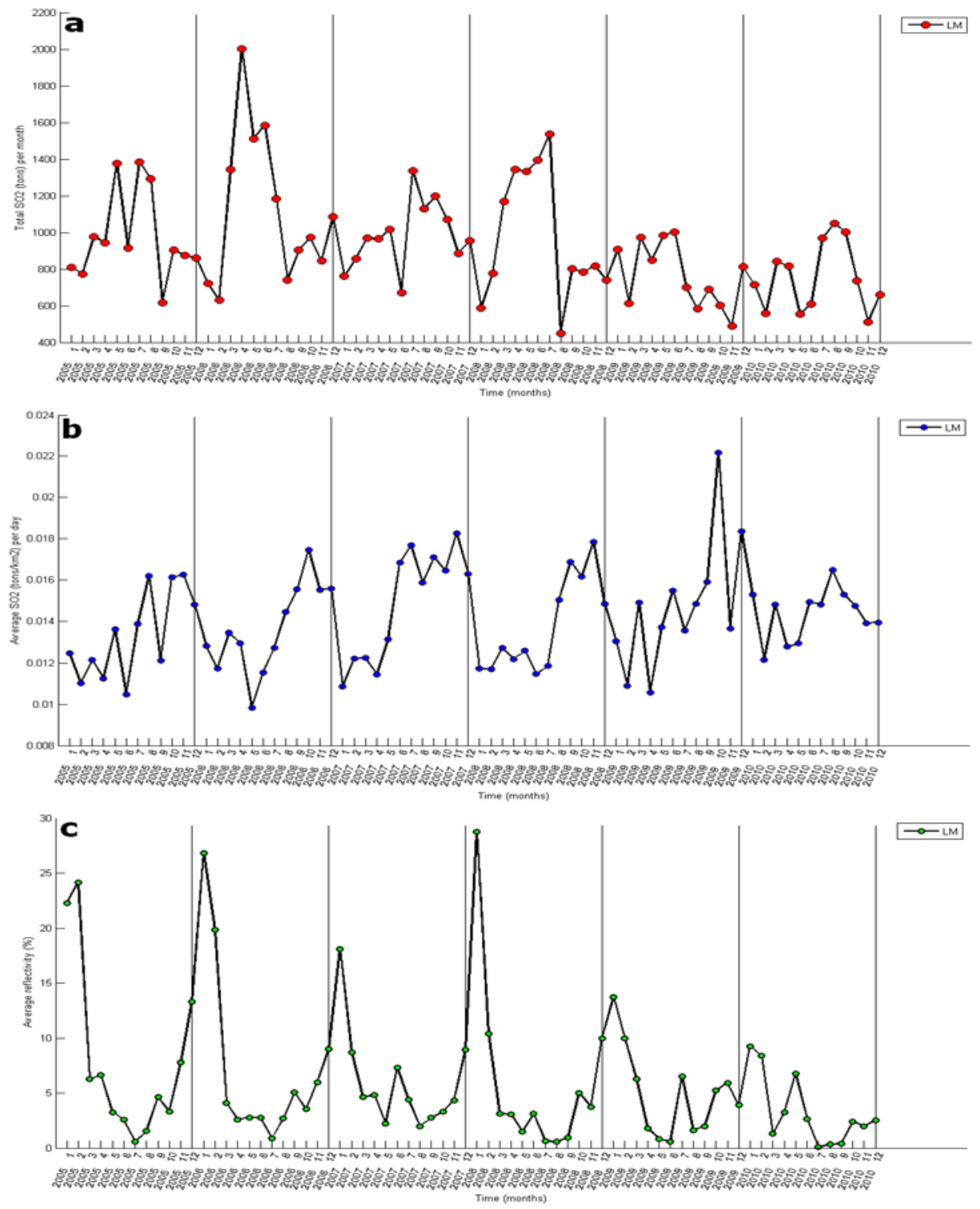

Figure VI.6: time series of Lastarria Medium area for various parameters calculated from OMISO2time_series.m script: $a$. total $\mathrm{SO}_{2}$ burdens (tons); $b$. average $\mathrm{SO}_{2}$ burdens (tons $\left./ \mathrm{km}^{2}\right)$, c. cloud fraction (\%).

Total $\mathrm{SO}_{2}$ emissions for one month over LM range from 447.82 tons to 2001.87 tons, which correspond to 18.16 and 96.0 tons $/ \mathrm{km}^{2}$, respectively. $\mathrm{SO}_{2}$ emissions are not constant along the year and vary as a function of time. The annual cycle observed on background areas (higher $\mathrm{SO}_{2}$ totals in austral winter and lower $\mathrm{SO}_{2}$ totals in austral summer) is not clearly observed on LM time-series. However, this was expected as the 
$\mathrm{SO}_{2}$ totals over LM are the combination of the background noise and the emissions of Lastarria fumaroles. The absence of clear annual variations, caused by the noise, suggests that Lastarria fumaroles emissions are strong enough to cover these variations. Recovering Lastarria emissions comes down to understand the exact contribution of the noise and remove its influence.

Four local maxima are identified in LM emissions, respectively on May and July 2005 ( $\sim 1387$ tons produced for each of these months, with an average of $\sim 46$ tons $/ \mathrm{km}^{2}$ ), on April, May and June 2006 (between $\sim 1500$ and $\sim 2000$ tons per month, with an average of $\sim 57.4$ tons $/ \mathrm{km}^{2}$ ), on July 2007 (1335 tons, 44.5 tons $/ \mathrm{km}^{2}$ ) and on June and July 2008 ( $\sim 1450$ tons per month, 49.5 tons $/ \mathrm{km}^{2}$ ). The maximum monthly emission for 2009 is $\sim 1000$ tons (34.5 tons $/ \mathrm{km}^{2}$ in June) and $\sim 1048$ tons (37.4 tons $/ \mathrm{km}^{2}$ in August) for 2010 .

Thus, the total $\mathrm{SO}_{2}$ emissions drop by about $50 \%$ in $2008-2010$ compared to the period 2005-2007. All the maximum values are reached during austral winter, which is in good correlation with the observations made on the influence of cloud coverage (figure IV.6.c). Indeed, cloud coverage follows a clear annual cycle over Lastarria area, with elevated values (above 20\%) in January and December, and values below 10\% for austral winter months. $\mathrm{SO}_{2}$ values measured for months associated with high cloud coverage are not significant because of the influence of cloud coverage on the detection of the instrument (see IV.1.a for details).

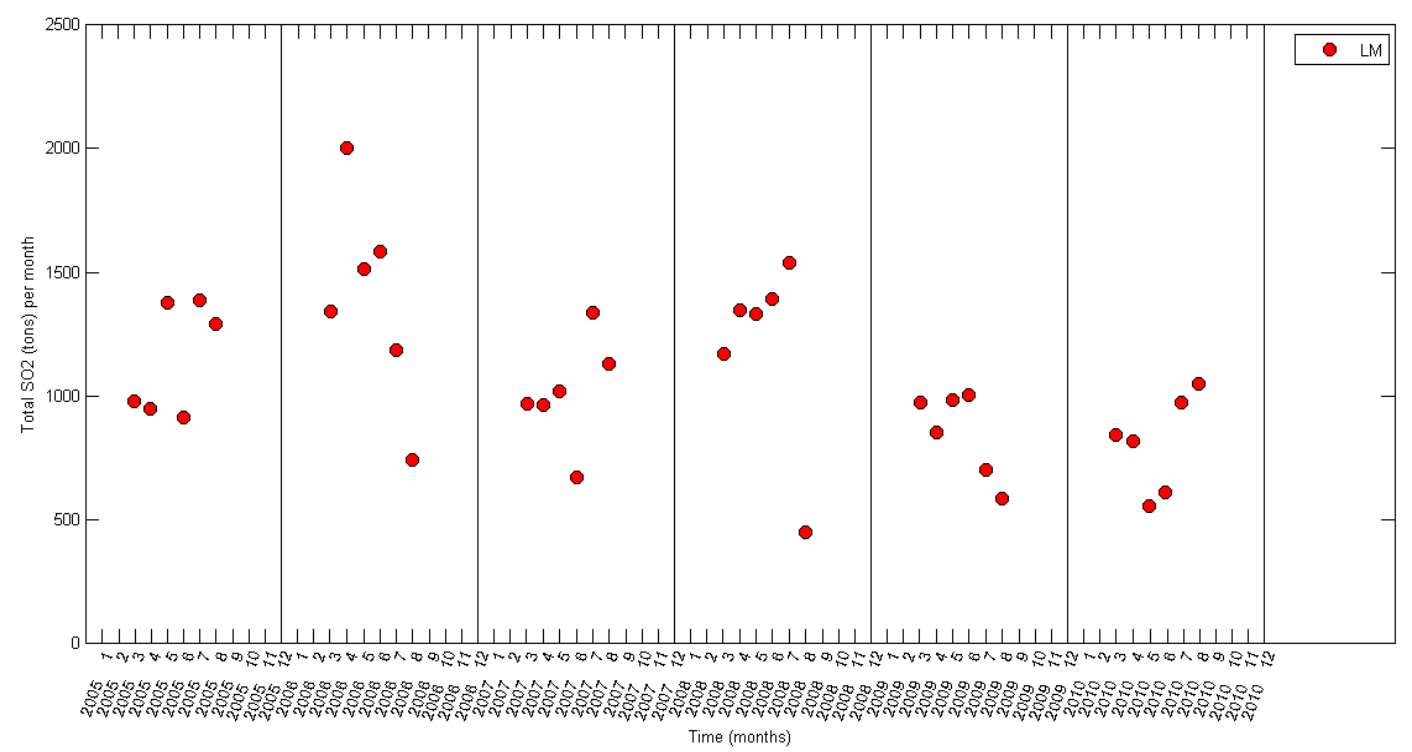

Figure IV.7: total $\mathrm{SO}_{2}$ burdens (tons) per month at LM for March to August, every year from 2005 to 2010 .

Thus, the actual $\mathrm{SO}_{2}$ emitted from Lastarria have to be evaluated based on the record made in the austral winter months rather than the austral summer months, affected by an enhanced errors caused by the higher cloud coverage (figure IV.7). According to these results, Lastarria's total $\mathrm{SO}_{2}$ emissions appear to be constant from 2005 to mid-2008, with an average value of $\sim 1200$ tons of $\mathrm{SO}_{2}$ detected per month, whilst an average of $\sim 822$ tons of $\mathrm{SO}_{2}$ was detected per month in 2009-2010. 
It is possible to interpret these variations in two ways. Figure IV.7 can show a constant decline in $\mathrm{SO}_{2}$ emissions at Lastarria volcano, continuously from 2005 to 2010. It can also show a brutal reduction of the emissions occurring around 2007-2008, while the $\mathrm{SO}_{2}$ emissions in 2005-2007 stay constant with an average value of about $\sim 1220$ tons/month, and the emissions from 2008 to 2010 stay also constant with an average of about $\sim 910$ tons/month. However, the low SNR ratio and the important contribution of the background do not permit to conclude on this point.

\section{InSAR results}

We obtained 23 scenes from the swath 2282, 16 from the swath 2318 and 20 from the swath 6404, covering periods of 2626, 1716 and 1611 days, respectively. An example of retrieved displacement map is shown, for each swath, in figure IV.9. Lastarria ground displacement signal is observed on each swath, and is in good correlation with previous results. It shows positive displacements of the ground in the direction of the satellite for all swaths, meaning that the inflation affecting Lastarria volcano area has a 3-dimensional component.
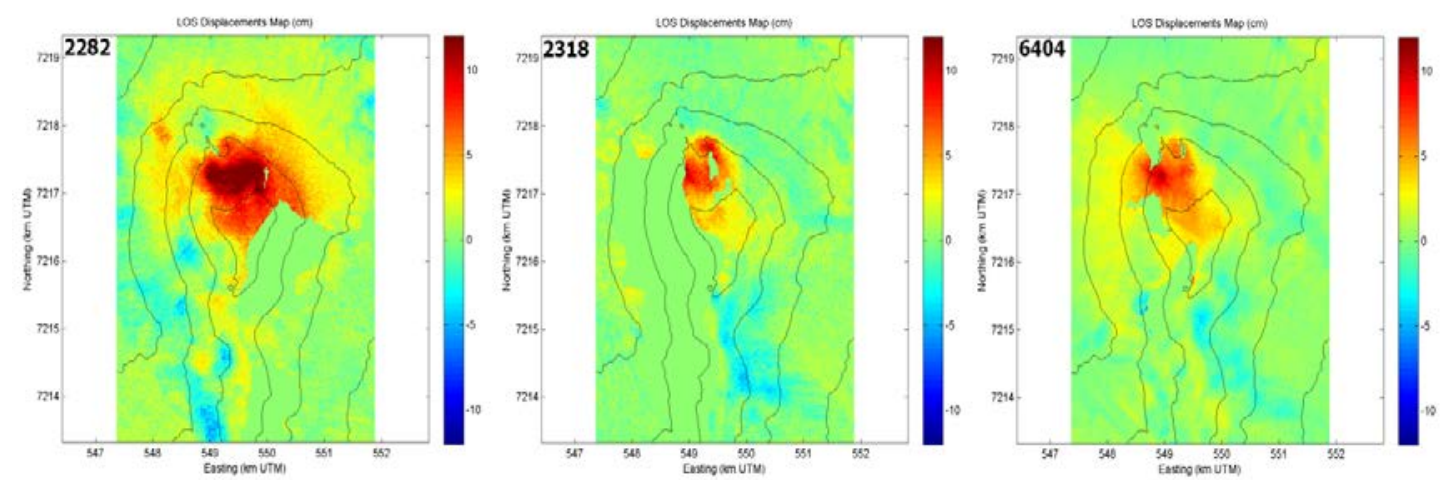

Figure IV.9: example of interferograms illustrating LOS displacements for the three swaths (2282, 2318 and 6404 from left to right) covering periods of 2626, 1716 and 1611 days, respectively. Black lines represent the topographic outline of the relief.

The center of the inflating area is located North-West of the summit of Lastarria volcano sensu strico. Its location is correlated for the different swaths, which means that the maximum displacements are taking place at the same geographical location for the three measured directions. 

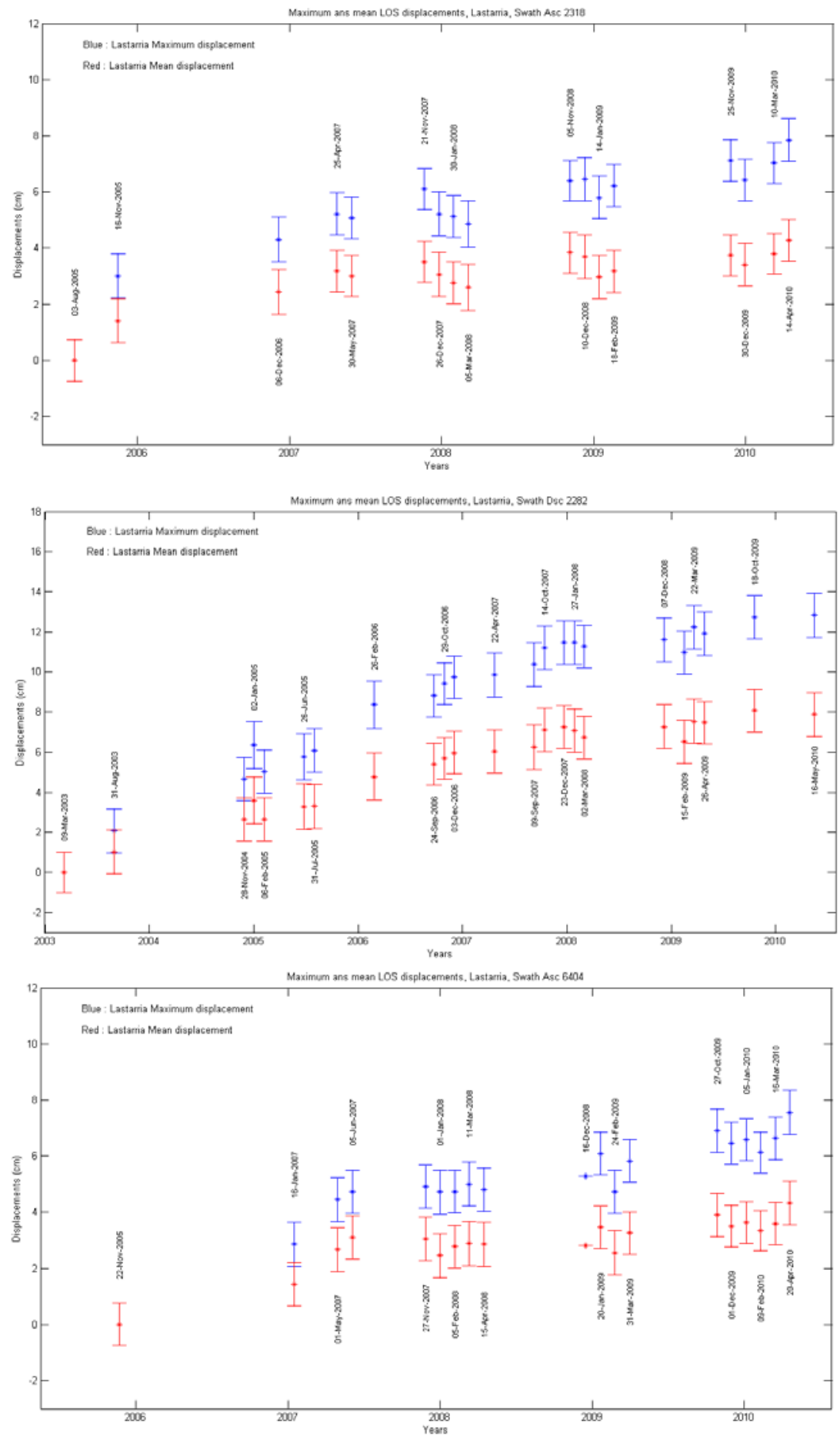

Figure IV.10: time-series of maximum and mean ground displacements $(\mathrm{cm})$ in the LOS of the satellite for the three swaths. 
Time-series of the displacements have been calculated for each swath in order to estimate the rate of displacements and to clarify the temporal evolution of the deformation. Results include the maximum and mean displacements rates calculated in a $100 \times 200$ pixels window centered on the location of maximum displacement (figure IV.10) that both appear to follow the same trends for each swath. The standard deviations associated with each value are derived from the uncertainty arising from the network inversion process during time-series calculations (details in III.2.c).

Mean displacement rates have been calculated on squared areas of $100 \times 200$ pixels containing Lastarria deformation signal. Results respectively range from $0.34 \mathrm{~cm} /$ year on the period November 2005 to April 2010 for swath 6404, $0.47 \mathrm{~cm} /$ year for the same period on swath 2318 and $1.11 \mathrm{~cm} /$ year from March 2003 to April 2010 on swath 2282 . The higher value obtained for swath 2282 is partly explained by the larger period of time covered by this swath (more than 2600 days and only $\sim 1650$ days only for swathes 2318 and 6404). As a result, swath 2282 is the only one to record the displacements on the period 2003-2005 with a sufficient number of measurements to allow interpolating the results. The estimated displacement speed for this particular period is $1.52 \mathrm{~cm} /$ year for swath 2282, while the rate for the period 2007 to 2010 drops to $0.54 \mathrm{~cm} /$ year. This last value is still higher, yet closer, than the displacement rates found for swathes 22318 and 6303.

Maximum displacement rates range from $0.80 \mathrm{~cm} /$ year for the swath 2318, $0.95 \mathrm{~cm} /$ year for the swath 6404 and up to $2.44 \mathrm{~cm} /$ year for the first period and 0.94 for the second period of the swath 2282. Thus, the large-scale temporal evolution of Lastarria ground deformation is characterized by a first period of constant deformation with higher displacement speed $(1.52 \mathrm{~cm} /$ year) from 2003 to about 2007. Then, from 2007-2008 to 2010, the rate of displacement clearly decreases drops and switch to about $0.50 \mathrm{~cm} /$ year in the direction of swath 2282 to $1.30 \mathrm{~cm} /$ year. However, although the displacement rate changed after 2007, the deformation remains constant during this second period at the first order. Constant displacements are also observed on swathes 2318 and 6404 that all show a similar temporal evolution (close displacement rates) although with lower displacement speeds.

In addition, because the ground displacements are following such a constant evolution, it has been possible to use a linear regression fit model for each swath. The results of the modeling are found in figure IV.11 with the calculated slopes (in $\mathrm{cm} /$ year). Two linear regression curves have been used instead of one to fit the variations of swath 2282, and both results are shown in figure IV.11. 

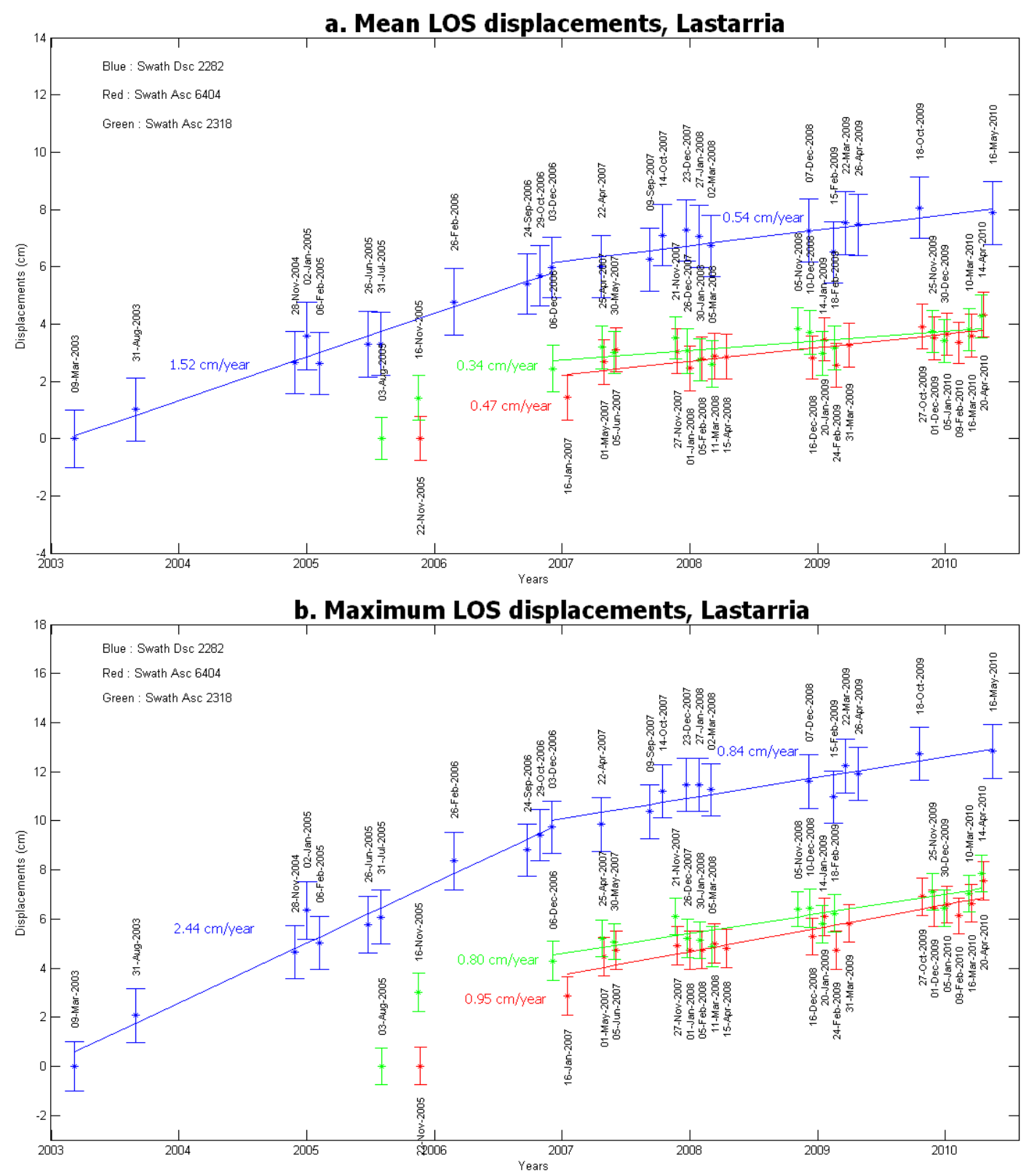

Figure IV.11: time series of the ground displacements in the LOS of the satellite for the swaths 2318 (green), 6404 (red) and 2282 (blue), and associated standard deviations for a. mean displacement rates and $b$. maximum displacement rates. Linear regression are plotted for each swath and the coefficients corresponding to the curves' equations $(Y=a X+b)$ are displayed in colors corresponding to each swath/track, with corresponding displacement rates. Two linear regressions have been calculated for the swath 2282, for the periods 2003-2007 and 2007-2010, respectively.

On the contrary, some other variations in the displacements dynamics are observed on a smaller scale. These small scale variations are only observed on shorter periods, and do not last typically more than a few months. From November 2007 to March 2008, swathes 2318 and 2282 show the same diminution of the displacement rate, while from December 
2009 to April 2010, the swathes 6404 and 2318 follow the exact same variation with decreasing displacements at first follow by the same period of re-increasing displacements. Both diminution and increasing of the displacement occurred at a similar rate for the two swaths. However, these variations are small in intensity and may not be significant in regards to associated standard deviations. In addition, the poor temporal resolution of the interferometric calculations does not allow concluding on a small-scale evolution of ground displacements and deformation dynamics at Lastarria volcano.

\section{Discussion}

Interpretation of the results is limited by the issues encountered in $\mathrm{SO}_{2}$ and GSD calculations. Further development and investigations on the subject would focus on improving and précising the present results, in order to have a better constrain of the $\mathrm{SO}_{2}$ OMI measurements in one hand, and to obtain more GSD values from the same database in the other hand.

$\rightarrow$ Comparison between Lastarria and the copper smelter signals

The characterization of Lastarria $\mathrm{SO}_{2}$ emissions is challenged by the detection limits of the instrument and contribution of background noise to the recorded signal. However, the presence of anthropogenic sources of $\mathrm{SO}_{2}$ located in the same region and thus affected by a similar noise as Lastarria volcano is a unique opportunity to compare the natural $\mathrm{SO}_{2}$ signal from Lastarria volcano with anthropogenic $\mathrm{SO}_{2}$ emissions from the copper smelters. Because atmospheric $\mathrm{SO}_{2}$ produced by copper smelters originates from industrial extraction and treatment of copper, it can be theoretically considered as constant on a monthly average. Correlations coefficients have been calculated on monthly total $\mathrm{SO}_{2}$ emissions (variable 3) for all areas, and are presented in table V.1.

Good positive correlations are found between background areas (55.6\% to $85.5 \%)$, as expected as they do not contain any source of atmospheric $\mathrm{SO}_{2}$. The maximum correlation (85.5\%) found between B2 and B4 was expected as B4 is superimposed to $\mathrm{B} 2$, as well as the very good correlation between B2 and B1. The high correlation between B1 and B2 (82.9 \%) confirms the similar variations observed in both these areas, and that a general background noise can be estimated from large areas, overwriting the local variations. 
Table V.1: correlation coefficients (in \%) calculated on a monthly basis for all areas regarding their total $\mathrm{SO}_{2}$ missions (variable 3).

\begin{tabular}{|c|c|c|c|c|c|c|c|c|c|c|}
\hline LM & LS & S1 & S2 & S3 & S4 & B1 & B2 & B3 & B4 & \\
\hline & 52.3 & 77.6 & 75.9 & 86.1 & 49.2 & 76.9 & 67.2 & 55.0 & 46.6 & LM \\
\hline & & 27.0 & 34.2 & 52.2 & 44.1 & 27.8 & 15.4 & 13.0 & 3.2 & LS \\
\hline & & & 78.1 & 69.6 & 34.4 & 70.4 & 67.9 & 58.3 & 51.3 & S1 \\
\hline & Scale & & & 75.4 & 45.2 & 71.7 & 73.1 & 63.7 & 61.2 & s2 \\
\hline & $90 \%$ & & & & 59.5 & 72.8 & 56.8 & 47.8 & 38.6 & s3 \\
\hline & $80 \%$ & & & & & 45.5 & 26.9 & 12.4 & 13.1 & S4 \\
\hline & $70 \%$ & & & & & & 82.9 & 74.7 & 55.63 & B1 \\
\hline & $60 \%$ & & & & & & & 79.7 & 85.5 & B2 \\
\hline & $50 \%$ & & & & & & & & 72.1 & B3 \\
\hline & & & & & & & & & & B4 \\
\hline & Correlat & on (\%) & avera & $02 \mathrm{ma}$ & produc & per km & er day & ariable 3 & & \\
\hline
\end{tabular}

LM has a strong correlation with S1, S2 and S3 as well as with B1, B2 and B3. This is coherent with the previous results, as the background noise can contribute for about 50 to more than $70 \%$ of the $\mathrm{SO}_{2}$ burdens on a month for all these areas.

Strong correlations are found between S1, S2 and S3, while S4 is not correlated with any area with the exception of S3. S1, S2 and S3 also show a good correlation with LM and background areas. In order to determine which ones of these smelters are suitable for comparison with LM emissions, maps of the annual $\mathrm{SO}_{2}$ burdens are plotted for these four regions. They show that the $\mathrm{SO}_{2}$ emitted is not differentiated from the background noise for $\mathrm{S} 2$ and $\mathrm{S} 3$. The respective $\mathrm{SO}_{2}$ emissions for $\mathrm{S} 2$ and $\mathrm{S} 3$ are 2 or 3 times lower in intensity than LM, and appear to be lost in the background (figureV.1), and therefore variations recorded in these areas are similar to the noise recorded on B1 and B2, causing the very high correlation. These areas are not suitable for comparison with Lastarria $\mathrm{SO}_{2}$ emissions. 

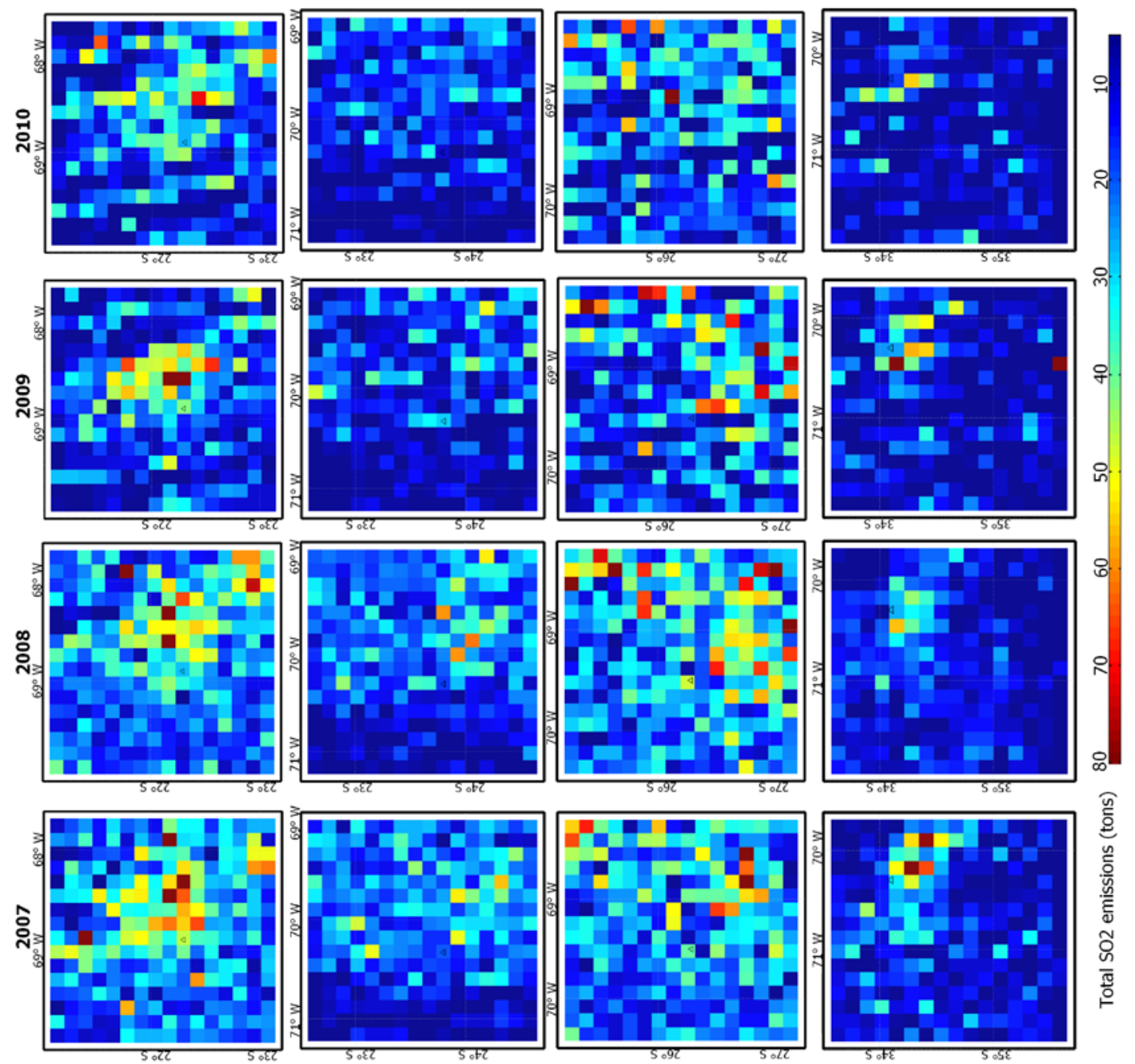

ํㅡㄹ
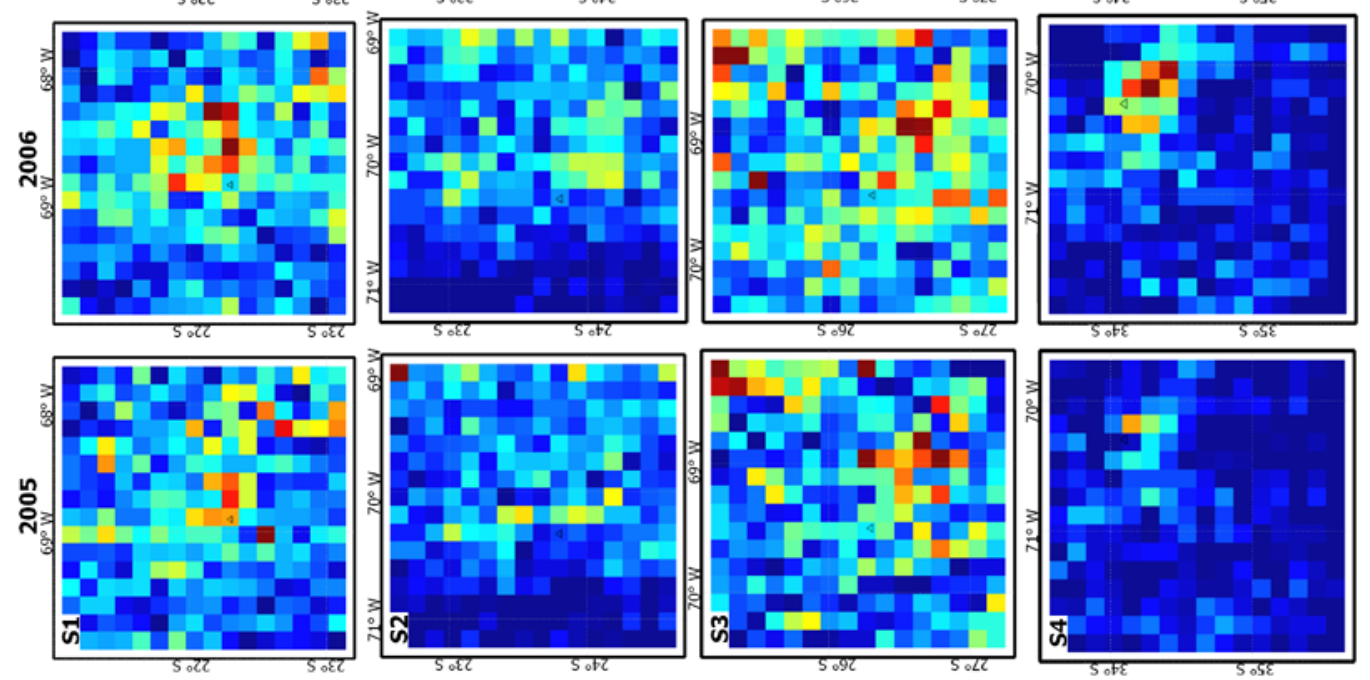

Figure V.1: annual maps of total $\mathrm{SO}_{2}$ burdens for $\mathrm{S} 1, \mathrm{~S} 2, \mathrm{~S} 3$ and $\mathrm{S} 4$. Positions of each copper smelter (triangle). 
S4 does not show a good correlation with any of the background areas or the other smelters. This smelter is located at $33.5^{\circ} \mathrm{S}$ latitude, and the local background noise appears to be different, yet inferior than in Lastarria area. Therefore, the $\mathrm{SO}_{2}$ cloud emitted by $\mathrm{S} 4$ is clearly visible on annual maps, although its total $\mathrm{SO}_{2}$ emissions remain lower than LM in intensity (0.06 Tg for LM, $0.03 \mathrm{Tg}$ for S4 for the period 2005 to 2010). The correlation coefficient between the total emissions for these two areas is $49.2 \%$. Variations of monthly emissions of $\mathrm{SO}_{2}$ per unit area confirm this observation (figure $V .2$ ) and do not show a common tendency or annual correlated signal, which means that the instrument is detecting two distinct $\mathrm{SO}_{2}$ signals.

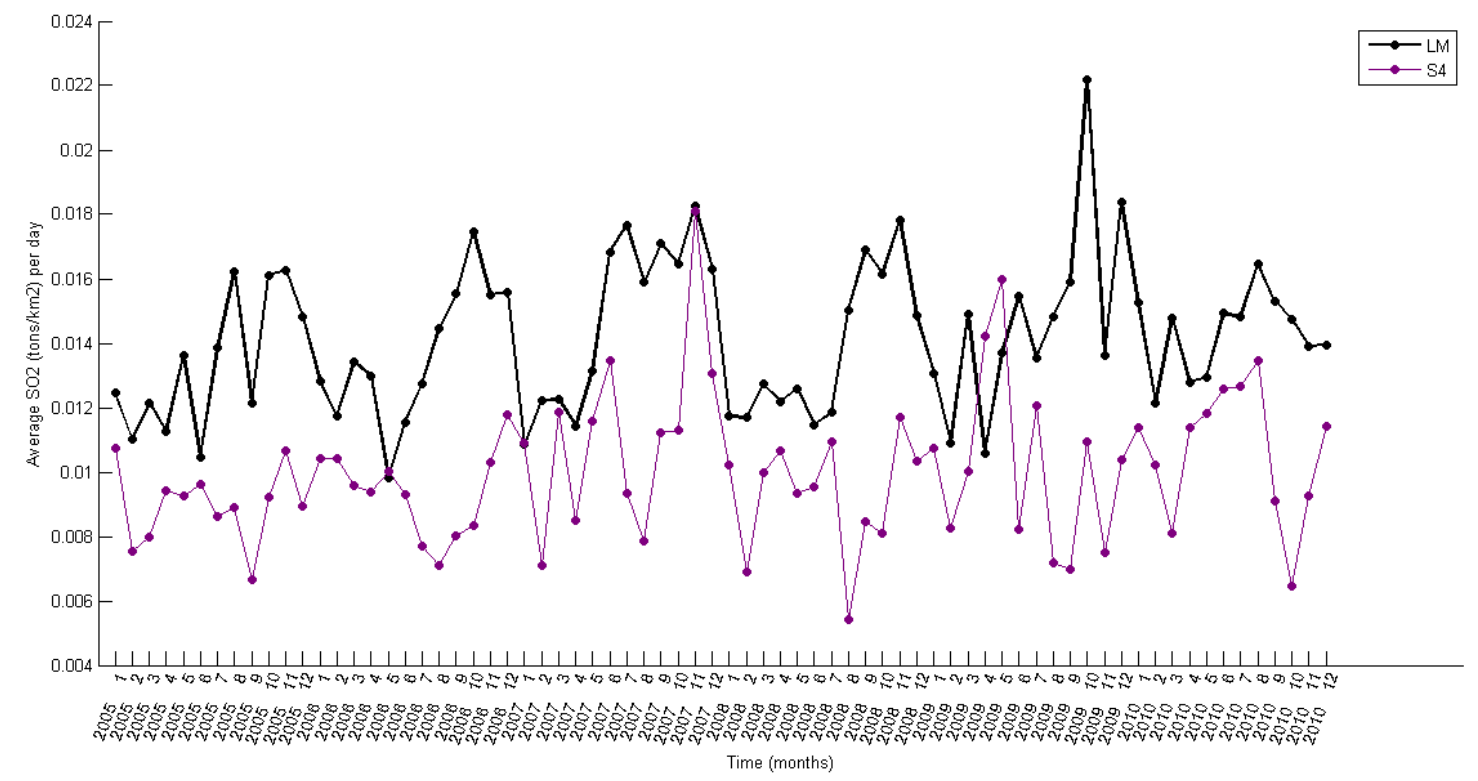

Figure V.2: monthly amounts of $\mathrm{SO}_{2}$ emissions in tons $/ \mathrm{km}^{2}$ for $\mathrm{LM}$ and $\mathrm{S} 4$.

However, both these signals are the combination of $\mathrm{SO}_{2}$ emissions from local sources (either Lastarria or the smelter) and local background noise (at least 50\%). Smelter 4 is located far southward from Lastarria volcano, and the interpretation to this de-correlation is that the signal is not affected by the same background noise as all the other areas (table V.1). Therefore, it is not possible to directly compare S4 and LM emissions without determining and correcting the signal from this local influence.

Smelter 1, finally, is affected by the same background noise as LM and emits a $\mathrm{SO}_{2}$ cloud visible on annual maps and distinguished from the noise. Thus, is represents the best chance of comparison with LM emissions (figure V.3). The averaged emissions in tons per $\mathrm{km}^{2}$ appear to be comparable in intensity, although emissions at Lastarria volcano are slightly higher. Annual-scale variations of the emissions corresponding to higher values in summer and lower values in winter, associated with cloud fraction influence for Lastarria volcano and recorded in background areas, are observed on both signals. Thus, the correlation observed between these two signals can be partly attributed to the noise influence. 


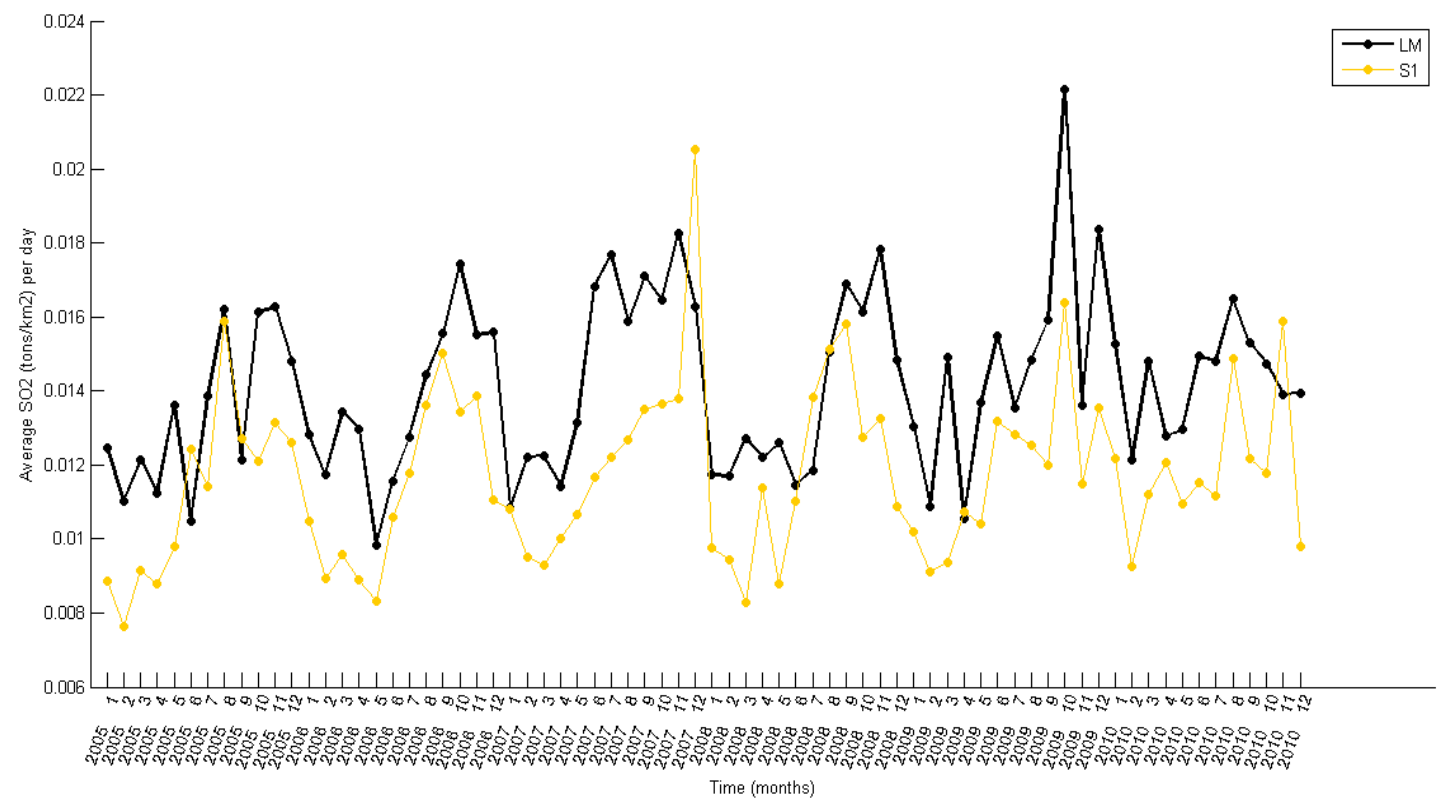

Figure V.3: time-series of average $\mathrm{SO}_{2}$ burdens for $\mathrm{LM}$ and $\mathrm{S} 1$.

Differences between the two signals include local peaks in the retrieved signal (i.e. November 2007 for S1, March 2009, peak in LM signal not observed in S1, etc.) and differences in amplitude changes when the two signals are experiencing similar trends.

However, interpretation of these differences would require a more complete investigation on these two signals. This implies to identify, for both signals, the contribution of the background noise on the totals retrieved and on the variations (annual cycle), and to characterize the influence of local factors (cloud coverage, reflectivity, winds, etc.). Then, a comparison of the two signals, on a monthly basis, would permit to highly their differences and thus to retrieve their specific variations.

To conclude, although the comparison between Lastarria and copper smelters emissions would be a great contribution to the characterization and the interpretation of $\mathrm{SO}_{2}$ degassing, it requires further correction of the signal (especially from local influences) before being exploitable. Hereabove, we found that a suitable anthropogenic source of $\mathrm{SO}_{2}$ have be located in close proximity to the volcano (in the range of hundreds of kilometers) to cancel local noise contribution, and would emit a sufficient amount of $\mathrm{SO}_{2}$ to be distinguished from the noise.

\section{$\rightarrow$ Limitations encountered with InSAR}

Interferograms calculated on Lastarria volcano area, for an extended period of 126 months, brought new insight on long-term evolution ground displacements occurring at Lastarria volcano. Two periods of relatively constant displacements have been identified and their respective rates calculated using a liner regression fit. Estimation of the displacement rates for the first period is based on 11 measurements from swath 2282 only. The general trends observed for swathes 2318 and 6404 on the same period, based 
on 3 and 2 values, respectively, suggest that the displacement rate follow a similar variation for the three directions investigated, but a better interpretation would require a higher number of data. Unlike OMI daily database, SAR images of the same zone are only available every few weeks or months, and this limited temporal density of measurements represents one of the main limitations of interferometric measurements. Using images from three different swaths increase the density of data available for a given period in addition to permit investigation of the displacements in different directions. However, 181 interferograms out of the 772 calculated have been removed from time-series calculations for accuracy reasons and to assure the reliability of the obtained results. 23 scenes of retrieved displacements have been used in time-series calculations for the swath 2282 over 30 interferograms available. This loss in temporal density of the data can be sort out by examining and re-calculating the interferograms concerned before integrating them to the calculations. Therefore, this represents the next step in specifying the evolution of Lastarria ground deformation signal, using the same database and on the same period, in order to achieve a better interpretation of the results. In addition, a further step would be to deduce the eastern and the vertical components of the deformations from the directions of the 3 swaths and to perform a principal component analysis from the time-series, to have an overview of the deformation signal in 3 dimensions.

This study aims to investigate the $\mathrm{SO}_{2}$ emissions associated with Lastarria volcano passive degassing, using the high spectral capacities of OMI instrument, to characterize their intensity and temporal evolution, in order to compare with ground displacements calculated by InSAR on the same area and for the same period. However, high uncertainties associated with OMI measurements and recovering of low-level $\mathrm{SO}_{2}$ emissions have constituted an important limitation in the exploitation and interpretation of the data. An estimation of the minimum $\mathrm{SO}_{2}$ mass emitted is possible, but a precise characterization of smaller-scale temporal evolution of the emissions remains difficult. The presence of a local and global influence of the noise has been evidenced, but further investigations are necessary to perform accurate corrections. The presence of anthropogenic sources of $\mathrm{SO}_{2}$ such as copper smelters close to Lastarria volcano represents a great opportunity to achieve this goal.

This study gives an overview of the limitations encountered to characterize $\mathrm{SO}_{2}$ emissions on low-level degassing in this area, and proposes a first overview of the local situation. However, more extended studies are necessary before accurate correction and interpretation of the OMI results, and this can be helped by the unique opportunity to compare anthropogenic and natural $\mathrm{SO}_{2}$ degassing located in the same remote area. Achievement of this goal would help developing the use of OMI instrument in regards to low-level volcanic degassing.

In conclusion, although several limitations have been encountered in both methods, combined OMI and InSAR results show some common patterns, and two periods of respectively high and low degassing and inflation rate have been evidenced. However, 
further investigations and conclusions on these similarities would require more investigations and improvements in both databases.

\section{Conclusion}

Lastarria is a quaternary stratovolcano of Northern Chile considered as inactive, which only recorded activity consists in persistent fumarolic degassing located near the summit area of the volcano. Lastarria is located on the North-West margin the Lazufre volcanic system, which is affected since 1998 by a large scale $\left(39 \times 45 \mathrm{~km}^{2}\right)$ ground deformation signal and has been inflating at a constant rate of $\sim 2.5 \mathrm{~cm} /$ year for the period 1998 to 2008. In 2003, a second, distinct deformation signal has been revealed by InSAR. Affecting a $6 \mathrm{~km}$ wide area centered on Lastarria volcano itself, it corresponds to an inflation with an estimated maximum displacement rate of $0.9 \mathrm{~cm} /$ year on the period 2003 to 2005. The ground deformation was following the same constant evolution as the Lazufre signal.

The present study extend the interferometric measurements from ENVISAT-ASAR instrument on a 126 months period from March 2003 to April 2010, using 3 swaths/tracks in both ascending and descending modes and using a $15 \mathrm{~m}$ oversampled SRTM DEM. Two distinct periods of constant displacements have been distinguished in the deformation and the corresponding rates have been estimated for each of the periods using a linear regression fit. From 2003 to 2007, the ground was deforming with a constant rate of $2.44 \mathrm{~cm} /$ year. Then, from 2007 to 2010 , the maximum inflation rate was $0.80 \mathrm{~cm} /$ year, $0.95 \mathrm{~cm} /$ year and $0.94 \mathrm{~cm} /$ year for the directions of the 3 swaths recorded (2318, 6404 and 2282 respectively).

At the same time, the $\mathrm{SO}_{2}$ emissions over Lastarria volcano have been recorded on a 72 months period from January 2005 to December 2010, using the NASA space-based spectrometer, Ozone Monitoring Instrument. OMI provided daily records of $\mathrm{SO}_{2}$ burdens emitted over Lastarria volcano and surrounding areas. Although monitoring passive volcanic degassing remains challenging, the $\mathrm{SO}_{2}$ signal originated from Lastarria volcano was clearly identified and differentiated from background noise and corrected from known issues. Consequent estimation of total $\mathrm{SO}_{2}$ burden released by Lastarria volcano is $67.0 \mathrm{kT}$ of $\mathrm{SO}_{2}$ on the total period covered by the study (2005-2010), with $45.2 \mathrm{kT}$ (67 $\%$ ) released from 2005 to 2007 corresponding to an average of 35.7 tons $/ \mathrm{km}^{2}$, and 21.8 $\mathrm{kT}$ released for the period 2007-2010 (26.8 tons $/ \mathrm{km}^{2}$ ). However, monitoring passive volcanic and low-level degassing remains challenging and consequently, these values represent the minimum estimation of Lastarria $\mathrm{SO}_{2}$ emissions. The important noise contribution to the Lastarria signal does not permit to identify a monthly or annual cyclicity of the emissions. Further investigations are necessary to investigate the relationship and possible dependency of the $\mathrm{SO}_{2}$ emissions and the Ground Surface Displacement. 


\section{References}

Aguilera, F., Tassi, F., Darrah, T., Moune, S., \& Vaselli, O. (2012). Geochemical model of a magmatic-hydrothermal system at the Lastarria volcano, northern Chile. Bulletin of volcanology, 74(1), 119-134.

Albino, F., Froger, J.-L., Rémy, D., Bonvalot, S., Gonzales, K., Cayol, V., Souriot, T. (2007) Monitoring volcanic activity in Central Andes with InSAR interferometry. IUGG 2007 Perugia, JGS 003 Earthquake and Volcano Geodesy.

Allmendinger, R. W., Jordan, T. E., Kay, S. M., \& Isacks, B. L. (1997). The evolution of the Altiplano-Puna Plateau of the Central Andes. Annual Review of Earth and Planetary Sciences, 25(1), 139-174. doi: doi:10.1146/annurev.earth.25.1.139

Anderssohn, J., Motagh, M., Walter, T. R., Rosenau, M., Kaufmann, H., \& Oncken, O. (2009). Surface deformation time series and source modeling for a volcanic complex system based on satellite wide swath and image mode interferometry: The Lazufre system, central Andes. Remote Sensing of Environment, 113(10), 2062-2075.

Atterna, E., Alpers, W., Askne, J., Gray, L., Herland, E. A., Hounam, D., Keyte, G. E., Le Toan, T., Rocca, F., Rohh, H., Wahl, T. (1998). ASAR Science and Applications. 59.

Bani, P., Oppenheimer, C., Allard, P., Shinohara, H., Tsanev, V., Carn, S., Lardy, M., Garaebiti, E. (2012). First estimate of volcanic SO2 budget for Vanuatu island arc. Journal of Volcanology and Geothermal Research, 211, 36-46.

Budach, I., Brasse, H., \& Díaz, D. (2013). Crustal-scale electrical conductivity anomaly beneath inflating Lazufre volcanic complex, Central Andes. Journal of South American Earth Sciences, 42(0), 144-149.

Budach, I., Brasse, H., \& Diaz, D. (2011). Imaging of conductivity anomalies at Lazufre volcanic complex, Northern Chile, through 3-D inversion of magnetotelluric data. Neustadt an der Weinsraße, 19-23.

Bürgmann, R., Rosen, P., \& Fielding, E. (2000). Synthetic aperture radar interferometry to measure Earth's surface topography and its deformation. Annual Review of Earth and Planetary Sciences, 28(1), 169-209.

Carn, S., Krotkov, N., Yang, K., \& Krueger, A. (in press). Measuring global volcanic degassing with the Ozone Monitoring Instrument (OMI).

Carn, S. (2011) OMIplot. https://vhub.org/resources/682. 
Carn, S., \& Lopez, T. (2011). Opportunistic validation of sulfur dioxide in the Sarychev Peak volcanic eruption cloud. Atmospheric Measurement Techniques, 4(9), 1705-1712.

Carn, S., Froyd, K., Anderson, B., Wennberg, P., Crounse, J., Spencer, K., Dibb, J., Krotkov, N., Browell, E., Hair, J. (2011). In situ measurements of tropospheric volcanic plumes in Ecuador and Colombia during TC4. Journal of Geophysical Research: Atmospheres (1984-2012), 116(D10).

Carn, S., Krueger, A., Arellano, S., Krotkov, N., \& Yang, K. (2008). Daily monitoring of Ecuadorian volcanic degassing from space. Journal of Volcanology and Geothermal Research, 176(1), 141-150.

Carn, S., Krueger, A., Krotkov, N., Yang, K., \& Levelt, P. (2007). Sulfur dioxide emissions from Peruvian copper smelters detected by the Ozone Monitoring Instrument. Geophysical Research Letters, 34(9).

Chance, K. (2002). OMI algorithm theoretical basis document, volume IV: OMI trace gas algorithms. Accessed on, 12(10), 2009.

CNES/Altamira-information. (1996). Philosophie et mode d'emploi de la chaîne logicielle interférométrique DIAPASON.

de Silva, S. (1989). Altiplano-Puna volcanic complex of the central Andes. Geology, 17(12), 1102-1106.

de Silva, S., \& Francis, P. (1991). Volcanoes of the central Andes: Springer.

de Silva, S., \& Gosnold, W. (2007). Episodic construction of batholiths: insights from the spatiotemporal development of an ignimbrite flare-up. Journal of Volcanology and Geothermal Research, 167(1), 320-335.

Froger, J.-L., Remy, D., Bonvalot, S., \& Legrand, D. (2007). Two scales of inflation at Lastarria-Cordon del Azufre volcanic complex, central Andes, revealed from ASARENVISAT interferometric data. Earth and Planetary Science Letters, 255(1-2), 148-163.

Gonzalez-Ferran, O. (1995). Volcanes de Chile.

Hanssen, R. (2001). Radar interferometry: data interpretation and error analysis (Vol. 2). Springer.

Hongn, F., Papa, C. del Powell, J., Petrinovic, I., Mon, R., \& Deraco, V. (2007). Middle Eocene deformation and sedimentation in the Puna-Eastern Cordillera transition $\left(23^{\circ}\right.$ - 
$\left.26^{\circ} \mathrm{S}\right)$ : Control by preexisting heterogeneities on the pattern of initial Andean shortening. Geology, 35(3), 271-274. doi: 10.1130/g23189a.1

Krotkov, N., Carn, S., Krueger, A., Bhartia, P., \& Yang, K. (2006). Band residual difference algorithm for retrieval of $\mathrm{SO} 2$ from the aura ozone monitoring instrument (OMI). Geoscience and Remote Sensing, IEEE Transactions on, 44(5), 1259-1266.

Levelt, P., Hilsenrath, E., Leppelmeier, G., van den Oord, G., Bhartia, P., Tamminen, J., de Haan, J., Veefkind, P. (2006a). Science objectives of the ozone monitoring instrument. Geoscience and Remote Sensing, IEEE Transactions on, 44(5), 1199-1208.

Levelt, P., van den Oord, G., Dobber, M., Malkki, A., Visser, H., de Vries, J., Lundell, J., Saari, H. (2006b). The ozone monitoring instrument. Geoscience and Remote Sensing, IEEE Transactions on, 44(5), 1093-1101.

Massonnet, D., \& Rabaute, T. (1993). Radar interferometry: limits and potential. Geoscience and Remote Sensing, IEEE Transactions on, 31(2), 455-464.

Massonnet, D., \& Feigl, K. (1998). Radar interferometry and its application to changes in the Earth's surface. Reviews of geophysics, 36(4), 441-500.

McCormick, B., Edmonds, M., Mather, T., \& Carn, S. (2012). First synoptic analysis of volcanic degassing in Papua New Guinea. Geochemistry, Geophysics, Geosystems, 13(3).

Naranjo, J. (1985). Sulphur flows at Lastarria volcano in the North Chilean Andes.

Naranjo, J. (1988). Coladas de azufre de los volcanes Lastarria y Bayo en el Norte de Chile: rheologia, genesis e importancia en geologia planetaria. Revista Geologica de Chile, 15(1), 3-12.

Naranjo, J., \& Francis, P. (1987). High velocity debris avalanche at Lastarria volcano in the north Chilean Andes. Bulletin of Volcanology, 49(2), 509-514.

Naranjo, J. (1992). Chemistry and petrological evolution of the Lastarria volcanic complex in the north Chilean Andes. Geological Magazine -London-, 129, 723-723.

Naranjo, J., Cornejo, P. (1992) Hoja Salar de la Isla, escala 1:250.000

Naranjo, J. (2010) Geologia del complejo volcanico Lastarria, escala 1:250.000.

Oncken, O., Luèschen, E., Mechie, J., Sobolev, S., Schulze, A., Gaedicke, C., Grunewald, S., Bribach, J., Asch, G., Giese, P. (1999). Seismic reflection image revealing offset of Andean subduction-zone earthquake locations into oceanic mantle. Nature, 397(6717), 341-344. 
Petty, G. W. (2006). A first course in atmospheric radiation. Sundog Pub.

Pritchard, M., \& Simons, M. (2002). A satellite geodetic survey of large-scale deformation of volcanic centres in the central Andes. Nature, 418(6894), 167-171.

Pritchard, M., \& Simons, M. (2004). An InSAR-based survey of volcanic deformation in the southern Andes. Geophysical research letters, 31(15).

Richter, A., \& Wagner, T. (2011). The Use of UV, Visible and Near IR Solar Back Scattered Radiation to Determine Trace Gases. In The Remote Sensing of Tropospheric Composition from Space (pp. 67-121). Springer Berlin Heidelberg.

Ruch, J., Anderssohn, J., Walter, T., \& Motagh, M. (2008). Caldera-scale inflation of the Lazufre volcanic area, South America: Evidence from InSAR. Journal of Volcanology and Geothermal Research, 174(4), 337-344.

Ruch, J., \& Walter, T. (2010). Relationship between the InSAR-measured uplift, the structural framework, and the present-day stress field at Lazufre volcanic area, central Andes. Tectonophysics, 492(1), 133-140.

Schilling, F., \& Partzsch, G. (2001). Quantifying partial melt fraction in the crust beneath the central Andes and the Tibetan Plateau. Physics and Chemistry of the Earth, Part A: Solid Earth and Geodesy, 26(4), 239-246.

Schilling, F., Trumbull, R., Brasse, H., Haberland, C., Asch, G., Bruhn, D., Mai, K., Haak, V., Giese, P., Muñoz, M. (2006). Partial melting in the Central Andean crust: a review of geophysical, petrophysical, and petrologic evidence The Andes (pp. 459-474): Springer.

Spinei, E., Carn, S., Krotkov, N., Mount, G., Yang, K., \& Krueger, A. (2010). Validation of ozone monitoring instrument SO2 measurements in the Okmok volcanic cloud over Pullman, WA, July 2008. Journal of Geophysical Research: Atmospheres (1984-2012), 115(D2).

Thomas, H., Watson, I., Kearney, C., Carn, S., \& Murray, S. (2009). A multi-sensor comparison of sulphur dioxide emissions from the 2005 eruption of Sierra Negra volcano, Galápagos Islands. Remote Sensing of Environment, 113(6), 1331-1342.

Trumbull, R., Wittenbrink, R., Hahne, K., Emmermann, R., Büsch, W., Gerstenberger, H., \& Siebel, W. (1999). Evidence for Late Miocene to Recent contamination of arc andesites by crustal melts in the Chilean Andes (25-26 S) and its geodynamic implications. Journal of South American Earth Sciences, 12(2), 135-155. 
Walter, T., Ruch, J., Manconi, A., Shirzaei, M., Motagh, M., \& Anderssohn, J. (2011). Die „Beule “von Lazufre. System, 1, 30.

Wölbern, I., Heit, B., Yuan, X., Asch, G., Kind, R., Viramonte, J., Tawackoli, S., \& Wilke, H. (2009). Receiver function images from the Moho and the slab beneath the Altiplano and Puna plateaus in the Central Andes. Geophysical Journal International, 177(1), 296-308.

Yang, K., Krotkov, N., Krueger, A., Carn, S., Bhartia, P., \& Levelt, P. (2007). Retrieval of large volcanic SO2 columns from the Aura Ozone Monitoring Instrument: Comparison and limitations. Journal of Geophysical Research: Atmospheres (1984-2012), 112(D24).

\section{Annexes}

Annex I: Matlab programs used to select and display the $\mathrm{SO}_{2}$ time-series and maps from $\mathrm{OMSO}_{2}$ data treated by OMIplot. Comprise 5 files: omISO2time_series.m is used to plot time-series, SO2maps. $\mathrm{m}$ is used to create maps of annual $\mathrm{SO}_{2}$ burdens over various areas and seleczone.m, so2correct.m and soipcorrect.m are functions used in the previous programs.

Annex II: list of all SAR images used for each swath (2282, 2318 and 6404), sorted by date (all dates are in MM/DD/YYY format).

Annex III: detailed list of monthly results calculated for Lastarria Medium area from the OMISO2time_series.m program in annex $\boldsymbol{I}$.

Annex IV: Documentations of permission to republish materials used in the report 